\title{
CONTRACTING PRACTICES FOR THE UNDERGROUND CONSTRUCTION OF THE SUPERCONDUCTING SUPER COLLIDER
}

Subcommittee on Contracting Practices

for the Superconducting Super Collider

U.S. National Committee on Tunneling Technology Geotechnical Board

Commission on Engineering and Technical Systems National Research Council

NATIONAL ACADEMY PRESS

Washington, D.C. 1989

This document is

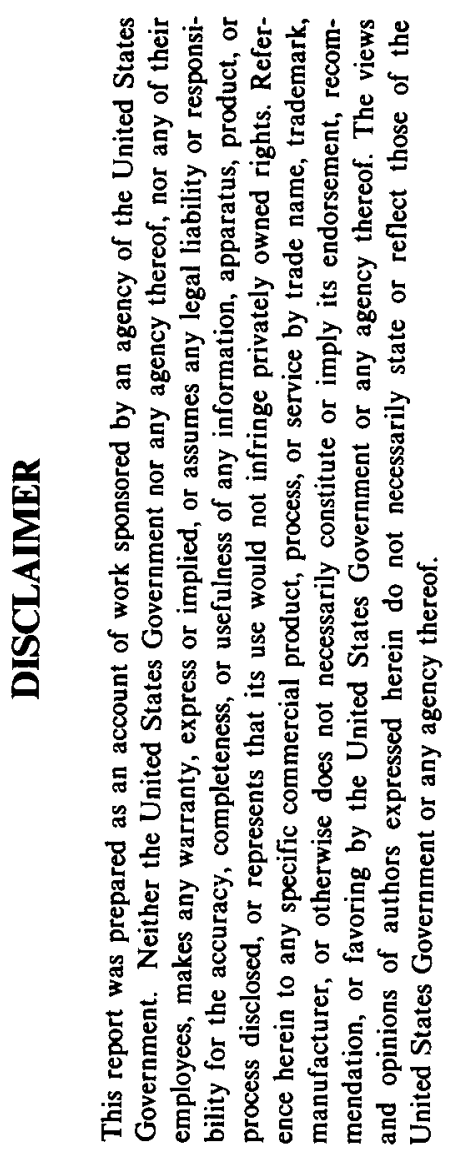

PUBLICLY RELEASABLE

$B$ any Stab

Authorizing Official

Date:

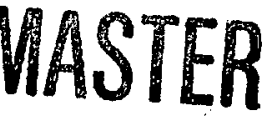

ASTRIBUTION OF THIS DOCUMENT IS UNLIMITED

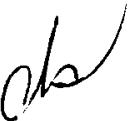




\section{DISCLAIMER}

This report was prepared as an account of work sponsored by an agency of the United States Government. Neither the United States Government nor any agency Thereof, nor any of their employees, makes any warranty, express or implied, or assumes any legal liability or responsibility for the accuracy, completeness, or usefulness of any information, apparatus, product, or process disclosed, or represents that its use would not infringe privately owned rights. Reference herein to any specific commercial product, process, or service by trade name, trademark, manufacturer, or otherwise does not necessarily constitute or imply its endorsement, recommendation, or favoring by the United States Government or any agency thereof. The views and opinions of authors expressed herein do not necessarily state or reflect those of the United States Government or any agency thereof. 


\section{DISCLAIMER}

Portions of this document may be illegible in electronic image products. Images are produced from the best available original document. 
NOTICE: The project that is the subject of this report was approved by the Governing Board of the National Research Council, whose members are drawn from the councils of the National Academy of Sciences, the National Academy of Engineering, and the Institute of Medicine. The members of the board responsible for this report were chosen for their special expertise and with regard for appropriate balance between government, industry, and academia.

This report has been reviewed by a group other than the authors according to procedures approved by a Report Review Committee consisting of members of the National Academy of Sciences, the National Academy of Engineering, and the Institute of Medicine.

The National Academy of Sciences is a private, nonprofit, self-perpetuating society of distinguished scholars engaged in scientific and engineering research, dedicated to the furtherance of science and technology and to their use for the general welfare. Upon the authority of the charter granted to it by the Congress in 1863, the Academy has a mandate that requires it to advise the federal government on scientific and technical matters. Dr. Frank Press is president of the National Academy of Sciences.

The National Academy of Engineering was established in 1964, under the charter of the National Academy of Sciences, as a parallel organization of outstanding engineers. It is autonomous in its administration and in the selection of its members, sharing with the National Academy of Sciences the responsibility for advising the federal government. The National Academy of Engineering also sponsors engineering programs aimed at meeting national needs, encourages education and research, and recognizes the superior achievements of engineers. Dr. Robert M. White is president of the National Academy of Engineering.

The Institute of Medicine was established in 1970 by the National Academy of Sciences to secure the services of eminent members of the appropriate professions in the estimation of policy matters pertaining to the health of the public. The Institute acts under the responsibility given to the National Academy of Sciences by its congressional charter to be an adviser to the federal government and, upon its own initiative, to identify issues of medical care, research, and education. Dr. Samuel O. Thier is president of the Institute of Medicine.

The National Research Council was organized by the National Academy of Sciences in 1916 to associate the broad community of science and technology with the Academy's purposes of furthering knowledge and advising the federal government. Functioning in accordance with general policies determined by the Academy, the Council has become the principal operating agency of both the National Academy of Sciences and the National Academy of Engineering in providing services to the government, the public, and the scientific and engineering communities. The Council is administered jointly by both Academies and the Institute of Medicine. Dr. Frank Press and Dr. Robert M. White are chairman and vice chairman, respectively, of the National Research Council.

This project was sponsored by the U.S. Department of Energy, contract number DE-AC02-88-ER40453.

Copies are available from: Geotechnical Board, Suite HA-286, National Research Council, 2101 Constitution Avenue, N.W., Washington; D.C. 20418 


\section{Subcommittee on Contracting Practices for the Superconducting Super Collider}

\section{MEMBERS}

NORMAN A. NADEL (Chairman), MacLean-Grove and Co., Inc., ${ }^{*}$ Greenwich, Connecticut

LLOYD A. DUSCHA, U.S. Army Corps of Engineers, Washington, D.C.

JAMES P. GOULD, Mueser Rutledge Consulting Engineers, New York, New York

BRIAN P. HENKEL, Washington State Department of Transportation, Bellevue, Washington

JOHN E. KOSTER, Corroon \& Black, San Francisco, California

JACK K. LEMLEY, Consultant,** Boise, Idaho

FRANCIS X. McARDLE, General Contractors Association of New York, New York

JAMES H. MEINHOLZ, Milwaukee Metropolitan Sewerage District, Milwaukee, Wisconsin

JAMES E. MONSEES, Parsons, Brinckerhoff, Quade \& Douglas, Los Angeles, California

HARVEY W. PARKER, Shannon \& Wilson, Seattle, Washington

BOYD C. PAULSON, JR., Stanford University, Stanford, California

ROBERT J. SMITH, Wickwire, Gavin \& Gibbs, P.C., Madison, Wisconsin

\section{ADVISORY GROUP}

ANDREW F. DEMPSEY, Dempsey, Bastianelli \& Brown, Washington, D.C.

PETER M. DOUGLASS, Hart Crowser, Inc., Seattle, Washington

DAVID G. HAMMOND, Consultant, La Canada, Calif ornia

MEREDITH A. HILTON, Corroon \& Black, San Francisco, California

R. TENNEY JOHNSON, Counselor at Law, Washington, D.C.

THOMAS D. O'ROURKE, Cornell University, Ithaca, New York

EUGENE B. WAGGONER, Consultant, Vallejo, California

\section{STAFF}

LYNNE F. CRAMER, Study Coordinator

VIRGINIA M. LYMAN, Administrative Associate

DANA G. CAINES, Administrative Assistant

JENNIFER T. ESTEP, Administrative Secretary

GREGORY A. MOCK, Editor

* Now with Nadel Associates, Inc.

**Now with Transmanche-Link (Channel Tunnel) 


\section{U.S. National Committee on Tunneling Technology 1988-1989}

\section{EXECUTIVE OFFICERS}

PHILIP G. MEIKLE (Chairman), U.S. Bureau of Mines, Washington, D.C.

HARVEY W. PARKER (Vice-Chairman), Shannon \& Wilson, Seattle, Washington THOMAS D. O'ROURKE (Immediate Past Chairman), Cornell University, Ithaca, New York

\section{SOCIETY REPRESENTATIVES}

GARY S. BRIERLY, Brierly \& Lyman, Inc., Denver, Colorado, American Society of Civil Engineers

RICHARD E. GRAY, GAI Consultants, Monroeville, Pennsylvania, Geological Society of America

SUSAN R. NELSON, American Underground-Space Association, Minneapolis, Minnesota, American Underground-Space Association

JOSEPH W. NEUDECKER, Los Alamos National Laboratory, Los Alamos, New Mexico, Institute of Shaft Drilling Technology

RONALD E. SMITH, Woodward-Clyde Consultants, Gaithersburg, Maryland, Association of Engineering Geologists

\section{MEMBERS-AT-LARGE}

JAAK J.K. DAEMEN, University of Arizona, Tucson, Arizona

GERARD M. KENNY, Kenny Construction, Co., Wheeling, Illinois

JOSEPH W. LACOMB, Defense Nuclear Agency, Mercury, Nevada

BOYD C. PAULSON, JR., Stanford University, Stanford, Calif ornia

TIMOTHY P. SMIRNOFF, Howard, Needles, Tammen, \& Bergendoff, Kansas City, Missouri

RAYMOND L. STERLING, University of Minnesota, Minneapolis, Minnesota

JAMES D. WASHINGTON, Federal Highway Administration, Washington, D.C.

\section{STAFF}

LYNNE F. CRAMER, Director

VIRGINIA M. LYMAN, Administrative Associate

DANA G. CAINES, Administrative Assistant

JENNIFER T. ESTEP, Administrative Secretary 


\section{ACKNOWLEDGMENTS}

The members of the Subcommittee on Contracting Practices for the Underground Construction of the Superconducting Super Collider acknowledge with gratitude the contributions of many more individuals than can be conveniently listed here. Many colleagues gave helpful advice and suggested improvements in the report. The subcommittee particularly wishes to thank those participants in the various meetings who were not members of the subcommittee. Their participation in reviewing drafts of the report and offering constructive criticism is much appreciated. In this regard, a special note of thanks should go to Robert Matyas, Consultant, Ithaca, New York, Timothy Toohig, Deputy for Conventional Facilities, Universities Research Associates, and Priscilla Nelson, Professor, University of Texas-Austin.

The study was supported by the U.S. Department Energy. Without neglecting in any way the many persons in this agency who aided the study, several individuals merit special acknowledgment for their particular support and encouragement: John Scango (DOE Study Manager), Jerry Zimmer, Arnold Samuel, Robert Zick, Robert Weller, and G.L. Allen. 

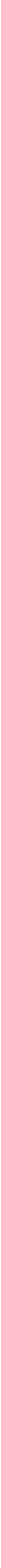


\section{PREFACE}

Underground projects are among some of the most expensive and complicated civil engineering ventures. A high degree of risk is always associated with underground projects because such projects take place in a medium that not only varies in composition, but one that affects and responds to geotechnical processes in a complex manner. In this environment, where design always involves the potential for modifications, construction proceeds with a mix of technologies that range from simple manual instruments, such as a pick and shovel, to sensitive and sophisticated mechanized equipment, such as a laser-guided tunneling machine that erects a segmented concrete lining as it advances. Thus, economic risk, geotechnical uncertainties, and complex technologies are inherent in underground projects. In this context, the principles and practice of contracting must be viewed as a fundamental means of managing the endeavor. Further, contracting mechanisms provide key operating links between project phases, which traditionally are considered to be separate and distinct entities. In this manner, contractual considerations become a governing force in the planning and execution of underground projects.

This report, Contracting Practices for the Underground Construction of the Superconducting Super Collider, presents a study of the contractual relationships among the parties involved in large underground engineering efforts by focussing on a single extraordinary underground construction project-the Superconducting Super Collider (SSC). The underground components of the SSC are critical elements of the overall project both in terms of cost and time. Achieving the goals of the SSC depends on the timely and cost-effective construction of more than 53 miles of $12-\mathrm{ft}$ diameter tunnel, approximately $15 \quad 30-\mathrm{ft}$ diameter shafts, 15 20-ft diameter shafts, 4 experimental halls up to $100 \mathrm{ft}$ by $300 \mathrm{ft}$, and additional ancillary underground structures. In this regard, an issue fundamental to project success is the contractual framework adopted for the geotechnical exploration, design, and construction phases of these underground facilities.

The present study took place under the aegis of the U.S. National Committee on Tunneling Technology of the National Research Council in response to a request by the U.S. Department of Energy. The committee selected a subcommittee of twelve individuals to define current and innovative contracting approaches appropriate to the SSC project. In addition to the subcommittee, an advisory group consisting of seven members contributed time and effort to the study. The subcommittee and its advisory group included members representing government, industry, and academia with expertise in the areas of geotechnical engineering, civil engineering, contract administration and regulations, construction management, insurance, construction and contract law, and labor practices. 
The subcommittee held five meetings during the course of the study. The first meeting consisted of briefings from the Department of Energy (DOE) and its contractors to introduce the study group to the overall goals of the SSC project and to note, where possible, the anticipated constraints of the project. The second meeting identified those issues that would play an important role in the success of the SSC project and noted how traditional and nontraditional contracting practices had addressed these issues on previous projects.

Prior to the first two meetings, the Department of Energy was still involved in the site selection process for the SSC, involving seven candidate sites. The lack of a specific site for the SSC project influenced the thinking of the group in these early phases of the study. By the third meeting, the Department of Energy had announced the proposed site-Ellis County, Texas-and the study group began to focus the report with this site in mind. The final two meetings were devoted to writing the report and reaching a consensus on the final recommendations.

It would be well to point out that the study leading to this report is, in part, a sequel to a series of earlier studies. Two studies, conducted under the aegis of the U.S. National Committee on Tunneling Technology, Better Contracting for Underground Construction (1974) and Better Management of Underground Construction Projects (1978), have been traditional references to the tunneling industry in the area of contracting practices. The third study, Avoiding and Resolving Disputes in Underground Construction (1989), was undertaken by the ASCE Underground Technologies Research Council.

Though all large underground construction projects are unique, they nevertheless share many basic risks and present many similar challenges in their management and execution. Thus, while this report addresses the concerns of the Department of Energy regarding a single underground project, the subcommittee hopes that the philosophy, analysis, and recommendations put forth here will find broad application throughout the underground construction industry in projects of similar scope or complexity. 


\section{CONTENTS}

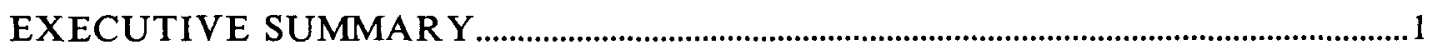

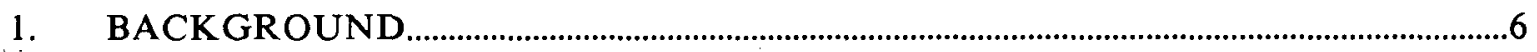

Components of the SSC, 6

The Designated Site, 8

SSC Construction Concerns, 12

Previous Studies, 13

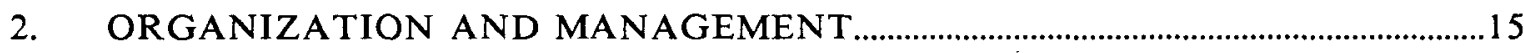

Organization, 16

Roles and Responsibilities, 18

Management of Construction Contracts, 21

Summary and Recommendations, 24

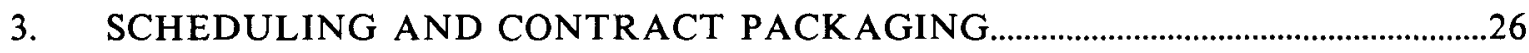

Major Factors That Influence Scheduling of the Tunnel Construction, 26

Contract Packaging for Tunnel Construction, 33

Design Decisions That Affect Schedule and Contract Packaging, 39

Influence of Unforeseen Factors on Schedule, 40

Other Needs, 41

Summary and Recommendations, 42

4. RISK ALLOCATION AND THE MANAGEMENT OF DISPUTES.......................44

Defining the Owner, 44

Risk Allocated to the Owner, 45

Risk Allocated to the Contractor, 47

Disputes, 47

Summary and Recommendations, 57 
5. TYPE OF CONTRACT

Legal and Regulatory Considerations, 58

Evaluation Considerations, 59

Alternative Contract Types (Based on Pricing Method), 60

Alternative Contract Types (Based on Contracting Structure), 63

Prequalifications, 67

Summary and Recommendations, 67

6. OTHER ISSUES.

Quality Control, 69

Constructibility, 71

Community Impacts, 72

Labor Issues, 73

Insurance, 74

APPENDIX 1: Geologic Details of the SSC Site

APPENDIX 2: Guidelines on Contractual Sharing of Risks-

International Tunnelling Association

APPENDIX 3: Establishing the Geotechnical Basis for Bid.

APPENDIX 4: Guidances From FAR and DEAR

APPENDIX 5: Possible SSC Insurance Specifications..........................................................91

REFERENCES 


\section{EXECUTIVE SUMMARY}

Contracts drawn between the parties of an underground construction project seek to define the requirements of the project, to assign the responsibility for its accomplishment, and to establish its cost. "A good contract does not merely divide the responsibilities of the project; it is a unifying force, an agreement committing both parties to a single common objective. Every provision in the contract must be an acknowledgment not only of the legitimate interests of the individual parties but of their common goal" (Executive Presentation-Recommendations on Better Contracting for Underground Construction, U.S. National Committee on Tunneling Technology, 1976).

This report was prepared by a specially appointed committee under the auspices of the National Academy of Sciences/National Research Council to address contracting and associated management issues essential to the successful execution of underground construction for the Superconducting Super Collider (SSC).

Fundamental to the success of underground construction projects is the art of good management, and management can be made significantly easier if the contracts under which all the players must operate reflect accurately the specific needs of underground projects. The contracts should recognize the complex and dynamic nature of underground construction and allow flexibility in executing the work. The contracts should provide a framework that allows problems to be avoided, solved, or-when a full solution is beyond the means of the managermanaged in such a way that the project can proceed.

Accordingly, the report begins with a discussion of organization and management issues to set the framework for the special contractual needs of tunneling and underground construction work. The roles and responsibilities of the primary players of the SSC project-the Management and Operating contractor $(\mathrm{M} \& \mathrm{O})$ and the Architect-Engineer/Construction Manager (AE/CM)-are discussed in some detail to set a philosophy for guiding the development of appropriate contracts.

A discussion of scheduling options and the need to formulate a contract packaging scheme that accommodates the schedule is included. Those special aspects of the SSC project that impact the development of the schedule are reviewed, including the magnet delivery schedule, the experimental hall construction, and the unique physical and geotechnical features of the site. These aspects are discussed in context with the unique and historically problematic aspects of tunnel construction, including the sequential nature of the work, the capacity of the tunneling industry, and the problems associated with site conditions that differ from those expected or upon which the contract bid was based. Finally, 
some general comments on design decisions that affect schedule and the need to include contingencies to accommodate unforeseen events that inevitably arise in tunnel construction are of fered.

An evaluation of the various types of risk that are typically associated with tunneling projects and an explanation of which risks should be allocated to the owner, which should be allocated to the contractor, and which should be shared is provided. Discussion is also presented regarding the following: disputes avoidance by use of an Executive Review Board; inclusion of a Geotechnical Design Summary Report (GDSR) in the contract documents; use of the GDSR as the geotechnical basis for bid (specifying anticipated ground quality and quantities with compensation based on unit prices); and the escrow of contractor's bidding documents. New approaches to resolve disputes quickly and equitably by utilizing Disputes Review Boards are recommended in the report.

The various options available in contract types are laid out in some detail, with advantages and disadvantages discussed-both in general and in terms of the SSC project. Flow-down provisions of Federal Acquisition Regulations (FAR) and Department of Energy Acquisition Regulations (DEAR) are noted and evaluated. A recommendation for a modified fixed-price contract that provides for payment based on unit prices, lump sum items, and price adjustment provisions is made with explanations of fered.

Additional issues of quality control, constructibility, labor, insurance, and community impacts are discussed, noting the impact on the project in general and the contracting mechanism in particular.

Some traditional contracting issues were not addressed by the subcommittee such as how to accommodate adequately the "Buy American" requirements of federal-funded construction. projects. This issue was not addressed because the DOE policy with respect to the SSC had not been clearly articulated at the time the study was undertaken.

The subcommittee preferred to withhold comment on the Buy American issue until the DOE policies were fully understood. It did note, however, that the U.S. tunneling industry presently has the capacity to undertake the construction of the SSC. The subcommittee would also comment that the inclusion of foreign companies in the bidding process is likely to improve the competition, and since much of the advanced tunneling technologies can be found abroad, the inclusion of foreign companies is likely to fertilize the U.S. industry with innovative practice.

In addition to the underground works, the SSC Laboratory complex will include extensive surface facilities and associated civil works. The subcommittee notes that the construction of these facilities is a significant undertaking in itself, and that coordination between the surface construction and the underground construction will be key to the success of the project. It was, however, beyond the scope of this report to make any further comments or recommendations regarding the surface structures.

\section{CONCLUSIONS AND RECOMMENDATIONS}

The conclusions and recommendations offered by this study can be summarized, by chapter, as follows: 
Chapter 2: Organization and Management

- The initial organization and contractual arrangements established for the project should carefully define and allocate the responsibilities of each of the participants.

- Effective decision-making will be facilitated by delegating authority commensurate with responsibility, with an eye towards delegating to the lowest level possible.

- Communications should be given high priority both within an individual organization and across organizations. To promote communication, standardized and networked computer systems, coordinated procurement activities, and an integrated scheduling mechanism should be instituted.

- Consistency across contracts should be promoted. A common understanding of contract rules by project superintendents, consistency of decisions among resident engineers, and dissemination of the outcomes of dispute resolution during the project should be encouraged.

- The infrastructure should be put in place at an early date to facilitate timely performance of the construction. The Texas National Research Laboratory Commission (TNRLC) is expected to play a very important and significant role in this effort and, accordingly, all of the organizational details and relationships among the TNRLC, DOE, M\&O, and AE/CM should be established at the outset.

\section{Chapter 3: Scheduling and Contract Packaging}

- The underground excavation can be completed within the time frame proposed by the DOE and the project should be able to adhere to the proposed magnet storage and installation scheme.

- Current information indicates that the construction of the tunnels and experimental halls is probably well within the capability and capacity of the tunneling industry, provided that tunnel bids are not solicited simultaneously with other significant tunneling projects.

- It appears that, under several anticipated packaging arrangements, the tunnels can be completed comfortably in advance of the need to store and install completed magnets.

- A variety of contract packaging schemes can be implemented, ranging from using as few as five long drives (up to $12 \mathrm{mi}$ in length) or a greater number of shorter drives. The selected mix of contracts should be based upon funding availability, equipment utilization, other industry capacity issues, and the desire to meet other public policy goals. It is recommended that the status of the industry be carefully and continually monitored as the time approaches to begin construction of the tunnels.

- The design, construction, and operation of experimental halls should be scrutinized closely. Given a moderate range of ground conditions for the site, these excavations should proceed as planned. However, the size and complexity of these excavations make them vulnerable to unexpected ground conditions and contingencies in both design and construction should be planned.

- Existing equipment, which can be rebuilt to suit the particular needs of the SSC project, can be utilized for the initial tunnel boring contracts. New equipment will likely be required for later contracts. A detailed survey of the industry is needed to provide a better understanding of equipment availability. 
- In planning and scheduling the discrete construction contracts for the conventional, nonscientific construction elements, every effort should be made to avoid simultaneous site occupancy by more than one contractor. attention.

- The problems of incremental congressional funding should be given

- The project should factor some buffer into the schedule to accommodate differing site conditions, environmental impacts, or other problems that might disrupt the progress of the work.

\section{Chapter 4: Risk Allocation and the Management of Disputes}

- Contract documents will be easier to formulate if an allocation of risk between contractor and owner is established early in the planning and design stages.

- Comprehensive scheduling that is adhered to by all the parties-M\&O, $\mathrm{AE} / \mathrm{CM}$, TNRLC, construction contractors, and subcontractors-is a necessity for the project and should be a first-order activity for the M\&O.

- The scope of the geotechnical investigation should be performed in general accordance with the publication, Geotechnical Site Investigations for Underground Construction (U.S. National Committee on Tunneling Technology, 1984).

- A Geotechnical Design Summary Report, with no disclaimers, should be included as part of the contract documents to serve as the basis for bid.

- A geotechnical basis for bid approach to contracting should be evaluated by the $\mathrm{AE} / \mathrm{CM}$ to determine its appropriateness for this project.

- An Executive Review Board should be established and utilized to facilitate decision making across contracts.

- Disputes Review Boards should be utilized on each construction contract to encourage the resolution of disputes in a timely and equitable manner. documents.

- Bidding requirements should include provisions for escrowing of bid

\section{Chapter 5: Type of Contract}

- The risk allocation methods recommended in this report-ample geotechnical information made available to all bidders, the inclusion of a Geotechnical Design Summary Report, the development of a geotechnical basis for bid, and disputes review boards to resolve disputes concurrently with work performanceameliorate the risks usually imposed on contractors under traditional fixed-price contracts and therefore make it more possible for tunneling industry contractors to undertake contracts of the size $(\$ 100,000,000)$ being recommended for the SSC project.

- The packaging of contract tasks, separate contracts for experimental halls and tunnel segments, and the limitation of contract size to $\$ 100,000,000$, as recommended in this report, open up opportunities to bid on portions of the SSC underground construction to a large number of contractors.

- Under these circumstances; the benefits usually associated with fixedprice contracting-lower price fostered by competition, incentive to complete on time and within budget, relative certainty of owner's cost exposure-appear both desirable and attainable for the SSC project.

- While either cost-plus or fixed-price contracting is feasible, fixed-price with provision for payment using unit prices, lump sum items and adjustment 
provisions is recommended. Design-construct contracting could be utilized to advantage for the experimental halls if they are to be excavated underground, assuming adequate performance specifications for equipment access and installation, and detailed specifications for interfaces with the tunnels.

- To the extent permitted by the federal guidelines, bidders on the larger and more complex underground construction should be required to be qualified by experience record and proven financial capability. However, as the project work advances, an effort should be made to package contracts to match the capability of smaller, less experienced contractors. For these smaller contracts, prequalification procedures could be relaxed.

\section{Chapter 6: Other Issues}

- Project-wide wrap-up insurance can be adapted to any of the discussed types of construction contract.

- If strict construction tolerances are to be made a part of this project, effective programs in quality control and quality assurance may be desirable.

- Constructibility reviews should receive high-level management attention to ensure that it is integrated into the planning, design, and construction.

- A comprehensive assessment of the impact of the SSC project on the Ellis County community should be an early objective of the program. Day-to-day management of community impacts should be delegated to the AE/CM but education and awareness of all parties should be a part of the program.

- A number of issues relating to job harmony and labor relations must be managed effectively by the $\mathrm{AE} / \mathrm{CM}$ to ensure that labor disputes do not impede the work of unaffected contractors.

In completing this study, the subcommittee would like to comment on the use of advanced technologies for the underground construction of the SSC. Just as the SSC represents an opportunity for the United States to open up new technologies in physics, so too the SSC can become an opportunity to advance the science and engineering of underground construction. The subcommittee suggests that the $\mathrm{AE} / \mathrm{CM}$ be given incentives to develop and implement innovative ideas related to construction methods and equipment. These ideas could apply to tunneling, shaft construction, tunnel lining, mucking methods, or use of new materials-concepts that could result in time savings, cost savings, or a higher quality final product. A project such as this, with approximately 53 miles of tunnels, 25 large-diameter shafts, and experimental halls of great depth and width, surely invites an active effort to introduce innovative methods and equipment. 


\section{BACKGROUND}

In January 1987, after three years of study by the U.S. Department of Energy and at the encouragement of the nation's physics community, President Reagan approved the construction of the Superconducting Super Collider (SSC). In January 1989, after exhaustive review of candidate sites, the Department of Energy designated Ellis County, Texas (near Dallas/Fort Worth) as the location of the new collider. With a circumference of 53 miles and an anticipated cost of $\$ 4.4$ billion, the SSC will be the largest and one of the costliest scientific instruments in the world. As such, it provides a major challenge to those public agencies and private contractors who must join forces to construct it.

\section{COMPONENTS OF THE SSC}

This study was undertaken when the project was in the conceptual design phase. As work on the design and environmental impact statement progresses some elements of the project may change. However, the basic concepts contained in this report with respect to contracting and management should remain the same.

The SSC will consist of a series of particle accelerators that will boost protons to energies of 20 trillion electron volts $(\mathrm{TeV})$ and propel them to nearlight speeds. Twin beams of these high-energy protons will circle the accelerator's 53-mile oval track in opposite directions 3,000 times per second. When allowed to interact; the counterrotating protons will collide with energies of 40 $\mathrm{TeV}$, yielding conditions similar to those existing in the first few moments after the "Big Bang," when the cosmos took its fiery birth. By studying the exotic particles and phenomena that result from these collisions, physicists can explore the building blocks of matter and the fundamental forces that govern their interaction.

Five critical components will make up the SSC project: the collider ring, which is the main particle accelerator; the injector assembly, which provides partially accelerated protons to the main accelerator ring; the experimental areas, where collisions will take place and the massive detectors required to monitor them will be located; a "campus" of laboratories and administrative and support buildings; and an infrastructure of roads and utilities, including an elaborate cryogenic plumbing system.

The collider ring will consist of two evacuated beam tubes surrounded by superconducting magnets to guide and focus the proton beam. A tunnel approximately $10 \mathrm{ft}$ in cross-section (finished diameter) and forming an oval $17 \mathrm{mi}$ 
across at its widest will be needed to accommodate the beam tube with its nearly 9,500 electromagnets and the liquid helium-based cooling system that permits superconductivity in the magnet materials.

The collider ring tunnel will be at least $30 \mathrm{ft}$ below grade to provide shielding from possible transient radiation produced by the proton beams. Vertical shafts will provide tunnel access every five miles and will be marked by a cluster of surface buildings housing refrigeration facilities and electrical utilities. Intermediate shafts midway between the access shafts will provide ventilation and emergency egress. The land area within the collider ring, exclusive of the 1000-ft-wide band containing the ring itself, will not be impacted by the ring and will remain available for uses not connected to the SSC.

The injector assembly will make use of a cascade of 4 accelerators to bring protons nearly at rest up to an energy of $1 \mathrm{TeV}$ and near-light speed, at which time they will be injected into the collider ring for final acceleration to $20 \mathrm{TeV}$. A 500-ft-long linear accelerator will provide first-stage acceleration to 0.6 billion electron volts $(\mathrm{GeV})$. Successive boosts from a low-energy synchrotron (820 $\mathrm{ft}$ in circumference) and a medium-energy ring ( $1.2 \mathrm{mi}$ in circumference), both using conventional magnets, will bring the proton energies up to $100 \mathrm{GeV}$. Acceleration in a final high-energy booster ( $4 \mathrm{mi}$ in circumference) utilizing superconducting magnets will bring the proton energy to $1 \mathrm{TeV}$, ready for injection in to the main ring. Construction of the injector assembly may be by cut-and-cover or tunneling methods. The choice of construction method is dependent on specific site conditions and the final design of the assembly.

The experimental areas, also known as collision or interaction halls, will number four initially, with provision for two more in the future. To accommodate the facility's massive detectors, some collision halls will be approximately $300 \mathrm{ft}$ in length, $100 \mathrm{ft}$ in width, and $115 \mathrm{ft}$ in height. They will account for more than half the total excavation volume at the SSC site. Current plans do not specify whether all of the collision halls will be located near the campus area or whether some will be located at a satellite campus on the opposite side of the ring.

Detectors for the SSC will far surpass existing collider detectors in both size and complexity due to the high particle collision rate $(100 \mathrm{million} / \mathrm{sec})$ of the SSC and the large quantity and high energy of collision products. Resolving the precise paths of the hundreds of particles that can arise from a single proton collision and capturing the most energetic of these particles will require detectors that may exceed 40,000 tons, with more than a million data channels leading from them. Thus, collision hall floors and subsoils will have to bear extremely massive and concentrated loads.

The SSC campus area will encompass approximately 500 acres and will accommodate roughly 2,500 workers in 15 or more buildings. These buildings will include a central laboratory and auditorium, with associated administrative and technical offices; industrial and shop buildings; warehouses; and auxiliary support facilities such as fire, rescue, security, visitor services, waste management, and vehicle storage buildings.

The SSC's infrastructure system must accommodate the facility's power, water, transportation, communication, and refrigeration needs. A main electrical substation located on the campus site will serve the campus buildings, the injector system, and half of the main collider ring; a second substation will be located on the ring's opposite side. A road network will connect the campus facilities, the injector facilities, and the ring access shafts. Water used for cooling will be processed in special treatment facilities. 
Among the SSC's inf rastructure requirements, none is more challenging than the need for a reliable cryogenic system to bathe the SSC magnets and beam tube with liquid helium to maintain the low temperature required for superconductivity (approximately $4.5 \mathrm{Kelvin}$ ). While the technology has been successfully proven at Fermi National Accelerator Laboratory's Tevatron collider in Illinois, the SSC's cryogenic system will be some 13 times larger.

\section{THE DESIGNATED SITE}

The site selected for the Superconducting Super Collider facilities is located near the community of Waxahachie in Ellis County, Texas. This rural setting is a 45-minute drive from the major metropolitan resources of Dallas-Fort Worth. Figure 1.1 shows a plan view of the site and Figure 1.2 shows the proposed profile.

\section{Geologic Setting}

The project site lies within the Blackland Prairie physiographic province and the drainage basin of the Trinity River. Topographic relief across the site is approximately $350 \mathrm{ft}$, with elevations ranging from 400-750 $\mathrm{ft}$ above mean sea level.

North Central Texas is underlain by a thick sequence of sedimentary rocks that dip gently southeastward toward the Gulf of Mexico. These rocks form broad northeast-trending outcrops. The units decrease in age from Paleozoic inland to Quaternary at the Coast. The outcropping units in Ellis County belong to the Upper Cretaceous Gulf Series, except for thin deposits of alluvial material along streams and on terraces.

The Gulf Series includes the Taylor, Austin, Eagle Ford, and Woodbine Groups; the Austin and Taylor groups outcrop at the site. These are covered locally by Quaternary Terrace deposits and recent alluvium in the modern streams. Although the Taylor, Austin, and Eagle Ford Groups are subdivided into recognizable formations, the traditional names Taylor Marl, Austin Chalk, and Eagle Ford Shale are used in this report.

Further details on the geology of the Ellis County site are contained in Appendix 1.

\section{Tunneling and Underground Construction}

The proposed tunnel alignment is planar, with a 0.23 degree slope. Tunnel elevation is established by minimum cover requirements below Waxahachie Creek and the desire to maintain some thickness of Austin Chalk between the tunnel invert and the Eagle Ford Shale below.

Some $38 \mathrm{mi}$ ( 70 percent) of the tunnel ring will be in Austin Chalk, while $15 \mathrm{mi}$ (30 percent) will be in Taylor Marl. As observed in core samples, the nature of the contact between the Taylor Marl and the Austin Chalk varies from sharp, of ten faulted, to transitional, with no sharp delineation. This description also applies to the contact between the Austin Chalk and the Eagle Ford Shale. 


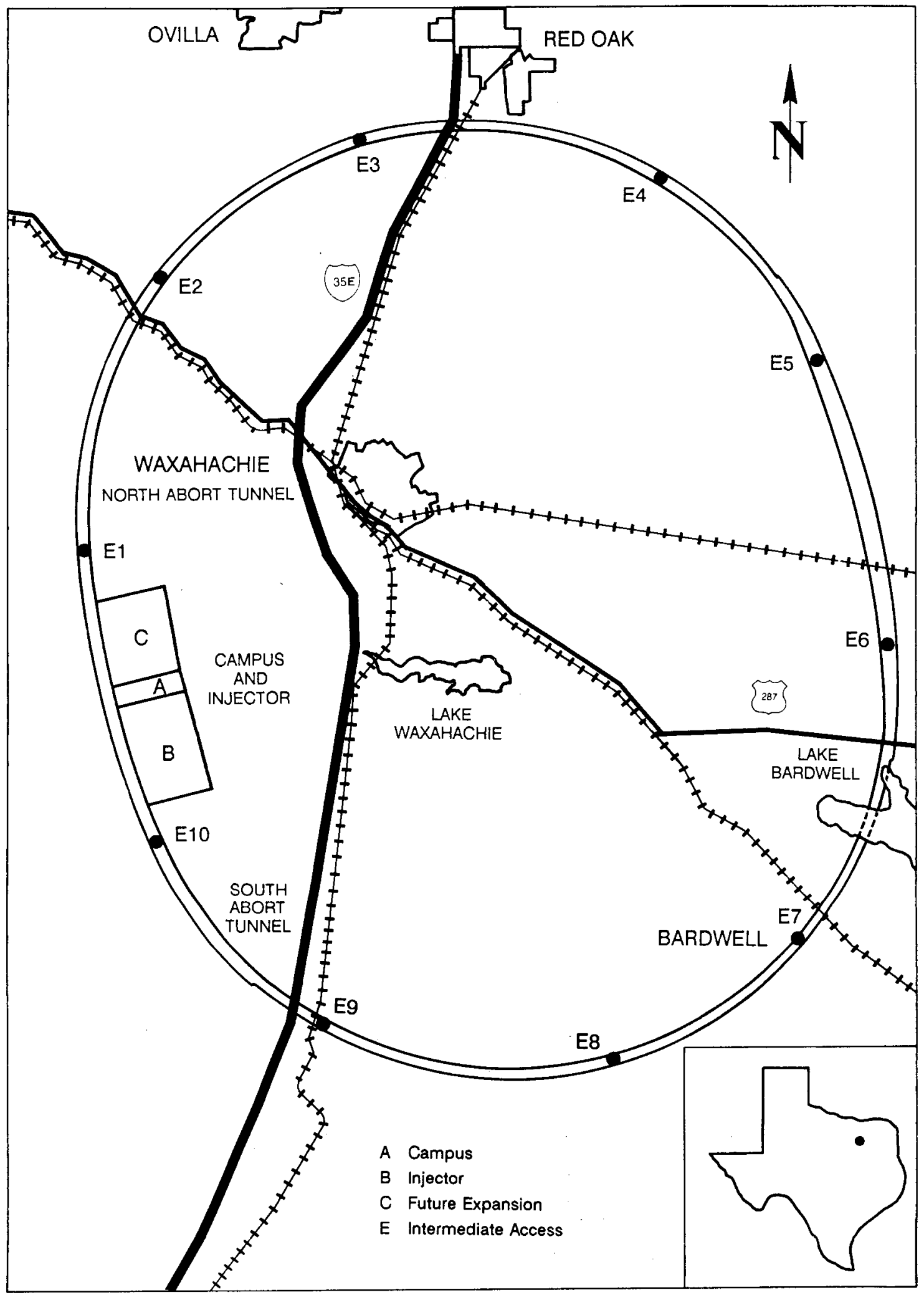

FIGURE 1.1 A plan view of the proposed Superconducting Super Collider site, showing Waxahachie and surrounding communities. 


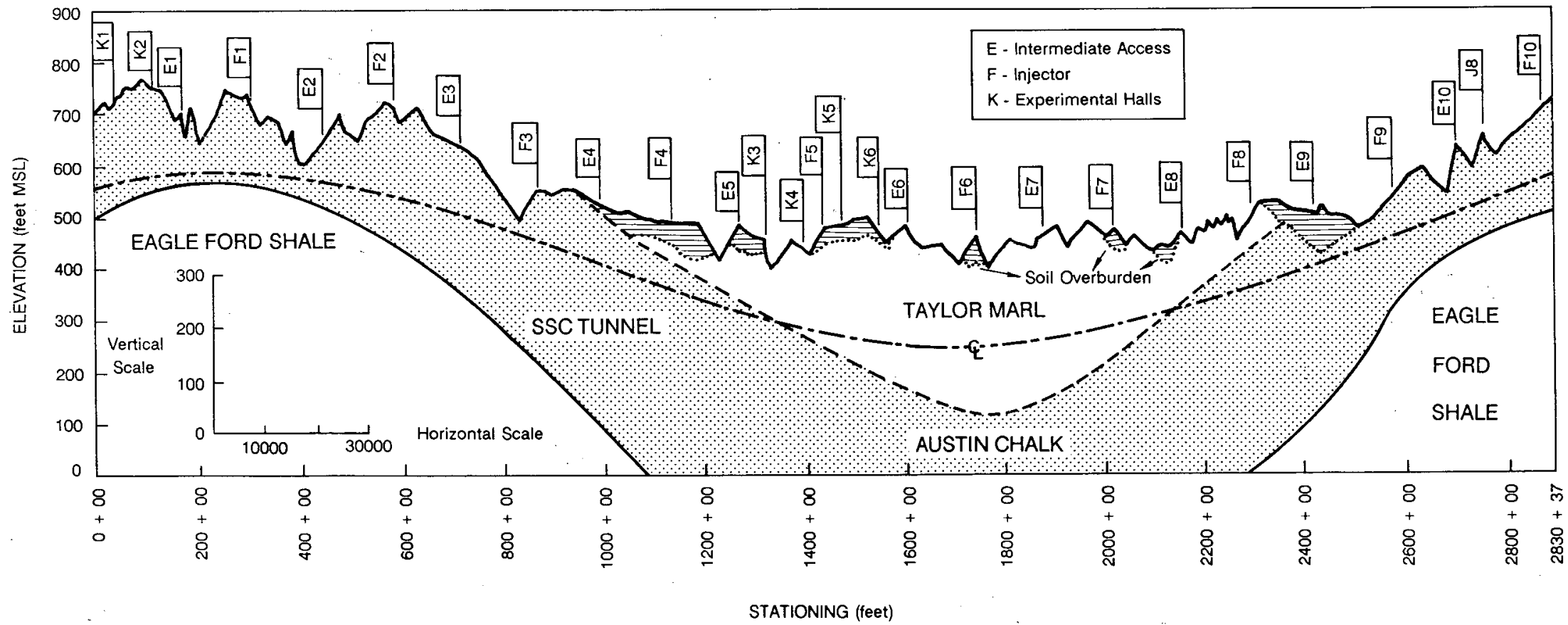

FIGURE 1.2 Geologic profile along the proposed SSC collider ring. 
Structural contour maps of the top of the Eagle Ford Shale and the top of Austin Chalk show that no significant faults or folds are present. Regional strike and dip are uniform.

Experimental hall excavations will range in depth from 165 to $220 \mathrm{ft}$, while shaft depths will range from 65 to $230 \mathrm{ft}$. These structures will be constructed through the terrace deposits where perched water conditions are expected. Groundwater flows associated with these units are expected to be controllable with normal construction methods. The soils developed on the Taylor Marl and the Austin Chalk consist of moderate to high shrink-swell clays and silty clays. The shrink-swell properties of these soils are understood and are routinely accommodated in both temporary and permanent construction in the region of the site.

The permeability of fresh Austin Chalk at the site is very low $(1.6 \mathrm{x}$ $\left.10^{-8} \mathrm{~cm} / \mathrm{sec}\right)$, as is the permeability of the Taylor Marl $\left(1.0 \times 10^{-8} \mathrm{~cm} / \mathrm{sec}\right)$. During construction, groundwater inflows in the tunnel should be minor and limited to seepage from rare joints and fractures connected to the surface. Such occurrences will be treated using routine methods. Problems with water inflows while tunneling under Bardwell Lake are not anticipated because the tunnel is nearly $160 \mathrm{ft}$ below the lake bottom in the relatively impervious Taylor Marl.

\section{Difficulties and Advantages for Underground Construction}

The rock encountered at the Ellis County site presents favorable conditions for efficient excavation by tunnel boring machines. The Austin Chalk and Taylor Marl are notably uniform and equipment design can be optimized for superior performance in these materials. Recent projects provide documentation of the advance rates possible in these formations. Average advance rates for the Austin Chalk have been $65 \mathrm{ft}$ per 8 -hr shift, while average advance rates in the Taylor Marl of $135 \mathrm{ft}$ per 24-hour day have been achieved. ${ }^{1}$

The strength of both the Austin Chalk and Taylor Marl is low enough to promote efficient mechanical excavation but high enough that initial support requirements will be minimal. The rock is nonabrasive, which will reduce the number of cutter changes required; maintenance of the equipment will be facilitated by the dry conditions.

Potential problems that may arise in tunneling through these units include the impact of mixed face conditions occurring at the transition between these two materials. Such a juxtaposition will occur in at least two locations around the ring. Nonetheless, the material strengths are not expected to be so different as to cause extreme problems for excavation by either soft-ground or hard-rock equipment.

Most of the tunnel is expected to be self-supporting during the excavation. The Texas National Research Laboratory Commission (TNRLC) proposal (1988) indicates that protection against slaking and loosening conditions in the Taylor Marl could be provided by the precast segments installed as temporary and final support. The proposal suggests that 3 to 4 in. of shotcrete will serve this purpose in the Austin Chalk.

${ }^{1}$ Texas National Research Laboratory Commission. 1988. Proposal for site selection submitted to DOE. Germantown: U.S. Department of Energy. 
The Eagle Ford Shale will be encountered at the base of the excavations for two of the experimental halls (locations $K-1$ and $K-2$ in Figure 1.2), where special consideration will have to be given to this unit's potential for swelling, as well as settlement under the heavy loads of the detectors.

\section{SSC CONSTRUCTION CONCERNS}

The scale of the SSC will dwarf present state-of-the-art colliders in the United States, Europe, Japan, and the Soviet Union. Its experimental program, particle detectors, and data analysis techniques will all require a high order of innovation and international collaboration.

Yet the challenge the SSC offers the underground construction industry is less one of innovation in construction techniques-traditional cut-and-cover methods or the use of tunnel boring machines should suffice-than of innovation or careful scaling up of management and contracting practices. Principal issues include the sharing of project risk between the SSC contractors and the facility's owner; control of project cost and schedule; construction contract package size and the interface between contractors; and consonance of contracts with regulations governing federal projects.

Although it is planned that management of the SSC facility and its construction will not be undertaken directly by the U.S. Government, the government's influence will still be felt in the area of contracting practices. The Department of Energy has selected Universities Research Association, Inc. (URA) as Management and Operating contractor $(\mathrm{M} \& O)$ for the establishment of the facility and a subsequent five-year span. Responsibility for engineering and construction of the SSC will be assigned, when an Architect-Engineer/Construction Manager (AE/CM) is retained.

Though construction contracts will be managed and executed by the project's $\mathrm{AE} / \mathrm{CM}$, resolution of contract disputes is an area of possible concern, since the U.S. Government cannot, by law, be bound in advance by the results of arbitration: Any risk sharing scheme must, of necessity, reflect this fact.

While the land area affected by the SSC totals some 15,000 acres, most of this will be obtained by the government in a stratified fee arrangement for subsurface rights, since surface use is not required above most of the collider ring. Surface ownership by the government need only apply to the cluster containing the experimental areas-about 5,000 acres-and the campus/injector area-about 3,500 acres.

The State of Texas will be responsible for acquiring the necessary lands for SSC use, as well as providing roads and utilities to the SSC site. In addition, the state government must arrange for adoption of uniform building codes throughout the construction site, despite the fact that construction may take place in several local jurisdictions.

Coordination of underground construction schedules with the fabrication and installation schedules for the detectors, the superconducting magnets, and the cryogenic plumbing will play a critical part in meeting cost and start-up goals of the SSC. Plans call for immediate installation of magnets as they are fabricated to avoid the need for magnet warehousing. Thus, construction schedules must proceed in tandem with magnet fabrication and construction delays must be kept to a minimum. Each 5-mi tunnel section is independent in terms of cryogenic system and power supply and will be commissioned as completed. Thus, portions of the construction phase and the system test phase can take place simultane- 
ously, with completed SSC segments available for low-power testing while construction proceeds elsewhere.

\section{PREVIOUS STUDIES}

It has long been realized that underground construction presents special challenges in project management and contracting practices. One reason is that the level of uncertainty, and thus risk, inherent in such projects is typically higher than in comparable-scale construction above ground. For instance, crucial geotechnical factors often are not completely known or understood prior to construction in spite of improved geotechnical analysis. Such factors assume a greater importance than in above-ground construction and can introduce considerable variability in the cost and complexity of construction.

Adding to the management burden is the fact that underground construction, by its nature, incorporates special techniques, equipment, and skills to accommodate the severe environment in which it takes place. It is not surprising, then, that underground projects are particularly dependent on sound management and contracting practices for their success. Recognizing this, several past studies have addressed these topics with notable effect.

Better Contracting for Underground Construction (U.S. National Committee on Tunneling Technology, 1974) was among the first reports to elucidate the concept of sharing risk between owner and contractor in order to lower project bids and total project costs, as well as avoid costly delays due to litigation or other disputes. In order to facilitate this sharing of risk, the report recommended:

- inclusion of differing site condition clauses in contracts (especially with respect to water problems) and the provision of contract change procedures to accommodate unforeseen site conditions,

- full disclosure of all relevant geotechnical data and analyses, without the use of disclaimers,

- assumption by the owner of responsibility for designing or establishing criteria for contractor design of most temporary tunnel support systems required during construction, and

- use of arbitration to quickly settle claims.

In addition, the report suggested including escalation clauses in contracts to cover inflation; prequalifying bidders to assure that work goes only to qualified contractors; and considering the use of wrap-up insurance (a single, coordinated insurance program provided and administered by the owner and covering all construction contracts awarded during a project).

Building on this earlier work, the U.S. National Committee on Tunneling Technology published Better Management of Underground Construction Projects in 1978. Here, the need for an integrated management approach to the construction of major underground projects was explored in detail, with identification of key stumbling blocks in efficient project management and recommendations concerning formulation of project goals, the assignment of responsibility, the distribution of risk, and the importance of timeliness and scheduling.

The committee stressed that delayed decisive action is the primary cause of management problems in underground construction. They recommended that clear 
lines of responsibility must be established and that the practices controlling contract awards, contract forms, and contract changes should be refined "to permit the project management team the level of decision authority required to take prompt responsive action in contract matters."

The report emphasized the need to develop a procedure for solving design or field problems without incurring work stoppages or other delays. In this regard, it suggested the use of a professional review board to settle claims and disputes that cannot be solved easily by normal contract administration procedures before the completion of the work.

The international community has also focussed its effort in the area of management and contracting for underground construction projects. The International Tunnelling Association (ITA) has adopted 19 recommendations that were developed by its Working Group on Contractual Sharing of Risk (see Appendix 2). The guidelines include discussion on the inclusion of changed conditions clauses in contracts, the need to fully disclose subsurface information, and the benefits of eliminating disclaimers on the geotechnical data. Prequalification of contractors is recommended and indexing certain price variations is discussed. Steps to avoid and resolve disputes are also outlined.

The ITA guidelines include such subjects as ground support, ground characterization, bidding and awarding the contract, mobilization payments, measurement problems, performance bonds, and coordinated insurances. Also included are discussions of the engineer's role during construction, permits, rights-of-way, water problems, and provision of plant, equipment, services, and materials by the owner.

Though industry and public agencies responsible for most underground construction have adopted many of the suggestions contained in the reports mentioned above, the size and complexity of modern underground construction and the escalating cost of litigation continue to drive the refinement of mechanisms to resolve disputes between owner and contractor. In Avoiding and Resolving Disputes In Underground Construction (Underground Technology Research Council, 1989), the authors focus on four key risk-sharing provisions that contracts for major underground construction projects should incorporate. These provisions include:

- a differing site conditions clause (as recommended in earlier reports and commonly used today);

- a requirement to incorporate the geotechnical design summary report, which records the design engineer's interpretation of geotechnical data regarding anticipated site conditions directly into the contract to establish a concise geotechnical base line allowing clear identification of differing site conditions when they occur;

- an agreement to place all bid documents in escrow, where they can be used to establish the intent and expectations of the contractor at bid time;

- and an agreement to establish a disputes review board.

It is with these reports as precedents that the present study makes its recommendations for sound contracting practices for the underground construction portion of the Superconducting Super Collider project, whose magnitude and scope make such sound practices all the more imperative. 


\section{ORGANIZATION AND MANAGEMENT}

The Superconducting Super Collider comprises a large-scale engineering, procurement, and construction project-a "megaproject" comparable in scope and technical complexity to urban transit systems, nuclear power plants, and industrial complexes. In general, the construction industry has proven its capability to handle such megaprojects, but there have been a few well-publicized failures as well. The subcommittee believes that the differences between successful ventures and those that have fallen short derive largely from differences in organizational structures and management systems.

The SSC appears to be well within the physical and technological scope of successful megaprojects; however, it does pose unique challenges in both technology and administration that will require careful formulation of its organizational structure and management policies. The SSC brings together people from diverse professional cultures-specifically, the high-energy physics community and the construction industry. Depending on how roles are defined and responsibilities allocated, these varied backgrounds can either complement each other in a unified team, or engender conflicts that impede progress, increase costs, and delay completion.

The subcommittee recognizes that underground construction represents only a portion of the overall SSC program. Nonetheless, this tunneling portion of the project should not be seen in isolation from the construction of the advanced technical facilities of the collider itself. Rather, the subcommittee stresses that the tunneling and the other major components of the SSC must be viewed as a single system from both technical and management points of view to obtain the best result. General principles for achieving this objective are as follows:

- issue an overall management plan,

- prepare plans to ensure proper and timely staffing throughout the life of the project,

- establish policies and procedures for effective prosecution of the work in accordance with an of ficial budget and schedule,

- develop procedures for integration of technical systems and conventional construction,

- establish responsibility for coordinating infrastructure development and administration of the work site(s),

- establish policies and procedures for controlling work changes and promoting expeditious problem solving, 
- review constraints affecting the team or any team member's ability to perform (e.g., availability of skilled manpower, lack of specialized equipment, etc.), and

- establish policies on outside advisory boards or panels for constructibility reviews.

\section{ORGANIZATION}

There are several organizational approaches to managing large, complex, and costly projects (U.S. National Committee on Tunneling Technology, 1978; Sperry, 1976, 1981). At a minimum, the organization must consist of a separate, dedicated project team containing all its own organizational resources (managers, technical staff, support staff, facilities, and equipment) to accomplish the project. Further, it should have a clear and concise mission or scope of responsibility. Such an organization can then adopt a contracting philosophy that encourages prompt, coordinated, cost-effective actions; equitable sharing of risk; and a "one-team" approach (including contracted forces) with a management structure and contracting practices designed for positive achievement.

Figure 2.1 summarizes the general organizational relationships among the parties to the SSC project. Some of the key parameters and constraints that must be considered in terms of organization are as follows:

- Responsibilities: Tasks must be defined and allocated among the Department of Energy (DOE), the Management and Operating contractor (M\&O), the Architect-Engineer/Construction Manager (AE/CM), and the construction contractors in a manner appropriate to their respective responsibilities.

- Authority: Authority commensurate with responsibilities must be delegated in a manner that reaches low enough in the organization to facilitate effective decision-making on a routine and consistent basis.

- Communication: Standards and communications issues such as a common Computer-Aided Design and Drafting (CADD) system, an integrated schedule and control system, coordinated procurement, and consistent contract administration must be clearly addressed at the project's inception. In addition to establishing the commonalities of formal communication for these systems, it is essential that a positive and direct communication mechanism be established regarding time, cost, quality, and construction operations.

In addition, the issue of organizational fragmentation should receive some attention. The performance of megaprojects constructed in the last two decades, such as urban rail transit systems, nuclear power plants, and synfuel plants, seems to indicate that those projects with less fragmentation of responsibilities have been more successful than those that spread responsibilities across disjointed and even competing organizations, whether across multiple firms or even across divisions within a single firm. For example, the San Francisco Bay Area Rapid Transit District (BART) formed a highly integrated, autonomous joint venture (PBTB: Parsons-Brinckerhoff-Tudor-Bechtel) to carry out design and construction of its urban rail system. The project appeared to proceed more efficiently than transit projects with separate design firms, a separate construction manager, and diverse contractual standards.

Experience with many large-scale industrial construction projects, where almost all design and construction is accomplished by one organization, seems to 


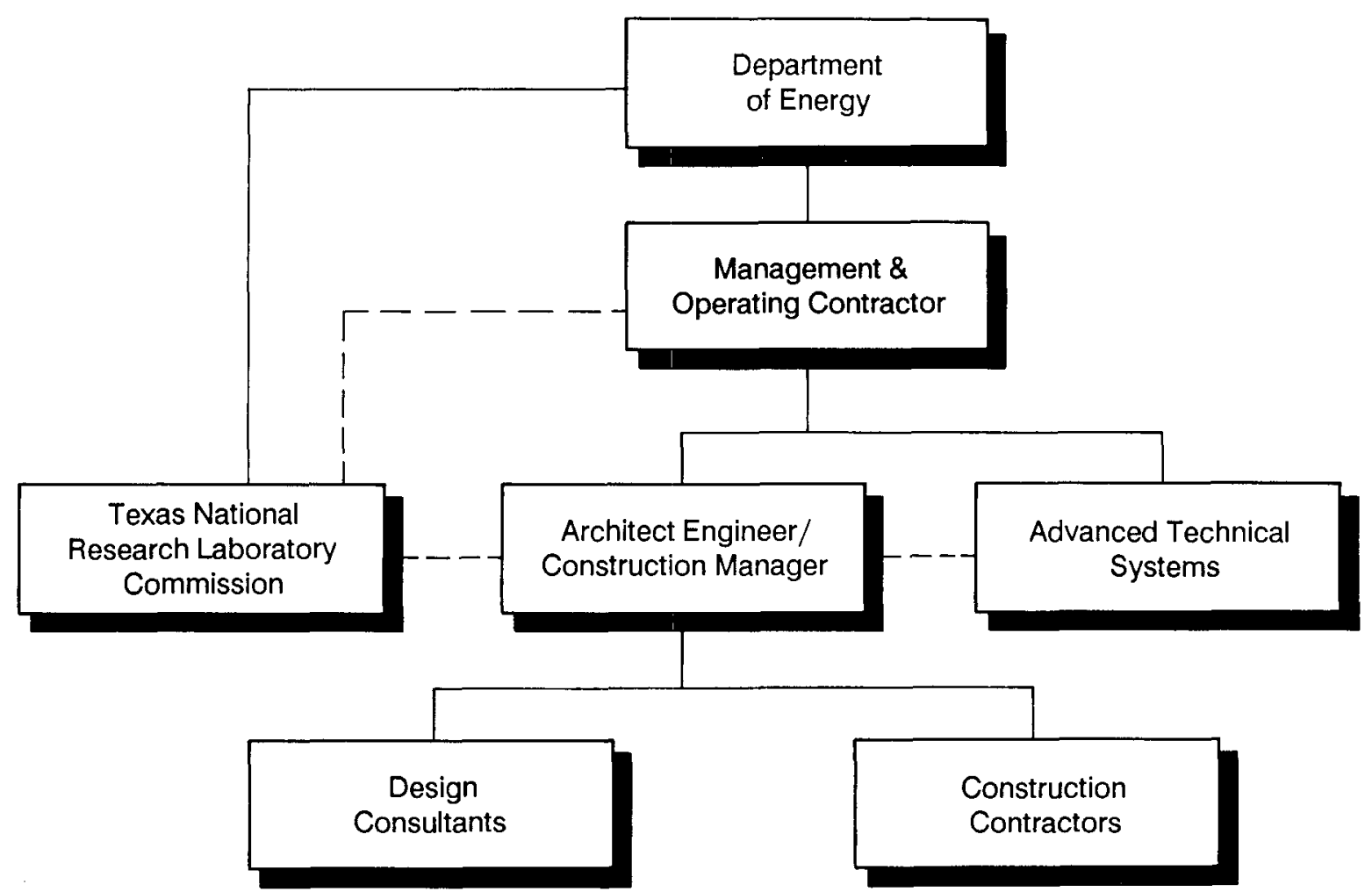

FIGURE 2.1 The Organizational Hierarchy for the Superconducting Super Collider.

bear out the benefits of integration. Nuclear plants designed and constructed by a single firm, such as those at Palo Verde and San Onofre in California, seem to have been more successful (with some exceptions) than those where work was accomplished by an Architect-Engineer/Construction Manager not performing direct construction, or by a separate Architect-Engineer and Construction Manager. Syncrude, a technically complex $\$ 7$ billion tar sands mining and refinery project remotely located in northern Alberta, substantially held to budget and schedule in spite of a 7,000-person work force and a yearly cash flow of over $\$ 2$ billion. It was largely a design-construct, single-firm project.

Such integration can be achieved in various ways, including joint ventures that transfer resources from several parent firms to an autonomous project organization. The key is management leadership. Regardless of the method by which it is achieved, the subcommittee recommends that a commitment to reducing fragmentation and achieving effective integration should figure strongly in the selection of the $\mathrm{AE} / \mathrm{CM}$. 


\section{ROLES AND RESPONSIBILITIES}

In discussions below, the subcommittee explores the joint and separate roles and responsibilities it believes the Management and Operating contractor (M\&O) and the Architect-Engineer/Construction Manager (AE/CM) should assume in their dealings with underground construction contractors.

\section{Joint Responsibilities}

The M\&O and the AE/CM should have a clear, unduplicated, and widely understood delineation of responsibilities, assignment of tasks, and delegation of authority. This will of fer construction contractors clear guidelines within which to work, minimize confusing and contradictory policies and actions, and promote prompt and equitable resolution of questions and problems.

The $M \& O$ and $A E / C M$ organizations should jointly address communications and construction standards. These include standardization of CADD and project management software and operating systems, policies, and procedures; the balancing of decentralized versus centralized procurement; issuance of consistent standards for subcontracting; the performance of interference checking (for objects designed mistakenly to occupy the same space) between facilities designed at the M\&O and AE/CM levels; and the scheduling and sequencing of contractors in areas of limited access.

Standards that must apply across both conventional construction and advanced technological systems should be developed and communicated from the M\&O level, with the aid of the AE/CM. Otherwise, standards substantially limited to conventional construction should be controlled by the $\mathrm{AE} / \mathrm{CM}$.

\section{M\&O Roles and Responsibilities}

The $\mathrm{M} \& \mathrm{O}$ will largely reflect the culture of the high-energy physics research community for whom the SSC will be built. In general, this will be an asset to construction. In building other national laboratories housing colliders or accelerators, such as the FermiLab in Illinois or the Stanford Linear Accelerator in California, the physicist-managers appear to have been goal-driven, team-oriented pragmatists. They displayed a strong technical and management interest not just in the systems involving advanced technology, but in the details of the "conventional construction" as well. The resulting laboratories are generally utilitarian and economical in their civil and architectural design standards; they are fundamentally machines to do basic science, not monuments to institutions.

Nonetheless, the M\&O must assure that the natural scientific curiosity of its physicist-managers does not lead it to either bypass the AE/CM or otherwise second-guess its efforts by too directly involving itself in detailed management of the construction contractors. For this reason, the responsibilities of the M\&O should be explicitly defined:

- The M\&O should assume overall responsibility for accomplishing the project and managing the broad technical, design, and construction activities required to build the project and place it into operation.

- The M\&O's organization should include a staff of experienced managers and other professionals whose functions are to direct the project; to assist and 
coordinate the consultants, designers, and contractors in resolving problems; and to identify and remove potential roadblocks.

- The M\&O should define realistic and attainable goals and objectives applicable to all members of the team, delineate clearly the responsibilities of each of the major elements of the project team, and officially delegate authority to the major team members. Authority should be commensurate with the responsibilities assigned.

- The M\&O should assure that the interfaces among the parties involved in the project are properly managed. Specifically, the M\&O must be responsible for interfaces between the Advanced Technical Systems Group (whose prime concern is the supercollider machinery itself, including the particle detectors) and the $\mathrm{AE} / \mathrm{CM}$.

- The M\&O should select an AE/CM with broad experience and capabilities proven in designing and managing construction of underground projects of similar size, cost, and complexity. The contract with the AE/CM should provide for appropriate incentives and disincentives to encourage the success of the construction contractors and the overall execution of the project in a timely manner that assure high quality. Among the elements that should be considered are: timely completion of shop drawing review; allowances for staff training and development; staff retention and longevity; and allowances to complete the final contract measurement, documentation, and claim/dispute resolution. The AE/CM organization should be augmented, as required, by consultants, specialists, and other professional assistance under contract to the AE/CM.

- The M\&O should manage the advanced technical systems of the project and delegate functional management of the conventional facilities-tunnel, access shafts, collision halls, utilities, and campus facilities-to the AE/CM.

plan.

- The M\&O must prepare and disseminate a risk and liability allocation

- The M\&O should structure its relationship with the AE/CM without undue administrative constraints by the Department of Energy on contract awards, approvals of changes, progress and completion payments, and other contractual duties integral to project management. Suggested guidelines in the area of procurement policy are presented later in a separate section.

The M\&O's contract with the AE/CM should be designed to complement and encourage the success of the construction contractors and the overall project. Among the elements that should be considered are: incentives for timely completion of shop drawing review (and disincentives for failures); direct allowances for staff training and development; incentives and direct resources for staff retention and longevity; and incentives and allowances to complete the final contract measurement, documentation, and claim/dispute resolution.

\section{AE/CM Roles and Responsibilities}

The M\&O should delegate to the $A E / C M$ the responsibility and authority for effective program management of design and construction of the SSC conventional facilities. The $\mathrm{AE} / \mathrm{CM}$ is expected to be a separate and dedicated project team. If it is a joint venture, it should be substantially independent from its parent firms and should possess, in its own right, the organizational resources to accomplish the project. 
There must be strong coordination of the AE/CM with the system-wide program managers of the M\&O. Only in this way can integration of the conventional design and construction with the design, procurement, and installation of the advanced technical systems (e.g., sequencing of tunnel sections with electrical and mechanical systems, cryogenics, magnets, and detectors) be achieved.

For the tunnel construction contracts, the AE/CM must have direct contractual authority and appoint experienced construction professionals to be responsible for contract administration. As expressed previously, the contracting representatives of the AE/CM must have authority commensurate with their responsibilities and be able to resolve modifications or problems and implement remedial actions at the levels closest to the needed actions. Some specific AE/CM roles and responsibilities should be as follows:

- The AE/CM should be responsible to the M\&O for managing the design and construction programs.

- The AE/CM should function as an extension of the M\&O in scheduling, managing, and accomplishing the design, construction, and installation of all facilities to meet the project goals and objectives for conventional construction. In turn, the M\&O must define its role to reduce any unnecessary constraints on the $\mathrm{AE} / \mathrm{CM}$ in execution, review, and decision making regarding engineering and construction matters.

- The AE/CM should establish design criteria setting forth standards of quality and specify requirements to be met within prescribed schedules and budgets. It must be clear that the end product is a completed project ready for operation.

- The AE/CM should establish realistic budgets and schedules, monitor and control them, and provide adequate mechanisms for revisions and updates.

- As agent for the M\&O, the AE/CM should award and manage construction and related procurement contracts, and determine the most effective form of contract.

- The AE/CM should survey the tunneling industry market before the time the SSC project goes out for bid, identifying all known major projects likely to compete for resources in the same time period. For example, major tunneling projects worth a total of $\$ 3$ billion are likely in New York City and Boston within the expected SSC construction window. A glutted market may limit competition and increase prices, thus becoming an obstacle to the successful completion of the SSC. The AE/CM should consider the size and bid timing of contract packages to minimize the economic impacts of competing projects elsewhere in the United States.

\section{TNRLC Roles and Responsibilities}

In proposing the Ellis County site for the SSC, the State of Texas offered some specific assistance with a direct bearing on the successful execution of construction. It is the subcommittee's understanding that TNRLC will serve as the state's agent in providing this assistance and fulfilling its responsibilities. The most important elements of the state's assistance involves insuring the availability of the necessary infrastructure (utilities, highways, disposal sites, etc.) and real estate and providing for the TNRLC to serve as the single point of contact for all the permits required by the construction contractors and for assistance in overcoming regulatory hurdles. 
An agreement to this effect should be executed between DOE and TNRLC. This agreement should clarify the role of TNRLC, allocate the specific responsibilities, and establish the formal linkage through subagreements with the M\&O and $\mathrm{AE} / \mathrm{CM}$.

\section{MANAGEMENT OF CONSTRUCTION CONTRACTS}

The following sections elaborate upon specific management issues deemed particularly important to the SSC project.

\section{Phillosophy}

The M\&O should begin with a statement of management philosophy that focuses attention on the conventional facilities and does not allow them to be taken for granted. Likewise, it is important that the parties responsible for the conventional facilities appreciate the overall scope of the project, including the advanced technical systems. In addition, there should be both formal and informal education of the M\&O staff about the underground contracting world and its risks. This process will build team unity and prepare the organization for the deviations in progress and cost that may occur.

\section{Allocation of Risk and Responsibility}

The M\&O should address early, and with expert assistance, its policy on the assignment of risk and responsibility. This policy should recognize the nontraditional roles assumed by the $\mathrm{AE} / \mathrm{CM}$ in areas such as insurance program management (see Chapter 6) and the development and management of support facilities. It is desirable that this assessment be accomplished previous to the selection of the $\mathrm{AE} / \mathrm{CM}$, because decisions made in this area may well affect the form that the contract between the $M \& O$ and the $A E / C M$ assumes, as well as the willingness of $\mathrm{AE} / \mathrm{CM}$ firms to participate in the project. Chapter 4 provides more detailed guidance on the subject of risk allocation.

\section{Procurement Policies and Authorities}

The subcommittee understands that the $A E / C M$, under contract to the $M \& O$, will award the construction contracts for the SSC work. It is expected that there will be a number of construction contracts to be awarded in amounts of \$25-100 million and perhaps larger. Normally, contract awards in excess of a \$25 million threshold must receive the approval of the procurement executive of the DOE. For this project, the subcommittee sees needless delay with this approval process in force.

To promote project efficiency, the subcommittee recommends that DOE grant the $A E / C M$ authority for construction related contracts sufficient to effectively carry out its responsibilities (i.e., up to $\$ 100$ million). Another option would be to establish at the SSC site a DOE field office responsible for approving contract systems or specific actions that will fall into these upper cost levels. In either case, contractual authority would be exercised locally, avoiding delays. 
The subcommittee thus recommends that the DOE procurement executive grant the $A E / C M$ the authority to award fixed-price, competitively bid construction contracts up to $\$ 100$ million. The procurement process used to bid such contracts could be reviewed and approved by DOE initially.

Alternatively, the procurement executive for the DOE's SSC field office may wish to review a model bid solicitation in excess of $\$ 25$ million after which the $\mathrm{AE} / \mathrm{CM}$ could act on its own.

As for changes negotiated after construction contracts are initially let, DOE approval is a logical requirement at a lower dollar threshold, since competition does not come into play in change orders. A limit of 5 percent of the original contract amount or $\$ 500,000$, whichever is greater, would seem appropriate, assuming the procurement system of the AE/CM is accepted. Any such approvals should be delegated to the DOE office at the SSC site.

\section{Sof tware Standards}

As stated earlier, the M\&O should define and enforce the sof tware standards and systems for Computer-Aided Dèsign and Drafting (CADD) sof tware, scheduling, and cost reporting to insure best management practice. The M\&O should consider engaging a manager to coordinate computer hardware and sof tware systems and to institute a training program to aid this coordination. This approach has been recently adopted in the Boston Harbor clean-up and the Central Artery Underground-two Massachusetts megaprojects that involve major tunnel construction. The advantages are that engineering communication is standardized and small design or construction firms have a greater chance at effective project participation. Standard engineering communication across all phases of the project should also reduce errors.

\section{Project Completion}

Defining project completion is often vexatious, leading some bidders to assume that retainage (the 5-10 percent that is typically withheld from a contractor's payments until its contract is complete) will not be released until the end of the contract, and thus build higher finance costs into their bids. The M\&O will improve price and project comity if it comes to an early agreement with the $\mathrm{AE} / \mathrm{CM}$ on measurable criteria and thresholds for substantial completion, beneficial occupancy, final completion, and cleanup.

In addition, prior agreement on these criteria is critical to achieve timely hand-over of the tunnel elements-a necessity to minimize friction with the advanced technical system contractors who will occupy the tunnels and halls after they are constructed.

\section{Stop Work}

Despite good intentions, it is of ten unclear who can issue orders to temporarily or permanently stop work on a project. The M\&O and the AE/CM can reduce confusion if they clearly define the line of authority and the process of

confirming change orders. This understanding should be fully incorporated in the 
contract documents and all contractors and senior contractor personnel should receive formal training on these issues.

\section{Permits and Agreements}

Timely acquisition of permits is essential to maintaining the schedule on any major project and can prove troublesome. The M\&O, primarily through TNRLC and assisted by the $\mathrm{AE} / \mathrm{CM}$, should be responsible for all permits and authorizations and for ensuring that the necessary infrastructure is available to allow the SSC construction to proceed in an orderly and timely manner. In this way, the $M \& O$ can reduce the risk of project delay, and thus the cost. It does not appear to be cost-effective to transfer the permit or site availability risk to the $\mathrm{AE} / \mathrm{CM}$ or the contractors.

The M\&O must issue clear instructions to the $A E / C M$ and coordinate with TNRLC concerning the terms of any agreements involving permits or other regulatory matters. The M\&O must supervise and coordinate the efforts of its own staff and that of the AE/CM to assure that acceptable and timely agreements are being reached. If necessary, the $M \& O$ must intercede with appropriate local and state authorities. For major issues, the Executive Review Board should become involved.

\section{Federal Regulations}

There will be substantial "flow-down" of federal procurement and acquisition rules to the work of the $\mathrm{AE} / \mathrm{CM}$ and the tunnel and excavation contractors. Early on, the M\&O should establish with the AE/CM the extent of this flow-down on rules concerning Disadvantaged Business Enterprises (DBE), Small Business Enterprises (SBE), and other federal requirements. The M\&O should then provide organizational support to achieve the project's objectives on these issues. Achieving these objectives will be critical to satisfying the interests of the Department of Labor, various affirmative action agencies, and other federal entities within and outside the DOE project management group. A more detailed discussion of "flow-down" is included in Appendix 4.

\section{Flow of Funds}

The flow of funds to contractors is critical to project harmony. The financial needs of the project must be communicated to the Congress and the Office of Management and Budget. Concomitantly, the realities of the Congressional appropriations process must be accommodated in planning the SSC project. The M\&O and the AE/CM should come to early agreement on:

- mobilization components (payments to set up temporary plants and equipment needed to support construction),

- progress payment procedures,

- payment retainage criteria and standards, and

- interim payment mechanisms pending resolution of disputes on changes and any unit overruns. 
These agreements must be quantified and training modules developed so that those involved in money flow on every side and on all contracts understand what is to be done to get paid and to ensure the continuity of cash flow. The importance of this continuity must be communicated to all.

\section{Site Support Systems}

Tunnel sections will be occupied serially by various contractors. It would be cost-effective for the $\mathrm{AE} / \mathrm{CM}$ to assume responsibility for organizing, providing, and allocating construction site support systems, including temporary roads, site utilities, environmental management, and muck disposal. Depending on location, this site management role might extend to security, location of trailer housing sites, and other issues as well. The responsibility of the $A E / C M$ in this regard would last until project completion and acceptance by the M\&O.

\section{Consistency Across Contracts}

The presence of multiple contractors in the field, whether undertaking similar work or not, requires particular attention to the consistency of decisions and good communication. The $M \& O$ will be more successful in managing multiple contractors if it motivates the $\mathrm{AE} / \mathrm{CM}$ to develop systems for periodic training of contracting staff in administrative procedures. Likewise, project harmony will be enhanced if the M\&O promotes communication that increases:

- consistency of decisions among resident engineers;

- common understanding of contract rules by project superintendents; and

- communication of the outcomes and supporting rationale of dispute resolution.

An informal system of communication will inevitably develop; a formal system will help improve clarity and accuracy, speeding acceptance of agreements. To enhance communication, consistency, and timeliness in decision making, the subcommittee recommends that an Executive Review Board be formed and utilized, as described in Chapter 4.

\section{SUMMARY AND RECOMMENDATIONS}

Three considerations should guide the organization and management philosophy of the SSC project.

- The responsibilities of the parties should be clearly articulated and tasks allocated appropriately.

- Authority commensurate with responsibilities should be delegated effectively. Authority delegated to the lowest possible level of the organization's structure will facilitate efficient decision making.

- Communication should be emphasized across the project-both laterally and vertically throughout the organizational structure. Communications will be facilitated with an integrated schedule and control system, coordinated procurement, and standard computer hardware and sof tware. 
The responsibilities of the $M \& O$ should clearly revolve around technical guidance, overall project coordination, and management of the advanced technical systems. The AE/CM should design the conventional facilities under the guidance and standards provided by the $M \& O$, manage the construction of the facility, and monitor the schedule and budget of the conventional facilities. The M\&O and $\mathrm{AE} / \mathrm{CM}$ should jointly address communication and construction standards to engender consistency across the project. 


\section{SCHEDULING AND CONTRACT PACKAGING}

The scheduling process is one that will discipline the overall planning of the SSC project. As the project progresses, the scheduling activity then takes on an additional dimension as a primary tool for communicating to all the project participants the status of each project element, as well as the progress of the project in total. This scheduling process, with the real-time data it generates, will allow management a broader range of control and greater facility to actively manage the discrete portions of the program.

The subcommittee has attempted a general review of the schedule for the tunnels, accompanying shafts, and excavation halls, to gain an understanding of which parts of the construction fall on the project's critical path. Critical path items must be given special attention because progress of the entire project will be delayed if these individual items are delayed. The schedule is also usef ul to test various contract packaging schemes.

In considering the materials presented in this chapter, the reader should understand that only a partial examination of the underground construction portions of the schedule has been presented here. A full understanding of the project can come only by incorporating the underground work into a comprehensive master schedule.

\section{MAJOR FACTORS THAT INFLUENCE SCHEDULING OF THE TUNNEL CONSTRUCTION}

There are several major factors that will impact the scheduling of the underground construction of the SSC project. Some of these factors are common to all large civil engineering projects, while others are peculiar to the SSC project. A brief description of these factors follows.

\section{Magnet Delivery Schedule}

According to DOE's current plan, SSC magnet sections, once delivered, will not be warehoused separately on site, but will be inserted directly into finished tunnel segments for assembly. The intent is to minimize magnet storage costs, which can be significant, and to push forward the schedule by concurrently installing and testing the magnets while construction of the remaining segments of tunnel continues. The interdependence of construction operations with the magnet storage is thus complex, and a detailed design, construction, and magnet 
storage schedule is needed to assess adequately the impact and practicality of the storage concept. This must be a first priority of the M\&O contractor.

To accommodate magnet storage in the tunnel, a complete section of tunnel must be excavated (and lined if required) prior to the installation of mechanical, electrical, and utility systems. Subsequently, the magnet may be installed and connected with the cryogenics. Current projections anticipate that approximately 7 magnets per working day will be delivered over a period of approximately 1,100 working days (4.5 years). As it enters the tunnel, each magnet is $55 \mathrm{ft}$ long, so that each day's delivery of magnets requires approximately $385 \mathrm{ft}$ of completed tunnel-tunnel that is excavated, lined, and has all mechanical, electrical, and utility systems installed. In reality, however, the tunnels will be completed in increments of approximately $21 / 2 \mathrm{mi}$ or $13,200 \mathrm{ft}$. Thus, to match magnet delivery, a completed tunnel increment will have to be provided every 34 working days, or about every $11 / 2$ months.

The assumption that tunnel increments will be $21 / 2$ miles is only approximate. The actual length of the increment will be dependent on the final shaft locations that will be located according to specific site conditions and the final configuration of the lattice. The subcommittee further assumed that the tunnel construction would be coordinated so that as one increment (between two shafts) was completely excavated, the tunnel construction would move ahead to the next increment, freeing up the previous increment for the tunnel completion work and eventually the installation of magnets via the shafts. Ultimately, the plan calls for the cryogenic and power supply to serve two increments or approximately five-mile sections.

The subcommittee believes that surface "surge" storage for magnets should be available on site. The magnet delivery schedule is aggressive and may impact the scheduling and packaging of the tunnel construction. It is essential that all tunnel segments be completed in a sequence such that each segment can receive magnets in a timely and organized fashion. The subcommittee recommends that a surface "surge" storage contingency be available so that any significant hold on the tunnel construction (the flow of funds to the project, for example) would not negatively impact the magnets. This sequence and actual surge capacity are beyond the scope of this study, but both illustrate the need for detailed planning of all civil works activities.

\section{Sequential Construction and Shaft Access}

It is important to recognize the linear, or sequential, nature of tunnel construction. First, the tunnel must be driven and supported. Reports from the TNLRC suggest that a precast segmented concrete lining will be installed immediately following the excavation in the Taylor Marl, whereas in the Austin Chalk, the lining could consist of approximately three inches of shotcrete, applied after excavation of the tunnel is completed.

Special alcoves and niches must be excavated and because of the mucking operation, it is likely that alcove and niche excavation will also be performed after a given segment of the tunnel has been excavated. Invert completion and concreting will occur after the alcove and niche excavation has been completed, 
accompanied by installation of the final lining where required. ${ }^{1}$ Mechanical and electrical equipment must then be installed, followed by the cryogenic devices and magnets. These operations are generally sequential and initiation of one is dependent on completion of another.

Complicating the linear aspect of construction is the limited access into the tunnel. All of the operations described above are accessed through only a few construction shafts, and it is likely that adjacent contracts will require access from the same shaft as work at the interface between the contracts occurs. Access to a single shaft will not likely be required by two different contractors at the same point in time, except possibly for the correction of nonconforming work that may have been inadvertently overlooked. Careful scheduling and rigid final acceptance inspections as the work is completed will help alleviate interface problems.

\section{Experimental Hall Construction}

The experimental halls pose many of the more difficult technical challenges due to their size and the loads that are anticipated from the experimental equipment. Some of the experimental halls are relatively large (approximately 100 by $300 \mathrm{ft}$ in plan) excavations. Because of their size, the excavations will be at greater risk of being impacted negatively by unexpected and adverse geological features than the running tunnel. Therefore, it is important to understand fully the geologic conditions at the hall locations. These extensive excavations are probably not on the critical path of the overall schedule, but special attention should be given to the halls to avoid the negative impact of surprises during construction.

Were this a typical civil works project, geotechnical exploration at the final design level would be completed prior to fixing the location of these underground halls. However, the SSC schedule requires that the lattice (the 3-dimensional arrangement of all magnets around the ring) be fixed early (3rd quarter, 1989). Once the lattice is fixed, the footprint on the surface is known, which in turn fixes the land acquisition requirements. The ring may be subsequently relocated, but only in its entirety (rigid body movement allows tilting, rotation, or lateral shifts). Accordingly, there will be enormous resistance to any adjustments in location that might improve or optimize geotechnical conditions at the hall locations.

Geotechnical exploration and evaluation at the final design level should be undertaken as soon as possible, with exploration concentrated at the experimental hall locations. Should exploration detect serious adverse geotechnical features that jeopardize the technical feasibility or timely completion of the experimental halls, some adjustment of the ring location should be considered, understanding the limitations imposed by the fixed lattice. It is necessary, however, that any adjustments in the ring, either due to design changes related to operational requirements or to geologic considerations, be made prior to the start of construction. That is, construction contracts should not be let until all decisions relating to final siting of the ring are set.

${ }^{1}$ Rock conditions in some reaches may require that the invert be treated soon after excavation to prevent softening or heave of the invert. 
Tunnel Construction-Basic Assumptions

\section{Tunnel Cross-Section}

The permanent tunnels must provide sufficient space for installation and maintenance of the supercooled magnets, vehicular transportation, utilities, and drainage. Preliminary design shows that a cross-sectional area within the finished tunnel lining of $78.5 \mathrm{ft}^{2}$ will be required to accommodate equipment and personnel. A permanent tunnel with the requisite cross-sectional area may be constructed with circular boring machines or with road header-type equipment, which could excavate a horseshoe-shaped cross-section.

\section{Machine Delivery Time}

Tunnel construction enters the critical path of the schedule with the initiation of construction of the first shaft. For a tunnel driven with circular cross-section, the subcommittee assumes that an existing used machine could be obtained and rehabilitated for use on the first segment of tunneling. With this assumption, construction of the first shaft might take on special emphasis. Should the first shaft be one of the deep ones $(200 \mathrm{ft} \pm)$, then excavation at 3-5 $\mathrm{ft}$ per shift could possibly take almost as long as machine delivery. Thus, the contractor must be prepared to mobilize and begin work quickly in order to complete the shaft prior to the arrival of the first machine. Successive machines are assumed to be delivered at intervals of approximately 80 working days, so that there should be ample time to complete succeeding shafts before those machines are delivered.

\section{Shaft Locations, General Configuration, and Construction Advance Rate}

The packaging scheme for tunnel construction on the SSC will likely be based on some combination of the 20 segments that are separated by the so-called "E" and " $F$ " shafts. These shafts are required for access and ventilation (the "E" shafts) and for access for refrigerant piping and power to the tunnel (the " $F$ " shafts) and are proposed at 20 - and $30-\mathrm{ft}$ diameters, respectively. These shafts are well located to serve as tunnel construction access, but as discussed above, excavation of the shafts should not be on the critical path for tunnel construction. The length of tunnel between each of these shafts averages approximately $2.5 \mathrm{mi}$. Thus the tunnel contracts are likely to consist of multiples of $2.5 \mathrm{mi}$.

Both the Taylor Marl and Austin Chalk can be excavated by conventional excavation equipment; drill and blast are not likely to be required. The temporary shaft support might consist of steel ring beams and wooden lagging except in those areas that are waterbearing (at the contact between the alluvium and the marl), where steel liner plates might be considered. The final lining is likely to be cast-in-place concrete.

Access shaft construction requires careful attention by the designer and its scheduler. The subcommittee assumed that the construction contractor would be able to locate, procure, and refurbish, as necessary, an existing machine for the first tunnel drive. The subcommittee further assumed that it would take 120 working days between the issuance of Notice to Proceed (NTP) and the start of the tunnel drive for the first tunnel contract. The beginning access shaft must 
therefore be excavated and outfitted within the 120-day period. The subcommittee believes that this can be accomplished but notes that special attention must be given to this initial shaft construction and its location (it should be one of the shallower shafts).

Intermediate shafts can be constructed concurrently with tunnel excavation and should not be on the critical path. The subcommittee assumed that tunnel boring machines could be available for the follow-on contracts every successive 80 days. This allows at least 200 days $(120+80)$ between the issuance of NTP and the proposed start of construction for the second contrsct, 280 for the third, 360 for the fourth, and so forth. The construction of the deeper shafts must have a sufficiently long time between NTP and start of construction.

A second contracting option that the subcommittee considered feasible is to package all the shafts into one or two contracts, which would be undertaken prior to the award of the tunnel excavation contracts.

\section{Forward-Moving Mucking Operations}

To facilitate the schedule, it is intended that the mucking operations be moved ahead to each successive shaft as that shaft is reached by tunnel excavation. As the tunnel drive reaches and passes the next access shaft, it will free up the completed tunnel for cleanup and commencement of equipment installation. Should the schedule permit, it might be possible for the contractor to excavate the entire tunnel.

\section{Interface with Experimental Hall Excavation}

To avoid the possibility of putting the experimental halls on the critical path for tunnel construction, the utility bypasses around the experimental halls should be designed to clear construction limits for the experimental halls. The experimental hall contracts should include the tunnel segments between the hall and the mainline tunnel if the hall contract precedes the mainline tunnel construction.

\section{Advance Rates}

The proposal prepared by TNRLC includes some advance rates that have been achieved by different machines in a variety of tunnel sizes and lengths. The subcommittee reviewed these case histories, and studied the most recent data available from current tunneling operations in the same geologic units in which SSC tunneling will take place. The most recent data indicate that sustained drives of up to $200 \mathrm{ft}$ per day are attainable in the Austin Chalk, with up to $150 \mathrm{ft}$ per day attainable in the Taylor Marl. Normal tunneling operations will experience some downtime at the start of the job and periodically throughout the tunnel drive. When this normal downtime is factored into the overall progress anticipated by the tunnel boring machine, a lower average tunnel advance rate for the job can be expected. Table 3.1 demonstrates the assumptions made and shows the effect on the average tunneling rate. Note that these rates are for tunneling and initial support only; they do not include the effect of required tunnel final lining, alcove construction, or of installation of the more than twenty items of 
TABLE 3.1 Advance Rate Analysis

\begin{tabular}{|c|c|c|c|c|c|c|}
\hline Week & $\begin{array}{l}\text { Cumulative } \\
\text { Days }\end{array}$ & $\begin{array}{l}\text { Utilization } \\
(\%)\end{array}$ & $\begin{array}{l}\text { Assumed } \\
\text { Penetration } \\
\text { Rate (ft/day) }\end{array}$ & $\begin{array}{l}\text { Length of } \\
\text { Tunnel } \\
\text { Mined }(f t)\end{array}$ & $\begin{array}{l}\text { Cumulative } \\
\text { Length }(f t)\end{array}$ & $\begin{array}{l}\text { Average } \\
\text { Advance } \\
\text { Rate (ft/day) }\end{array}$ \\
\hline $\begin{array}{r}1 \\
2 \\
3 \\
4 \\
5 \\
6 \\
7 \\
8 \\
9 \\
10 \\
11 \\
12 \\
13 \\
14 \\
15 \\
16 \\
17 \\
18 \\
19 \\
20 \\
21 \\
22 \\
23 \\
24 \\
25 \\
26\end{array}$ & $\begin{array}{r}5 \\
10 \\
15 \\
20 \\
25 \\
30 \\
35 \\
40 \\
45 \\
50 \\
55 \\
60 \\
65 \\
70 \\
75 \\
80 \\
85 \\
90 \\
95 \\
100 \\
105 \\
110 \\
115 \\
120 \\
125 \\
130\end{array}$ & $\begin{array}{l}0 \\
15 \\
25 \\
35 \\
35 \\
25 \\
30 \\
40 \\
45 \\
20 \\
30 \\
30 \\
39 \\
25 \\
30 \\
30 \\
35 \\
27 \\
29 \\
34 \\
29 \\
29 \\
26 \\
35 \\
27 \\
30\end{array}$ & $\begin{array}{l}350 \\
350 \\
350 \\
350 \\
350 \\
350 \\
350 \\
350 \\
350 \\
350 \\
350 \\
350 \\
350 \\
350 \\
350 \\
350 \\
350 \\
350 \\
350 \\
350 \\
350 \\
350 \\
350 \\
350 \\
350 \\
350\end{array}$ & $\begin{array}{l}0 \\
263 \\
438 \\
613 \\
613 \\
438 \\
525 \\
700 \\
788 \\
350 \\
525 \\
525 \\
683 \\
438 \\
525 \\
525 \\
613 \\
473 \\
508 \\
595 \\
508 \\
508 \\
455 \\
613 \\
473 \\
525\end{array}$ & $\begin{array}{r}0 \\
263 \\
700 \\
1313 \\
1925 \\
2363 \\
2888 \\
3588 \\
4375 \\
4725 \\
5250 \\
5775 \\
6458 \\
6895 \\
7420 \\
7945 \\
8558 \\
9030 \\
9538 \\
10,133 \\
10,640 \\
11,148 \\
11,603 \\
12,215 \\
12,688 \\
13,213\end{array}$ & $\begin{array}{r}0 \\
26 \\
47 \\
66 \\
77 \\
79 \\
83 \\
90 \\
97 \\
95 \\
95 \\
96 \\
99 \\
99 \\
99 \\
99 \\
101 \\
100 \\
100 \\
101 \\
101 \\
101 \\
101 \\
102 \\
102 \\
102\end{array}$ \\
\hline
\end{tabular}

mechanical and electrical systems that must be installed before the magnets are brought into the tunnel.

Table 3.1 demonstrates how the average advance rate can be reduced considerably if the tunnel boring machine is not utilized fully. The table shows the typical schedule for a single $2.5 \mathrm{mi}$ tunneling contract. The number of days in the week has been reduced by common holidays, then some assumptions regarding downtime, the amount of time the machine is not operating, were made. In this table, downtime in the early part of the tunnel drive was attributed to operational startup and learning curve. Such delays are normally experienced in the beginning phase of the job, while the initial problems are worked out of the machine and the crew operating the machine gets over the learning curve and into a consistent work pattern. Initial startup delays are especially probable if a rebuilt machine is selected for the contract, because minor adjustments will be needed to tune the machine to the actual site conditions.

Downtime can be attributed to breakdowns of the machine itself, breakdowns of the muck removal system immediately following the machine, and breakdowns of the equipment used to install lining segments. Other downtime delays consist of factors that may be unrelated to the machine. Trains that transport the muck away from the machine to the shaft derail periodically, surveying crews need 
access to the tunnel to reset the tunnel guidance system, and utility lines must be periodically extended to the working face of the tunnel.

Table 3.1 was developed on the basis of recent tunnel construction experience in Austin Chalk and Taylor Marl with tunnels similar in size to those planned for the SSC. The records of tunneling show instantaneous machine penetration rates of 3 to $4 \mathrm{in} . / \mathrm{min}$ (which, if sustained, translates to 350 to $450 \mathrm{ft} / \mathrm{day})$. Penetration rate is defined as the advance rate while the machine is being operated in a forward thrust cycle. The rates in Table 3.1 are predicated on two 10-hr shifts per day. In addition, the tunneling records show the average overall utilization of the machines to be approximately 30 percent. The average advance rate of the machine was calculated in the table, and it can be seen that under typical tunneling construction assumptions of downtime the advance rate reduces to $102 \mathrm{ft} /$ day for a $2.5 \mathrm{mi}$ tunnel increment.

It should be recognized that the higher penetration rate of $450 \mathrm{ft} / \mathrm{day}$ could have been used in Table 3.1 to render an average overall advance rate of $150 \mathrm{ft} /$ day. While the greater advance rate is consistent with performance under favorable conditions, the conservative rate was selected as a prudent basis for reference and illustration.

The geology encountered during tunneling will also affect the advance rate of the machine. For example, the advance rate will likely be reduced as the machine traverses the transition between the Taylor Marl and the Austin Chalk. It will also be reduced if adverse ground conditions such as shear zones, faulted material, or local water are encountered.

Program size may have a negative impact on the construction progress of the SSC facility and the assumed advance rates for planning purposes should consider this factor. The amount of a given class or type of work in an area at any given time has an effect on all similar types of work because they are all drawing from a limited pool of equipment and talent. Effects of scale come into play at different times depending on the project location and depth of the work force available. An easily grasped example is that of master mechanics (or machine operators) required to keep the tunnel boring machines (TBMs) operating. This project may have five or more TBMs running at a given time, thus requiring perhaps fifteen master mechanics (or operators) for continuous operation. This is a large commitment of a very specialized expertise. Such a commitment by itself is certainly not unattainable, but when considered in light of other projects around the United States that also require master mechanics, it is possible that supply may not keep up with demand.

The SSC program will be affected in this manner, but the impact is difficult to quantify. The subcommittee considered practical advance rates in this report that are less than those anticipated by TNRLC, in part because there will be a large number of tunneling contracts under way concurrently.

The assumptions on advance rate are key to the tunnel schedule, and the subcommittee has opted here to show the effect on schedule with a conservative assumption as compared to the effect on schedule with an optimistic assumption. Given the downtime analysis and the likelihood of encountering periodic ground conditions that slow the progress of the machine, the subcommittee assumed a conservative advance rate of $100 \mathrm{ft} /$ day and an optimistic advance rate of 150 $\mathrm{ft} / \mathrm{day}$.

The subcommittee selected one possible scenario for tunnel contract packaging to study the relationship of magnet delivery and tunnel construction. The scenario assumes 5 major tunneling contracts consisting of 4 and 5 increments of $2.5 \mathrm{mi}$ ( 3.0 in the last contract to assure a $53 \mathrm{mi}$ ring). It was assumed that 
each contract would be excavated by one tunnel boring machine (TBM) or equivalent excavation equipment which would be erected at the bottom of the first shaft, mined through each of the succeeding shafts, then dismantled and removed through the final shaft. In each case, the final shaft where the TBM completes its drive would be the original erection shaft of the succeeding tunnel contract. Figures 3.1 and 3.2 chart the overall tunneling progress for the SSC project under these assumptions. Both figures demonstrate that the tunnels are not on the critical path for the project; that critical path is dictated by magnet delivery.

\section{CONTRACT PACKAGING FOR TUNNEL CONSTRUCTION}

Contract packaging will have to be developed as the program further matures. Many considerations will be involved in the decisions regarding size and scope of the individual contract packages. Public policy on small and disadvantaged business participation will be involved in the process. As they become better understood, the physical conditions of the site will also govern how these packages are developed. Resource availability could prove a governing factor. Certainly, matching the funding availability with the schedule requirements is also paramount to this packaging process. These issues, taken together, may require the use of small contract packages which, in turn, puts a greater burden on the $\mathrm{AE} / \mathrm{CM}$ in managing the project construction. In any case, a set of contract packages that balances the economic and public policy needs will have to be formulated to optimize the needs of the overall program after detailed analysis.

Long tunnel drives have some benefits, in that (1) the initial learning curve that every contract goes through will be limited to fewer contracts, (2) tunnel boring machine use will be optimized (the industry will focus attention on a few boring machines and resources will not be attenuated), and (3) management will be facilitated with fewer tunnel contracts. The subcommittee believes that economy and efficiency are also improved with long tunnel drives. Economy and efficiency demand that equipment acquisition and mobilization effort be minimized. Once acquired and erected, the underground construction equipment achieves greatest efficiency by advancing as long as possible without dismantling, transfer of ownership, and reassembly for use on another tunnel drive. The long-tunnel-drive concept means there would be only five acquisition and mobilization operations with equipment ownership by the five operating entities remaining constant throughout the entire underground construction period. This fact is bound to generate maximum attention to first-class operating and maintenance policies by each of the equipment owning entities to maximize their profit, which should also result in rapid and economical completion of the SSC project. Long tunnel drives also carry some risks, for example, (1) if problems arise in the form of disputes, contractor inexperience, or inappropriate equipment, a significant portion of the overall project can be held up, and (2) longer tunnel drives are likely to be bid by a limited number of contractors or consortia, which will reduce the competitiveness of the bids.

In general, the advantage of long tunnel drives should be considered carefully for the SSC. Long drives can promote rapid completion of tunneling to conform with magnet delivery schedules and expedite management of this large and relatively complex project. 

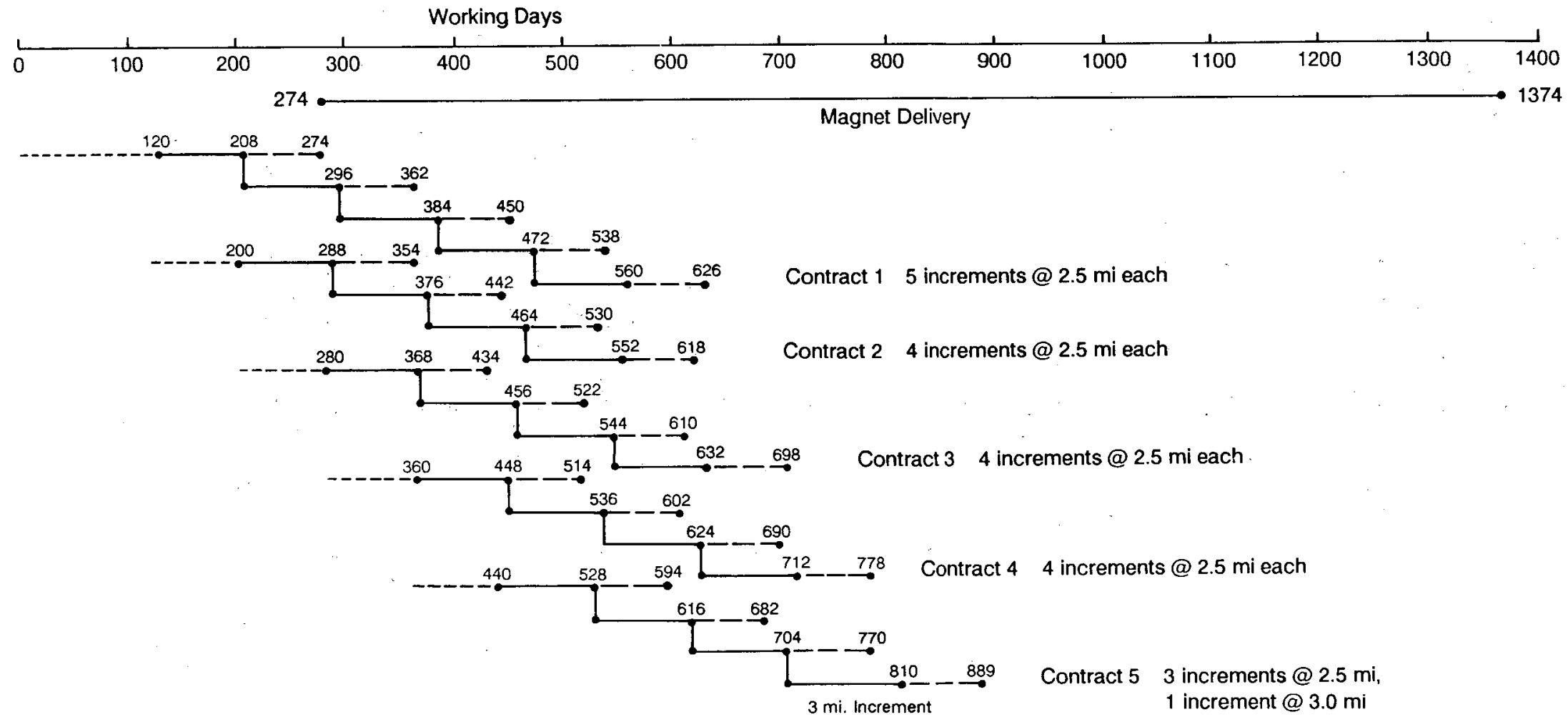

unnel Completion (200 ft/day)

All Tunnel Increments $=2.5$ miles except as shown

FIGURE 3.1 Possible Schedule for SSC Tunnel Construction 

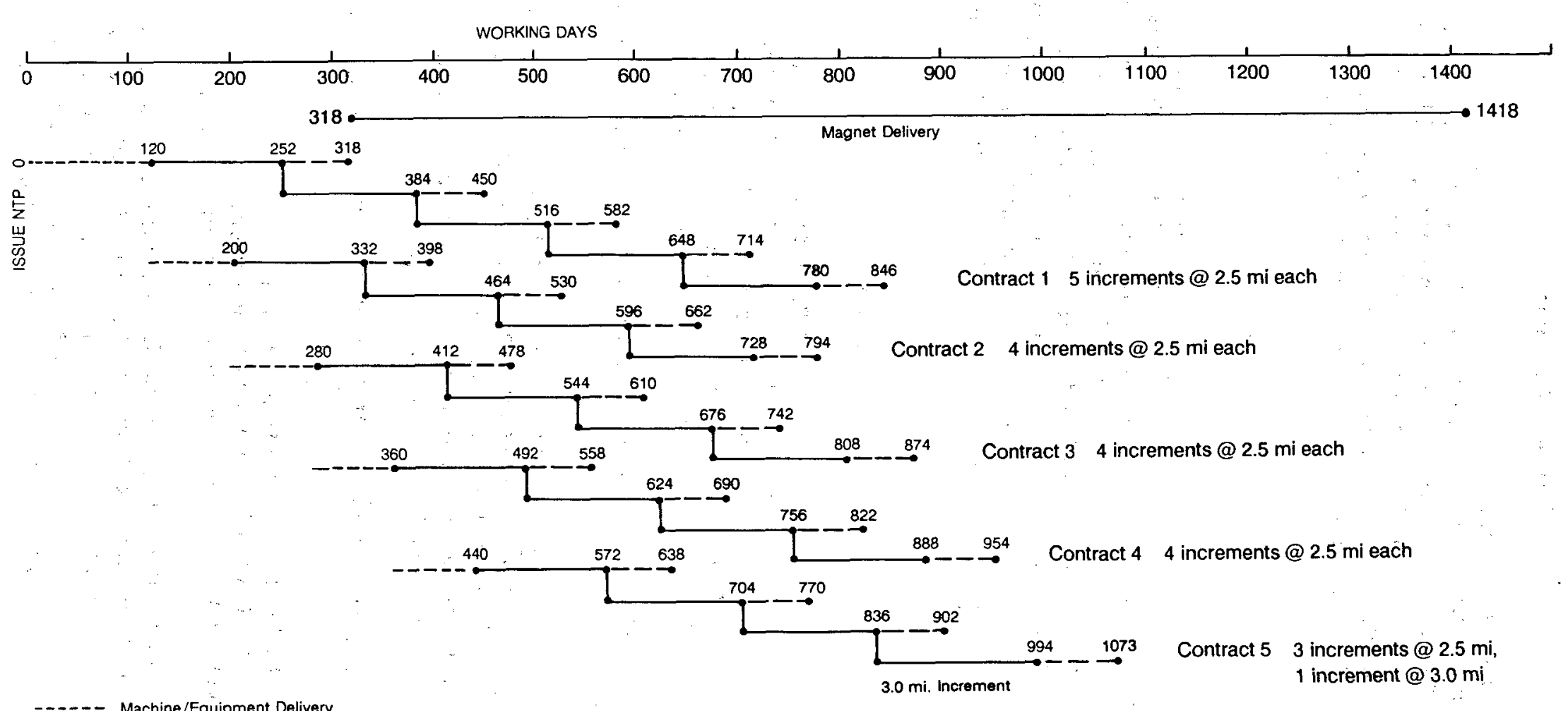

Machine/Equipment Delivery

Tunnel Excavation (100 ft/day)

- - Tunnel Completion (200 $\mathrm{t} / \mathrm{day})$

All Tunnel Increments $=2.5$ miles except as shown

FIGURE 3.2 Tunnel Schedule. Advance Rate $=100 \mathrm{ft} / \mathrm{day}$ 


\section{Industry Capacity}

In contract packaging one of the most significant factors is industry capacity. The subcommittee believes that the U.S. tunneling industry presently has the capacity necessary to accomplish this project provided the individual packages are scoped appropriately. Problems with capacity would only arise if other significant tunneling projects came up for bid in the country during the same time frame or if the contract packages were overly large or small.

\section{Contract Size}

The size of the contract will play a significant role in the packaging of these contracts. If the contract packages for construction are too large they will inhibit competition and likely result in increased costs for the project. On the other hand, should the packages be too small, then it may not be possible to secure or amortize the necessary equipment against the anticipated work, also creating negative cost impacts. Cost and schedule considerations suggest that the tunneling segments of the project be packaged into large contracts. An upper limit for such a package is approximately $\$ 100$ million-a reasonable value that can be accommodated by the industry.

\section{Tunnel Preparation}

Tunnel preparation consists of constructing niches and alcoves, installing concrete lining, and installing the mechanical, electrical, and utilities needed to support the installation of the cryogenics and magnets. The preparation work, for the purposes of this report, was assumed to be a part of the tunnel construction contracts. However, good arguments can be made to package this work separately as well.

The tunnel preparation work has different characteristics than that of the tunnel excavation work:

1. There is far less economy of scale in the tunnel preparation work.

2. The type and quantity of equipment required is less expensive and difficult to procure for the tunnel preparation work.

3. The tunnel preparation work is more akin to other common construction operations; is far less dangerous; and is less specialized. options:

The packaging of the tunnel preparation work could include a number of

1. inclusion in the tunnel construction contract,

2. small contract packages of 2 to 3 tunnel increments, or

3. one or two contracts that complete the tunnels for the entire ring.

Including the tunnel preparation work in the tunnel construction contract reduces the construction management effort because the interface is with one contracting entity per contract. Conversely, many small contracts increase the management effort, but provide opportunities for smaller, less well financed contractors to compete. Many small contracts would provide the project with 
some flexibility to stay within the incremental federal budget allocations, and the consequence of terminating a poor performer would be less disastrous. These options must be weighed as the final design and final magnet delivery schedule are firmed up. The actual packaging arrangement will depend on the overall goals of the entire project.

\section{Access Shafts}

The shaft construction work could be packaged in a number of ways as well:

1. as part of the tunnel construction contracts,

2. as separate contracts for one or more shaf ts, or

3. as a single contract for all the shafts.

The important consideration is to assure that the access shaf ts are completed prior to the arrival of the tunnel excavation. The subcommittee believes this can be accomplished via any of the contract packaging schemes suggested above.

\section{Timing of the Bid Date}

There will be a considerable number of tunnel projects undertaken in 1990 and 1991, the likely years when the contracts for the SSC will go out for bid. It is important that the bid dates be coordinated with other projects throughout the United States to avoid unhealthy competition for resources in what is a relatively small industry. The timing of the bid date can be a very important factor. Timing of the bid dates to permit early issuance of Notice to Proceed to allow sufficient time for procurement of the tunnel boring machine and other underground construction equipment, as well as allow sufficient time to excavate and outfit the first shaft are equally important.

\section{Example of Schedule and Contract Packaging}

The subcommittee prepared the tunnel schedule in Figure 3.1 as an example of the construction progress and coordination with magnet delivery that could be realized with a packaging strategy based on long tunnel drives. This schedule is based on the following assumptions, many aspects of which have been discussed in previous sections of this chapter:

- Adequate infrastructure is in place to support tunneling. This includes adequate haul roads, power, water, muck disposal sites, and relocation of utilities, if necessary.

- The first tunnel machine is delivered at the site 120 working days after Notice to Proceed (note that this assumes the first machine is a rebuilt, existing machine; if a new machine is required, an additional 100 days must be provided).

- Successive machines are delivered at intervals of 80 working days.

- An average advance rate (including tunnel machine installation, start up, learning curve, and downtime) of $100 \mathrm{ft}$ per working day ( 3 shifts) is achieved for tunneling. 
- An average overall advance rate of $200 \mathrm{ft}$ per working day is achieved for tunnel preparation (completion of lining, placing of invert, construction of niches, and installation of all mechanical and electrical systems). Tunnel preparation follows tunnel driving for each increment.

- Notice to Proceed is given at least 320 working days before delivery of the first magnet (note that this requires completion of design, advertisement, bidding, award, and delivery of notice to proceed). shown.

- Magnet delivery is uniformly distributed over the 1,100 working days

- Qualified workers are available to staff all contracts as required to keep them on schedule.

This schedule should be interpreted in the context in which it was prepared as a broad overview of tunnel construction. It summarizes only one reasonable approach to tunnel construction. The schedule demonstrates that the tunnels can be built in a reasonable order and at reasonable rates and that, in general, the tunnels do not fall on the critical path for the overall project. However, it is the overall approach, rather than the details (e.g., should the advance rate be 100,125 , or $150 \mathrm{ft} /$ day) that should be emphasized.

From this schedule, the following conclusions have been drawn:

- Overall, the tunnels can all be completed within the required time frame as defined by the delivery period for the magnets.

- Approximately 350 working days of float, or intervening time, exist between the completion of the last tunnel and the delivery of the last magnet. Thus, some unexpected delays in tunnel construction can be tolerated. A more optimistic assumption of advance rate further improves this outlook.

- Inspection of this schedule indicates that tunnel completion meets or exceeds the demand as indicated by magnet delivery. However, a formal "mass diagram" comparing tunnel availability and magnet delivery was not made. Such a diagram should be prepared as part of the comprehensive master schedule.

- Tunnel construction could be on the critical path early in the project if it should prove impossible to get delivery of the first tunnel boring machine in 120 working days from Notice to Proceed, or if design, bidding, or contract award should drive the Notice to Proceed closer than 320 working days to the first magnet delivery. Thus, if first magnet delivery date is January 1992, then the project geometry must be set, design completed, bids taken, and Notice to Proceed issued no later than September 1990. Failure to achieve this deadline would drive up magnet storage requirements.

- Successive Notices to Proceed should be issued at 80 day intervals.

- Tunnel preparation (lining, etc.) conceivably could go slower than $200 \mathrm{ft} /$ day. However, tunnel preparation is always concurrent with tunnel excavation except for the last increment of each tunnel. The schedule shows ample time to accommodate a modification in tunnel preparation rate should that be necessary.

\section{Construction Contract Package Mix}

The suggested contract packaging provides opportunities for the following contract mix: 
- Each experimental hall should be a separate package.

- The injector assembly should be a separate package.

- Tunnel packages should consist of a minimum of five contracts of approximately four $2.5 \mathrm{mi}$ increments. Some flexibility exists, however, and the final package mix could consist of more contracts, some with fewer increments.

- Tunnel packages may include shafts or they may be handled in separate contracts.

- The injector facilities should be individual contracts.

- Niches, alcoves, invert concrete, and other small and specialized pieces of work can be individual contracts in increments, grouped by larger increments, or packaged together with larger tunnel contracts.

With this range of contract packaging options to choose from, it is obvious that the final construction package mix can be developed to meet a variety of project objectives: funding, schedule, bonding limits, participation of SBE or DBE firms, or tunnel increment sequence. It is inappropriate for this subcommittee to attempt to recommend the final contract package mix at this time. The mix should be developed after geotechnical and design studies, final definition of magnet/mechanical requirements, real estate acquisition, and completion of the master schedule-all coupled with a detailed resource analysis.

As suggested by the second bullet above; this study assumed 5 tunnel contracts, each approximately $10 \mathrm{mi}$ long. As a result, there would be five initial tunnel access shafts spaced evenly around the ring. The final contract package mix may want to modify this pattern slightly to provide one or two shorter tunnel contracts or to provide a different spacing for initial tunnel access shafts. Such modification would appear possible, for example, by breaking of $f$ one or two increments from each of the first drives.

\section{DESIGN DECISIONS THAT AFFECT SCHEDULE AND CONTRACT PACKAGING}

There are a number of design and construction sequence decisions that can affect the total construction to a significant degree. For example, if there is to be a tunnel lining, it should be done closely behind excavation and not later as a change in design after examining the completed excavation. The contractor should be able to plan methods and equipment for the completion of the project when preparing the bid. Any late requirement for lining will require design changes with resulting unplanned delays and costs based on negotiation rather than competitive bid.

A second decision that could affect scheduling is whether shaft construction is made part of a tunnel sector package or grouped as one or more separate shaft construction packages that would commence before the tunneling contracts are let. These could be constructed in a fairly short time and then turned over to the tunneling contractor who would then be able to install and start the machine and get under way.

These are only two examples of early design decisions that need to be made if the most effective scheduling is to be achieved. It should also be recognized that once the designs are set, every effort should be made to avoid changes, particularly those resulting from the new or changing desires of those who will be operating the completed project. Design changes made after bid award will naturally increase cost and construction time. 
The subcommittee strongly recommends that the required diameter for the tunnels be determined very quickly, that the diameter be set (erring on the side of making it larger than needed if necessary), and that any thought of selective widening or "taking out a corner" later be dismissed. Tunnels of 10-12 ft diameter are generally the most cost-effective. Smaller tunnels are more expensive because working room is severely restricted. Larger tunnels are more costly because, among other things, the muck volumes are larger, the machines are larger, and the energy requirements are greater.

The subcommittee is confident that a 6 -in. increase in diameter over anticipated need would have no measurable impact on labor costs, equipment costs, or advance rates. Its impact, if any, would be on muck disposal. Overall, its impact is expected to be well below estimating accuracy at this time, perhaps within a level of 1-2 percent of the cost of tunneling. Certainly it would be less than the cost of attempting "dental" excavation at a later time to provide additional clearance at a corner or other tight spot.

\section{INFLUENCE OF UNFORESEEN FACTORS ON SCHEDULE}

Well-designed construction packages and accurate schedules depend on prudent and clearly understandable designs and specifications. These designs and specifications must be prepared by qualified professionals who base their work on data from thorough site investigations, an understanding of the desired finished product, and past experience with construction methods and similar design situations. There are, however, many unplanned issues which can arise during construction that will significantly impact the planned schedules. Some of these issues, and the nature of their impact, are discussed below. The list is not intended to be all-inclusive, but merely to be illustrative.

\section{Incremental Funding}

One of the issues involved in construction of federally owned projects such as the SSC is the manner in which the project funds are allocated. These funds, as a matter of government policy, are received in increments determined by annual congressional appropriations. These increments can vary from year to year in amount and under such constraints as Congress may determine. Construction projects such as the SSC will require large sums of money on a yearly basis extending over several years. It is extremely important that funding increments be adequate in amount, furnished on time, and be uninterrupted. Even a temporary lack of funds can result in construction delays of a serious and costly nature. The impact of delayed or disrupted funding during construction should be analyzed early on in the planning phases so that all parties clearly understand the costly nature of such delays.

\section{Environmental Impacts}

It is difficult to describe all of the environmental factors that can impact project construction, but there is no question that environmental problems can occur and result in construction delays not provided for during the design stage. Some of the possibilities include protection of rare plants or animals, unforeseen 
archeologic sites, or "acts of God" (e.g., weather conditions such as tornadoes or flash floods).

\section{Differing Site Conditions}

While certain additional site investigation is required prior to fixing the lattice and design of the SSC facility, the geological conditions are already well defined from the work done by the TNRLC. The Ellis County site has geological features that should not represent significant problems for the necessary tunneling. Recent histories of tunneling in both chalk and marl demonstrate that these materials are good tunneling materials in which the advance rates assumed in this report are achievable and where ground stability is not a serious concern. In addition, the tunnels are located above the permanent groundwater table, so that no significant water problems should be encountered.

These items (favorable ground quality and water conditions) should be emphasized in the Geotechnical Design Summary Report. Nevertheless, a consistent history of tunnel construction projects can be cited where geologic conditions actually encountered during tunneling were not those anticipated during the planning stages or at the time of contract bidding. These changes in geology can significantly impact the schedule-from weeks to months-and such changes should be factored in to the overall planning and scheduling of this project.

\section{OTHER NEEDS}

To encourage a smoothly operated project with adherence to schedule, the project will benefit from other factors as discussed in this section.

\section{Comprehensive Scheduling}

Comprehensive scheduling that includes all of the factors and issues to be considered in the overall project must be a first order activity for the M\&O contractor. The master schedule should include consideration of each step of the project development from the planning of the high energy physicists through design engineering, land acquisition, construction, and startup. When the AE/CM is retained, it too will necessarily have to schedule all of its activities in a manner that will be compatible with that laid down by the Department of Energy and the M\&O. Each successive contract let by the M\&O, or any of its subcontractors, should generate detailed schedules that will be compatible with and will support the M\&O's master schedule. For example, the construction contracts should require each contractor to submit an acceptable schedule for its work prior to processing the first application for payment. Positive incentives for timely performance and maintenance of updated schedules should also be included for all parties, including the $A E / C M$, the TNRLC, construction contractors, and subcontractors.

Comprehensive scheduling should give particular attention to the development of the local infrastructure to meet the needs of the construction. The infrastructure for the support of the facility must be under way prior to the completion of the design work for the underground construction. Access roads to each of the work sites, as well as primary access to the research campus, will be developed 
with the involvement of several different governmental organizations. The TNRLC has indicated that it is in a position to help coordinate and prioritize the work of these various governmental entities. Similar coordination requirements will be needed to assure that utility services such as power, communication systems, water, waste water removal and treatment, and gas will be available at the start of construction. Schedules must be developed by each of these entities and integrated into the program master schedule.

\section{Networked Computerized Schedule}

Successful management of the project schedule will be facilitated with a networked computer system where the hardware is compatible and the software is consistent for all levels of contracting operations-M\&O, designers, contractors, and subcontractors.

By utilizing a common format there will be an established communication link between all of the project constituents via the schedule itself. Through this communication link changes in duration or activities that were not expected at the time of the schedule's development will be included as they are recognized and communicated to each of the parties in the program. With this type of dynamic schedule, the program will become more manageable as the entire program is understood by each of the parties.

\section{Resource Studies}

Resources include items ranging from the availability of tunnel boring machines (TBMs), to the need for skilled and unskilled labor, to the capacity of the U.S. tunnel construction industry. When all of these factors are understood and weighed against the program schedule, then, and only then, can contract packages be fully defined.

To enable realistic scheduling of construction, the subcommittee recommends an immediate search of the industry as to availability of existing tunnel boring machines. The search should list the owner, location, size, condition, availability, cost, and detailed design characteristics of the machine. In addition, data regarding new machines should be collected. An understanding of the time necessary to manufacture (or remanufacture) the machines and the capability of the various manufacturers to meet the demand of the project must be gained.

\section{SUMMARY AND RECOMMENDATIONS}

As a general comment, it appears that tunnel construction will not be on the critical path of the overall project schedule. The exception to this comment is the initial shaft construction. The first tunnel construction shaft may be a critical path item if the assumption that an existing rebuilt machine can be utilized on the first contract holds true and 120 days are required for machine rehabilitation and delivery.

Long tunnel drives may be desirable to optimize the schedule, financing, and management of the construction.

Special consideration should be given to the planning and construction of the experimental halls. A cursory review of construction of these halls indicates that 
they are probably not critical path items. Nonetheless, the size and complexity of these excavations requires that they be given special attention, as there are a number of factors that may push these excavations onto the critical path. 


\section{RISK ALLOCATION AND THE MANAGEMENT OF DISPUTES}

Inherent in the planning, design, and building of any major construction project are numerous risks that must be assumed by the project's various participants. These risks range from the readily anticipated to the totally unforeseen and from those where responsibility is clearly assignable to those which become the subject of intense debate. Both the Construction Industry Institute publication, Contract Risk Allocation and Cost Effectiveness, and the American Society of Civil Engineers' Scottsdale Paper, Construction Risks and Liability Sharing, give valuable insights into risk allocation and the consequences thereof. This chapter endeavors to identify as many of these risks as possible; to recommend how they should be allocated among project participants; and to recommend some specific contracting practices directed at avoiding and resolving disputes.

Although the emphasis will be on risks associated with the design and construction process, some of the more global risk areas must be addressed as well, since they could foreseeably impact the design/construction process. For example, budgetary developments on a national scale that precipitate major funding changes for the SSC project are clearly not under the control of the design engineer or the construction contractor. Nonetheless, both parties would likely be affected. Thus, the potential impact of these budgetary fluctuations must be recognized and provisions made to assign responsibility for the consequences.

\section{DEFINING THE OWNER}

Any discussion of risk must start from a clear understanding of who assumes the roles of owner and contractor. The term owner is used here in the generic sense to describe the parties responsible for the payment of the project cost to the construction contractor. These parties include the design team as well as the funding agency, the $M \& O$, and the $A E / C M$.

The construction work itself will be subcontracted to third-party construction firms by the $A E / C M$, rather than by the $M \& O$. Under these circumstances, the $\mathrm{AE} / \mathrm{CM}$ will be acting on behalf of the owner under traditional concepts of relations with construction firms. Under normal practice, the DOE is ultimately responsible and pays all allowable costs incurred by the $M \& O$ and the $A E / C M$ in the performance of their contract and subcontract, respectively.

However the relationships between the DOE, the M\&O, and the AE/CM are structured, the subcommittee recommends that the interface with constructing firms be solely the responsibility of one organization, the AE/CM. 
In addition, as detailed elsewhere, the subcommittee recommends that consideration be given to contract provisions that include incentives and disincentives to maintain schedules, stay within budgets, maintain key personnel throughout the project, and foster smooth and rapid working communications between the construction contractors and the AE/CM.

\section{RISK ALLOCATED TO THE OWNER}

Construction costs are established by the scope of the work and the schedule within which the work is to be performed. The risk associated with fluctuations from the budgeted cost are determined by the type of contract mechanism selected for the performance of the work. For instance, a "cost plus" contract puts the risk of increases and decreases in the contract price squarely on the owner. The construction contractor bears little or no risk of loss even for its own mismanagement or inefficiencies. At the same time, as long as the profit factor does not grow with the contract cost (as with a "cost plus percentage of costs" type of contract), there is an incentive for the contractor to perform in the most efficient manner possible, since keeping costs low will maximize profit. Incentives and disincentives to enhance the contractor's motivation to keep costs low can also be developed.

The subject of contract type is considered fully in Chapter 5 and will not be discussed here. However, it should be noted that, from the standpoint of risk, the subcommittee finds that a lump-sum contract that forces the contractor to assume all risks, contemplated or otherwise, would be the least desirable. While at first blush this firm, fixed, unadjustable price contract may seem attractive to the owner, experience has shown that this kind of one-sided allocation of risk to the contractor yields the greatest amount of disputes and highest prices in the bidding. The contractor is forced to provide for numerous contingencies to assure it will have a sufficient cushion to absorb the unanticipated.

The subcommittee believes that a contract form that provides for payment based upon unit prices, lump sums, and price adjustments for changes, differing site conditions, and other deviations from well-defined bid assumptions would result in the best allocation of risk between contractor and owner. The subcommittee concludes that an equitable approach directed at reducing the contractor's risk is recommended. With reduced risk, the contractor will not need to include contingencies in its bid; that is, costs covering risks that it can neither foresee nor be certain would be allocated elsewhere.

Within the contract framework and associated with the performance of the construction contract, many foreseeable risks are likely to arise, some of which are easily assignable. Responsibility for the feasibility of the design clearly must rest with the owner and its design engineer. Likewise, the owner must assume responsibility for owner-initiated changes, either with respect to design or scheduling.

But while these responsibilities are clearly assignable in concept, actual allocation of risks in the field of ten is not as easily accomplished, nor are responsibilities always as sharply defined as in theory. For example, sometimes it is not obvious whether a "field fix" or change order has been undertaken for the convenience of the contractor or due to a faulty or impractical design. The prompt resolution of such problems, as well as recognition of their impacts on the project schedule, thus become important elements of any risk reduction strategy, 
particularly from the contractor's standpoint. The larger question of dispute avoidance is discussed in greater detail later in the chapter.

Also in the category of risks allocable to the owner are "acts of God," including severe weather conditions, floods, earthquakes, and other natural disasters. In U.S. contracting practice, such events resulting in delay or insurable losses have traditionally been considered excusable to the contractor, meriting only an extension of time without additional compensation. Thus, there is a sharing of the risk by contractor and owner that appears to be generally acceptable to the industry and which the subcommittee endorses for the SSC project.

Frequently, however, there arises a substantial question over whether a given natural event has produced an excusable delay. Therefore, it is important that the owner grant and the contractor accept appropriate extensions of time (and compensation, if appropriate) as the delays actually occur. The common practice of accumulating all delays for the grant of a major time extension at the end of a job and as a leverage element to affect the assessment of liquidated damages is not desirable and should be avoided.

The presence of differing site conditions on underground projects is clearly one of the most frequently encountered risks giving rise to costly disputes. While the differing site conditions clause generally used in federal contracts has considerable history and precedent, disputes continue to arise. The subcommittee suggests that responsibility for differing site conditions must be recognized by the owner if costly contingencies in bids are to be avoided.

One way to reduce possible disputes with regard to differing site conditions is to provide in the contract specific estimated quantities of various soil or rock types expected to be encountered. This procedure has been used on some Washington Metropolitan Transit Authority (WMATA) contracts during subway construction. Percentages of different soils were projected and price adjustments were provided to the extent that these percentages varied from the actual soil conditions encountered. However, even with such an approach, arguments may still arise over what soil type is represented by conditions exposed in the tunnel. Again, the prompt and fair resolution of such disputes is essential to a healthy contractual relationship.

Generally, the risk of changes in economic conditions-such as escalation and inflation-should be borne by the contractor, at least during the original term of the contract. However, strategies shifting this risk to the owner have, in many instances, produced savings to the project cost and such approaches are recommended for any contract with a duration exceeding two calendar years.

The Mt. Baker Ridge Tunnel, part of the Washington State Department of Transportation's (WSDOT) I-90 project, is an excellent example of the owner realizing significant savings because the department accepted the inflationary risk during the three-year life of the contract. In this instance, WSDOT protected the contractor against fluctuations in labor, power, fuel, and selected material costs. Variations in the above stated costs were shared 80 percent by the owner and 20 percent by the contractor. The total escalation allowance in the contract was $\$ 5,550,000$. Only $\$ 190,000$ was actually paid to the contractor, with the state thus realizing savings of $\$ 5,360,000$.

Other risks identified as allocable to the owner include the following:

- political actions, protests, picketing, and threats of terrorism not directly related to contractors' actions,

- site access and interface with other contractors,

- government-furnished equipment and materials, 
- delays of long duration associated with court actions not directly related to contractor's actions,

- design team coordination and management,

- constructibility, and

- cancellation or reduction in available funding.

\section{RISK ALLOCATED TO THE CONTRACTOR}

Generally, the contractor assumes the risk of being able to perform its contract obligations as established in the bid and contract documents. It is the contractor's responsibility to properly staff the job with qualified labor, supervision and management personnel, and the necessary equipment and materials to ensure their ability to perform. It is also the contractor's responsibility to manage its suppliers and subcontractors, coordinate their efforts, and assure that the project is performed in accordance with the contract specifications and within the governing time constraints.

The contractor must possess the financial strength to assure performance based upon the contract price and payment schedule established. The risk of inability to meet these obligations is assumed by the contractor's bonding company. Some control by the owner in this area can be obtained by prequalifying contractors on the basis of experience and financial strength.

While it should be the owner's responsibility to obtain project-wide permits and approvals (see Chapter 2), the contractor should be responsible for those permits associated with its peculiar performance obligations, such as use of haul roads, access to highways, and temporary storage of excavation spoils. The contractor should also assume the responsibility to perform in accordance with the project schedule, assuming it is well defined and realistic. Questions of insurable risk can be handled within the contract by clear definition of areas of responsibility. Also, some insurable risk may be covered by project-wide or "wrap-up" coverage (see chapter 6).

While the contractor must be responsible for staffing the job and for the maintenance of good labor relations, the risk of labor unrest due to major or area-wide problems should be shared with the owner. Consideration should be given to project-wide labor agreements, but care should be taken to avoid forcing contractors to become bound to union agreements that they have had no hand in negotiating. Likewise, unrealistic minority subcontracting and labor participation requirements should be avoided, even while taking care to comply with legal and regulatory requirements.

A summary of risks allocated to either the owner or the contractor is presented in Table 4.1 .

\section{DISPUTES}

\section{Avoidance of Disputes}

\section{Contract Documents}

The surest means of coping with the risk of contract disputes is to avoid them altogether through the preparation of complete and well-conceived contract documents. Key to this strategy is the provision of all geotechnical data to 
TABLE 4.1 Recommended Allocation of Risks

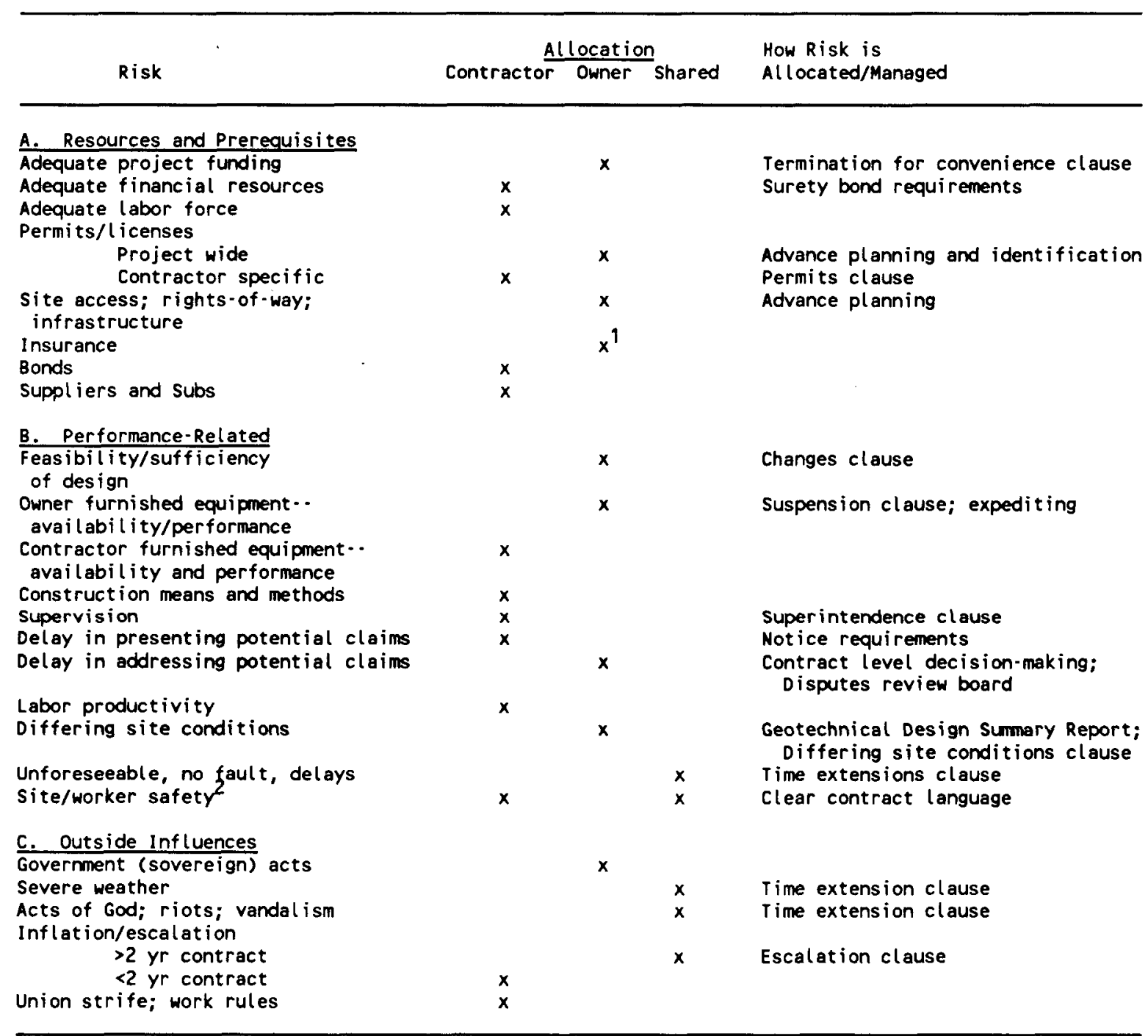

1 Assumes use of wrap-up insurance.

2 subject to stipulations laid out in the wrap-up insurance program.

prospective bidders, now a widely accepted practice in underground construction. Realistically, these data may lead to more than one interpretation of subsurface conditions, tunneling ground behavior, and the associated equipment and methods needed to accomplish the project in a cost-effective manner. Disputes in this area, and consequent disagreement over differing site conditions, generally revolve around what the contractor could have expected at the time of bidding, based on the available data. 


\section{Geotechnical Design Summary Report}

Establishment of a geotechnical base line in the contract documents to serve as the basis for identification of differing site conditions can effectively eliminate this source of dispute without precluding the contractor's development of its own interpretation and unique approach to construction. Inclusion of a Geotechnical Design Summary Report (GDSR), which has no disclaimers, in the contract documents has been effective in minimizing, if not eliminating, this area of dispute (Underground Technology Research Council, 1989). This document should be identified in the contract as the geotechnical interpretation to be used as the basis for identifying differing site conditions, whether or not it is the correct interpretation. All other geotechnical data must be made available, but clearly represented as subordinate to the GDSR in resolving questions of differing site conditions.

An example of the effectiveness of this approach is the Eklutna Lake Diversion tunnel project in Alaska. The GDSR clearly described the groundwater conditions and groundwater control requirements that the owner expected would be encountered during the $1.5-\mathrm{mi}$ tunnel construction. The contractor interpreted these conditions and requirements differently (based on available borings, pump tests, and engineering evaluations) and bid the project based on its own estimation that it could accomplish the tunnel excavation without dewatering.

When groundwater ultimately caused a 3-week shutdown, added cleanup costs to recover the heading, and implementation of an extensive dewatering system, the contractor bore the associated costs without dispute. Had the contractor been successful, it would have been entitled to any cost savings realized as a result of its more optimistic interpretation. If the GDSR had not clearly described the geotechnical base line, a costly dispute would have ensued over what, in fact, was the proper interpretation of available data at the time of bidding.

In developing the GDSR, it is important that adequate investigations be made to allow a reasonable delineation of expected conditions. However, it is essential that all parties accept that, while the GDSR may not be the correct representation of conditions, it is the one used to identify changed conditions. The owner's ability to assure the appropriateness of the GDSR resides in its selection of the $\mathrm{AE} / \mathrm{CM}$ and in its authorization of sufficient geotechnical investigations. The selection process of the $\mathrm{AE} / \mathrm{CM}$ must include the availability of qualified geotechnical personnel.

Improper execution of these responsibilities will likely result in higher construction costs than necessary, either in payment of claims resulting from differing site conditions, or for bids based on an overly pessimistic GDSR. There is no need for a contractor to incorporate contingencies to cover unanticipated conditions that are worse than the GDSR representation, as it is agreed that such conditions would be a differing site condition with resulting contract adjustment and payment.

\section{Scope of Geotechnical Site Investigation}

It is recommended that the scope of the geotechnical investigation at the Ellis County site be performed in general accordance with the publication Geotechnical Site Investigations for Underground Projects (U.S. National Committee on Tunneling Technology, 1986). As a general note, thorough investigations 
are generally more than of fset by savings in construction costs and avoidance of project delays. A good example might be the pre-bid excavation of test adits for the Mt. Baker Ridge tunnel in Seattle-again, a part of WSDOT's I-90 project-at a cost of approximately $\$ 600,000$. The successful contractor reported that the bid was decreased by about $\$ 15$ million strictly on the basis of information gained from these exploratory tests. As stated above, there were further savings of $\$ 3.36$ million realized by the owner because of risk-sharing provisions for fluctuations in highly volatile items such as labor, power, fuel and selected material costs.

\section{Predefined Adjustment Equations and Procedures}

In order to eliminate many sources of disagreement from the contract administration process, the contract documents should contain clear and accurate provisions that establish formulae or methods to predetermine value for disputable items such as profit on change orders, overhead, equipment rates, change order procedures, and force account procedures. Home office overhead rates (G\&A), although subject to wider variation within the industry, could also be preset in a range acceptable to the owner and contractor. A contract provision should also be included that would establish a generally accepted manual for determining the equipment rates to be used in pricing any change orders.

It is equally important for the contract to contain very clear provisions with respect to how change orders should be processed and what information should be included in a request for change orders. The same is true for force account provisions, which would enable the contractor to be paid on a timely basis for disputed work, pending negotiation of a change order or modification.

Some consideration should be given to include, as a unit price, a per diem value for extended project time. In the event of an owner-caused delay, this amount would be added to any change order, carrying with it entitlement to an extension of time. Numerous other equitable adjustment provisions-for example, for variations in estimated quantities or suspension of work-should also be included in the general provisions of the contract. These should contain language that clearly establishes the circumstances under which such adjustments would be invoked, and the provisions for required notice should be reasonable and clear.

\section{Geotechnical Basis for Bid}

New approaches to utilizing the geotechnical data have been used on recent projects that predict the amount and anticipated quality of ground within the contract documents. Such an approach is intended to provide an equitable basis for bid by carefully defining the work, and to limit the difficulties associated with differing site condition claims. In this method the bids are formulated with unit prices for given quantities of ground types, given support requirements, and given mining methods. Actual costs are computed from actual ground type quantities and the unit prices bid, with some negotiated adjustments as needed. A more detailed discussion of this approach with recent examples is included in Appendix 3. 


\section{Contract Administration}

As previously discussed, contract documents that contain adequate base line data against which decisions regarding changed conditions can be based and that provide methods for pricing changes should be considered a key method for avoiding disputes. The second and perhaps more important aspect of disputes avoidance is the administration of the contract.

Sufficiently delegated authority and an organization that has clear lines of communication and a sense of timeliness are all necessary requirements for good contract administration. These must be applied with a spirit of fairness to be workable.

Contract administration is most successful when taken seriously by both the owner's and the contractor's representatives on the job site. As emphasized in Chapter 2, decision making is most effective when accomplished at the lowest level possible. This assumes the use of experienced personnel to whom sufficient authority has been delegated. Timeliness of response to contractors' submittals, requests for change, and requests for payment are an important part of good contract administration. Timeliness benefits not only the contractor, but the owner as well. As a case in point, the contractor on the Milwaukee Metropolitan Sewerage District's \$46 million North Shore Tunnel suspended work in February 1988 due to conditions encountered while excavating the tunnel. The conditions were determined to be a differing site condition. During the time that an investigation was being conducted and a decision made on how to proceed, the owner incurred "contractor idle charges" of more than $\$ 60,000$ per day.

\section{Executive Review Board}

A timely decision-making process must be set up and maintained on the SSC project if schedules are to be met and costs kept under control. The multitude of players-DOE, M\&O, AE/CM, TNRLC, and contractors-each with its own agenda and concerns must be brought to a forum where decisions can be quickly made and implemented. The subcommittee strongly recommends that an Executive Review Board (ERB) be established. The purpose of the ERB is to bring decision makers together in the same room, where each can listen and contribute to a presentation of facts, and then offer and receive firm direction on "next steps" before the meeting adjourns.

Membership of the board should include key decision-makers of the DOE, the M\&O, and the AE/CM. The TNRLC, which the State of Texas created to oversee the expenditure of state monies on the SSC project, should also have a seat on the ERB.

The Executive Review Board process has worked well on the Washington State I-90 project, where many decisions relating to project changes must be referred to a higher authority within the state Department of Transportation, and also to the Federal Highway Administration for final approval.

\section{Disputes and Claims Resolution}

There is no disagreement among contractors and owners that litigation is both costly and time-consuming and that any action that eliminates litigation is desirable. As noted above, the first objective is to avoid disputes altogether 
through the preparation of unambiguous, constructible designs and fair contract documents incorporating a risk-sharing philosophy and then to administer these documents efficiently and in a spirit of cooperation. At no time should an adversarial relationship be allowed to develop between the owner and the contractor.

However, even under the best of circumstances, disputes are bound to arise occasionally when, for whatever reason, change orders or delays interrupt the progress of the work. Therefore, the subcommittee strongly recommends that Disputes Review Boards (DRBs) be utilized on all large contracts developed for SSC construction, underground or otherwise. DRBs have been used on over 30 projects totaling nearly $\$ 1.7$ billion in construction to date, with all disputes settled at or below the DRB level (i.e., no litigation). A discussion of DRBs, their formation, procedures, and experience to date, is presented in the ASCE publication Avoiding and Resolving Disputes in Underground Construction (1989), prepared by the Contracting Practices Committee of the Underground Technologies Research Council (UTRC). This report also contains suggested contract language and a three-party agreement which the subcommittee recommends be used in implementing DRBs on the SSC. The following paragraphs describe the general concepts of DRBs, relate some experiences, and provide specific recommendations for their use on the SSC project.

A Disputes Review Board is composed of three members selected for their industry expertise and experience on similar projects. One member is chosen by the contractor, one member is chosen by the owner, and these two members jointly select the third member, who generally acts as chairman. The board is formed at the start of the project and is active throughout construction. The DRB members stay abreast of job progress through regular site visits, meetings with the owner and contractor, and written progress reports. This familiarity with the project ensures timely and equitable resolution of disputes when they arise.

The existence of a DRB provides an assurance to the contractor that disputes will be addressed and resolved in a timely fashion. This assurance has led contractors to significantly reduce their bids on past projects. Experience has shown that when the option to use DRBs was offered in the contract documents, the contractor has always requested DRB formation at the outset of the job.

Only when negotiations between owner and contractor have reached an impasse are disputes taken before the DRB. Experience by the WSDOT on its I-90 project, where substantial underground and surface construction is involved and DRBs have seen extensive use, demonstrates that the mere presence of the board encourages resolution of disputes. Both the owner and the contractor try harder for agreement and are more realistic in their positions, since they know that industry experts will pass judgement based on the merits of the case.

A separate board should be impaneled for each contract, although an individual may sit on as many as two or three boards. Care should be taken not to appoint the same individuals to too many boards, thereby overloading the system and confusing the issues. Board members must be available on short notice ( 72 hours) if the $D R B$ is to accomplish rapid and timely resolution of disputes.

Experience on over 30 DRBs established to date indicates that only issues of entitlement have reached the boards. While money issues cannot be entirely separated from entitlement, generally only knowledge of the magnitude of the costs is necessary for the board to reach its decision. Once entitlement has been 
established, cost determinations and agreements can then be reached by the disputing parties.

The contract documents should clearly specify what procedures both parties should follow when an impasse is reached. Oral and written protests by the contractor must be timely. The owner should have a fixed time in which to reply to such protests and, if still unresolved, the dispute is then referred to the DRB for a hearing. Submittal of a dispute to the DRB must be a precondition to pursuing other formal dispute resolution procedures or litigation in a court of law.

Presentations to the DRB are initially made in writing by both parties. A copy of each party's written presentation is provided to the other party. At the board hearing, presentations are oral, but documented as necessary to substantiate the position presented. Board hearings are informal, attorneys are not generally utilized, and rules of evidence do not apply. Employees directly involved in the project make the oral presentations for both sides.

After the hearing, the board renders a timely, written decision and both parties have a specified time period to respond in writing, accepting or rejecting the board's decision. The findings of the board are not binding on either party, but may be utilized in subsequent litigation or other formal dispute-resolving mechanisms. It is believed unlikely that a court of law or arbitration panel would reverse a decision made by an impartial board of industry experts familiar with the project. This belief is a major deterrent to pursuing further litigation. Findings can be appealed back to the board if either party has new evidence to present.

Table 4.2 illustrates the results of Disputes Review Boards utilized on various projects to date.

\section{Escrow Bid Documents}

Placement of the contractor's bid documents in escrow (held by a third party) until project completion ensures that such documentation is available in its original form for reference in negotiations of contract pricing adjustments as the project proceeds. This practice is highly controversial, particularly among contractors, largely due to concerns about confidentiality of proprietary information. Clear statements that all bid materials remain the property of the contractor should protect against disclosure under Freedom of Information legislation. However, there is always some risk of misuse or possible access through legal action.

Despite the apprehension of some contractors, the practice of escrowing bid documents need not favor the owner and can be used to the contractor's advantage as well. For example, in one case, the contractor was able to show that a credit was not due the owner, as no cost had been included in its bid. Had the bid documents not been placed in escrow, the owner would not have accepted the contractor's contention.

Escrowed bid documents have seen varying degrees of use on past projects. The subcommittee believes that the existence and availability of this documentation leads to more honest and productive price adjustment negotiations on behalf of both the owner and the contractor. On some projects-the Downtown Seattle Transit Project, for example-the escrow bid documents were used extensively in price negotiations associated with change orders as well as claim issues, and were considered very useful. The subcommittee recommends that the escrowing process be considered for inclusion in SSC contracts. It is questionable whether review 
TABLE 4.2 Results of Projects Using Disputes Review Boards

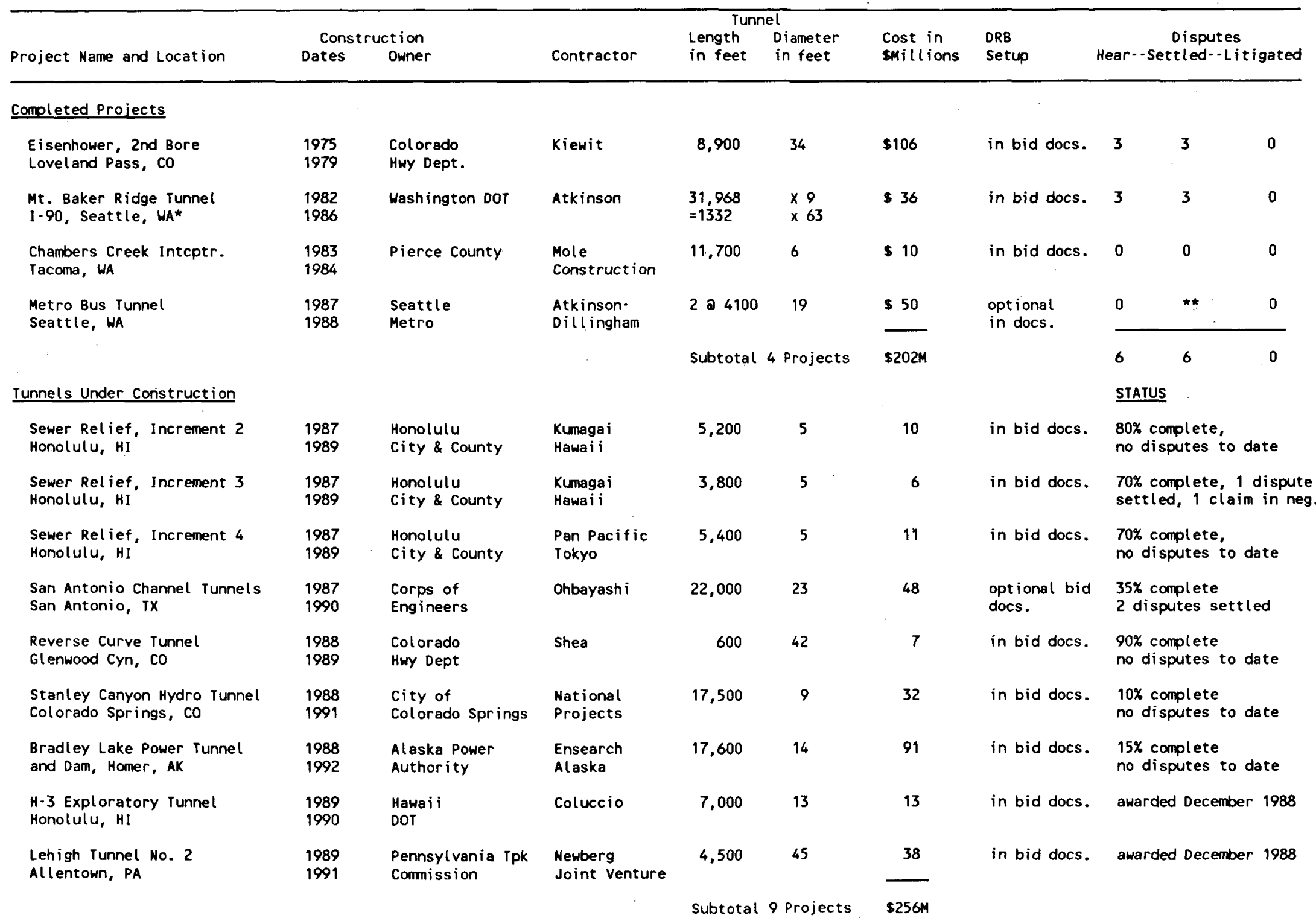




\section{Planned Tunnels}

\begin{tabular}{|c|c|c|c|c|c|c|c|}
\hline $\begin{array}{l}\text { Squilchuck Decline } \\
\text { Wenatchee, HA }\end{array}$ & $\begin{array}{l}1989 \\
1990\end{array}$ & $\begin{array}{l}\text { Asamera } \\
\text { Minerals }\end{array}$ & 12,000 & 14 & 8 & in bid docs. & bids Spring 1989 \\
\hline $\begin{array}{l}\text { Hanging Lake Tunnel } \\
\text { Glenwood Cyn, co }\end{array}$ & $\begin{array}{l}1989 \\
1994\end{array}$ & $\begin{array}{l}\text { Colorado } \\
\text { Highway Dept. }\end{array}$ & 2 a 4,000 & 42 & 85 & in bid docs. & bids May 1989 \\
\hline $\begin{array}{l}\text { Fort Lawton Parallel Tunnel } \\
\text { Seattle, WA }\end{array}$ & $\begin{array}{l}1989 \\
1991\end{array}$ & $\begin{array}{l}\text { Seattle } \\
\text { Metro }\end{array}$ & 8,500 & 12 & 25 & in bid docs. & bids June 1989 \\
\hline $\begin{array}{l}\text { Cumber land Gap Tunnel } \\
\text { Cumber land Gap, TN }\end{array}$ & $\begin{array}{l}1989 \\
1992\end{array}$ & $\begin{array}{l}\text { FHWA } \\
\text { for NPS }\end{array}$ & 4,200 & 40 & 60 & in bid docs. & bids summer 1989 \\
\hline $\begin{array}{l}\text { Brushy Creek Tunnel } \\
\text { Round Rock, IX }\end{array}$ & $\begin{array}{l}1990 \\
1992\end{array}$ & $\begin{array}{l}\text { Brushy Creek } \\
\text { Water District }\end{array}$ & 6,800 & 6 & 5 & in bid docs. & bids 1990 \\
\hline $\begin{array}{l}\text { H-3 Windward (Haiku) Tunnels } \\
\text { Honolulu }\end{array}$ & $\begin{array}{l}1990 \\
1994\end{array}$ & $\begin{array}{l}\text { Hawai i } \\
\text { DOT }\end{array}$ & 5,000 & 43 & 110 & in bid docs. & bids 1990 \\
\hline $\begin{array}{l}\text { H-3 Leeward (Hawala) Tunnels } \\
\text { Honolulu, HI }\end{array}$ & $\begin{array}{l}1990 \\
1994\end{array}$ & $\begin{array}{l}\text { Hawai i } \\
\text { DOT }\end{array}$ & 5,000 & 43 & 110 & in bid docs. & bids 1990 \\
\hline
\end{tabular}

TOTAL Tunnels 20 Projects $\$ 861 \mathrm{M}$

\begin{tabular}{|c|c|c|c|c|c|c|c|c|c|}
\hline \multirow{2}{*}{$\begin{array}{l}\text { Project Name and Location } \\
\text { Completed Other Projects }\end{array}$} & \multicolumn{2}{|c|}{$\begin{array}{l}\text { Construction } \\
\text { Dates Owner }\end{array}$} & \multirow[t]{2}{*}{ Contractor } & \multirow[t]{2}{*}{ Type of Work } & \multirow[t]{2}{*}{$\begin{array}{l}\text { Cost in } \\
\text { sMillions }\end{array}$} & \multirow[t]{2}{*}{$\begin{array}{l}\text { DRB } \\
\text { Setup }\end{array}$} & \multicolumn{3}{|c|}{$\begin{array}{l}\text { Disputes } \\
\text { Hear--Settled--Litigated }\end{array}$} \\
\hline & & & & & & & & & \\
\hline $\begin{array}{l}\text { El Cajon Hydro Project } \\
\text { Honduras }\end{array}$ & $\begin{array}{l}1980 \\
1986\end{array}$ & ENEE & Impregilo & Dam. & 236 & $\begin{array}{l}\text { after job } \\
\text { start }\end{array}$ & 5 & 5 & 0 \\
\hline $\begin{array}{l}\text { 3rd Lake Washington Floating } \\
\text { Bridge, I-90, Seattle, WA }\end{array}$ & $\begin{array}{l}1985 \\
1987\end{array}$ & $\begin{array}{l}\text { Washington } \\
\text { DOT }\end{array}$ & Atkinson & Bridge approaches & 27 & $\begin{array}{l}\text { after job } \\
\text { start }\end{array}$ & 4 claim & $\begin{array}{l}4 \\
\text { in }\end{array}$ & $\begin{array}{c}0 \\
\text { negotiation }\end{array}$ \\
\hline $\begin{array}{l}\text { Performing arts Center } \\
\text { Anchorage, AK }\end{array}$ & $\begin{array}{l}1986 \\
1988\end{array}$ & $\begin{array}{l}\text { City of } \\
\text { Anchorage }\end{array}$ & Kiewit & $\begin{array}{l}\text { Major multi-use } \\
\text { building }\end{array}$ & 45. & $\begin{array}{l}\text { binding in } \\
\text { bid docs. }\end{array}$ & $\mathbf{0}$ & $*$ & 0 \\
\hline & & & & Subtotal 3 Projects & $\$ 308 M$ & & 9 & 9 & 0 \\
\hline
\end{tabular}

* Constructed by means of 24 individual drifts

** Major claims settled without ORB 
TABLE 4.2 Results of Projects Using Disputes Review Boards (Cont.)

\begin{tabular}{|c|c|c|c|c|c|c|c|}
\hline Project Name and Location & $\begin{array}{l}\text { Cons } \\
\text { Dates }\end{array}$ & $\begin{array}{l}\text { uction } \\
\text { Owner }\end{array}$ & Contractor & Type of Work & $\begin{array}{l}\text { Cost in } \\
\text { SMillions }\end{array}$ & $\begin{array}{l}\text { DRB } \\
\text { Setup }\end{array}$ & Status \\
\hline \multicolumn{8}{|l|}{ Other Projects Under Construction } \\
\hline $\begin{array}{l}\text { First Hill Structure, I-90 } \\
\text { Mercer Island, WA }\end{array}$ & $\begin{array}{l}1987 \\
1989\end{array}$ & Washington DOT & $\begin{array}{l}\text { Paschen } \\
\text { Constructor }\end{array}$ & Roadways \& Lid & 62 & in bid docs. & $\begin{array}{l}80 \% \text { complete, } \\
\text { no disputes to date }\end{array}$ \\
\hline $\begin{array}{l}\text { Seattle Lid, I-90 } \\
\text { Seattle, HA }\end{array}$ & $\begin{array}{l}1987 \\
1989\end{array}$ & Washington DOT & $\begin{array}{l}\text { Kiewit- } \\
\text { Atkinson }\end{array}$ & Roadways \& Lid & 65 & in bid docs. & $\begin{array}{l}\text { 75\% complete } \\
\text { no disputes to date }\end{array}$ \\
\hline \multirow[t]{2}{*}{$\begin{array}{l}\text { Seattle Access } \\
\text { Seattle, WA }\end{array}$} & $\begin{array}{l}1988 \\
1989\end{array}$ & Washington Dor & Kiewit & $\begin{array}{l}\text { I }-5 \text { to } I-90 \\
\text { Interchange }\end{array}$ & 60 & in bid docs. & $\begin{array}{l}\text { bid November } 1988 \\
\text { start construction } 1989\end{array}$ \\
\hline & & & & Subtotal 3 Projects & $\$ 18 \pi M$ & & $\therefore$ \\
\hline \multicolumn{8}{|l|}{ Other Planned Projects } \\
\hline $\begin{array}{l}\text { Mt. St. Helens Highway Repl. } \\
\text { Geotech Ridge to Elk Rock, WA }\end{array}$ & $\begin{array}{l}1989 \\
1991\end{array}$ & Washington DOT & & Highway & 12 & in bid docs. & bids December, 1988 \\
\hline $\begin{array}{l}\text { H.3 Vindward Viaduct } \\
\text { Honolulu, HI }\end{array}$ & $\begin{array}{l}1989 \\
1991\end{array}$ & Hawa i DoT & & $\begin{array}{l}\text { Long span segmental } \\
\text { viaduct }\end{array}$ & 150 & in bid docs. & bids January, 1989 \\
\hline $\begin{array}{l}\text { Mt. St. Helens Highway Repl. } \\
\text { Hoffstadt section, WA }\end{array}$ & $\begin{array}{l}1989 \\
1991\end{array}$ & Washington DOT & & Highway & 17 & in bid docs. & bids March, 1989 \\
\hline $\begin{array}{l}\text { Mt. St. Helens Highway Repl. } \\
\text { Hoffstadt Creek Bridge, WA }\end{array}$ & $\begin{array}{l}1989 \\
1991\end{array}$ & Washington DOT & & Highway Bridge & 14 & in bid docs. & bids April, 1989 \\
\hline $\begin{array}{l}\text { Mt. St. Helens Highway Repl. } \\
\text { Elk Rock to Elk Creek, WA }\end{array}$ & $\begin{array}{l}1989 \\
1992\end{array}$ & Washington DOT & & Highway & 22 & in bid docs. & bids May, 1989 \\
\hline $\begin{array}{l}\text { Mt. St. Helens Highway Repl. } \\
\text { Elk Rock to turnaround, } \mathrm{HA}\end{array}$ & $\begin{array}{l}1989 \\
1992\end{array}$ & Washington DOT & & Highway & 15 & in bid docs. & bids June, 1989 \\
\hline \multirow[t]{4}{*}{$\begin{array}{l}\text { H-3 Leeward Viaduct } \\
\text { Honolulu, HI }\end{array}$} & $\begin{array}{l}1990 \\
1994\end{array}$ & Hawai i Dor & & $\begin{array}{l}\text { Long span segmental } \\
\text { viaduct }\end{array}$ & 100 & in bid docs. & bids 1990 \\
\hline & & & & Subtotal 7 Projects & $\$ 330 M$ & & \\
\hline & & & TOTAL other & 13 Projects & $\$ 825 M$ & & \\
\hline & & & TOTAL ALL PR & 33 Projects & $\$ 1.78$ & & \\
\hline
\end{tabular}

SOURCE: Awoiding and Resolving Disputes in Underground Construction (1989), Underground Technology Research Council. Reprinted with permission. 
of this documentation prior to actual use in price adjustment negotiations is appropriate. Suggestions have been made that a review for completeness and legibility be made prior to contract award. Such reviews are a major concern to contractors because there is potential for misuse of the documentation. The owner must also consider that unless it is prepared to reject the low bid on the basis of such reviews, there is no "hammer" to force the contractor to further supplement the original information submitted for escrow, and then the review is meaningless.

Although escrowed documents seldom see use, many believe the mere existence and availability of this documentation leads to more candid and productive price adjustment negotiations. The subcommittee thus recommends that the escrowing process be considered for inclusion in SSC contracts, unless it is believed such a provision could significantly reduce competition by eliminating potential bidders.

A discussion of the objectives, concerns, and experience in the use of escrow bid documents is included in Avoiding and Resolving Disputes in Underground Construction (UTRC, 1989). Suggested guidelines and contract language for implementation of escrow bid documents in the contract provisions are also contained in that report.

\section{SUMMARY AND RECOMMENDATIONS}

Inherent in the construction of any major project are numerous risks. These risks must be assumed by either the owner or the contractor. Table 4.1 summarizes the subcommittee's recommendations for the allocation of risks and how those risks are allocated and managed.

One of the most important factors in avoiding disputes is timely decision making. It is the committees recommendation to utilize an Executive Review Board to accomplish this end. In the event disputes do arise, a Disputes Review Board and Escrowed Bid Documents will expedite resolution and generally reduce final settlement costs. 


\section{5 \\ TYPE OF CONTRACT}

The type of contract utilized for procuring construction of underground facilities may be the most significant single factor in overall project cost. The type of contract can largely determine the division of financial risk between the owner and the construction contractor, and the incentives for timely performance, quality, and cost control.

Each type of contract has its own advantages and disadvantages, as well as certain prerequisites to its use. Certain regulatory and pragmatic constraints limit the utility of certain contract types. The subcommittee reviewed all the practical contract options for SSC underground construction.

The prevalent and traditional practice in underground construction is fixed-price contracting, based on lump sum and unit price bid items. Industry familiarity with this method, its obvious compatibility with public bidding statutes, and the increased use of risk sharing and risk allocation provisions in such contracting combine to support its continued use.

Cost-type contracts have been utilized in situations where the scale of the project, time constraints, and the range of geotechnical unknowns make it impractical for contractors to assume the risks accepted in fixed-price contracting.

In several recent projects the design-construct contracting option has emerged. In this option, a single contractor performs both the design and the construction of the entire project.

Before analyzing these alternatives, it is well to note that the particular legal and regulatory framework in which SSC conventional construction contracting will take place must be taken into account in any analysis of contract types and their implications for the SSC project. As mentioned earlier, the existence of several parties at different tiers of responsibility-the DOE, M\&O, AE/CM, and construction contractors-make the legal and regulatory environment a complex one. The extent to which the Federal Acquisition Regulations (FAR) and the Department of Energy Acquisition Regulations (DEAR) apply or "flow down" to the various parties is examined in detail in Appendix 4.

\section{LEGAL AND REGULATORY CONSIDERATIONS}

Under current planning, the SSC project will be managed for the Department of Energy by a Management and Operating contractor (M\&O). Subject to the Department's approval, the M\&O will select and enter into a subcontract with a qualified firm for architect-engineering, construction management ( $A E / C M)$ and 
related services, to include conceptual design and site surveys, preliminary studies and cost estimates. At a later time, the $M \& O$ may exercise an option for the $\mathrm{AE} / \mathrm{CM}$ to perform complete (preliminary and final) design and related services. Subsequently the M\&O may exercise another option for the $A E / C M$ to provide architect-engineer supervisory and inspection services during construction. The actual construction work will be subcontracted to third-party firms by the $\mathrm{AE} / \mathrm{CM}$.

Accordingly, the design and construction of the SSC will be contracted by a contractor/subcontractor rather than directly by the Department of Energy. Under these circumstances, the Federal Acquisition Regulations (FAR) and the Department of Energy Acquisition Regulations (DEAR) do not, generally speaking, directly govern that acquisition. Acquisitions by M\&Os are judged not by compliance with federal regulation but by conformance to what is known as the "federal norm" and certain policies set forth in the regulations as "guides" or incorporated in prescribed "flow-down" clauses for subcontracts awarded by M\&Os and their subcontractors. The DOE's contracting officers are charged with assuring that the M\&Os adhere to the federal norm and the specified policies and flow-down provisions.

It is generally understood that the federal norm consists of general notions of fundamental fairness, such as fair and effective competition and awarding subcontracts objectively on selection criteria that are clearly articulated in advance. The DEAR Section 970.7103 sets forth federal norm concepts in some detail. Certain socioeconomic policies of the federal government are included as guides within the federal norm, such as equal employment opportunity and set-asides for labor surplus areas. Lastly, certain specific procurement policies are flowed down by prescribed contract clauses to subcontractors, such as the "truth-in-negotiation" requirements for cost and pricing analysis, certification, and validation for most negotiated subcontracts over $\$ 100,000$ and the reimbursement only of costs that are "allowable" by government prescription.

With specific reference to acquisition of architect-engineer services and construction by the Department's M\&O's, the DEAR states that the provisions of the FAR and the DEAR relating to such acquisitions are to be "used as guides," not as inflexible commands that are legally enforceable. In addition, the DEAR contains certain specific policies to which the acquisition of architect-engineer and construction services are to conform (DEAR 970.7104-28[a]). These policies generally are the same as those that govern direct procurements by federal agencies, but they permit somewhat greater flexibility, subject to the concurrence or approval of the DOE. (See Appendix 4 for a fuller description of the pertinent guidelines to the M\&O.)

The various federal regulations and guidances pertinent to the acquisition of design and construction services for the SSC provide adequate flexibility to employ the acquisition methods and contract types recommended in this report.

\section{EVALUATION CONSIDERATIONS}

It is useful to analyze contract types on the basis of (a) pricing mechanisms and (b) contracting structures. The following factors are important in evaluating contract types under either classification and include the ability to:

- achieve and maintain cost control,

- achieve and maintain schedule control, 
- accommodate alternative designs,

- accommodate alternative construction methods,

- meet owner staffing needs, and

- attract and involve qualified contractors.

\section{ALTERNATIVE CONTRACT TYPES (BASED ON PRICING METHOD)}

The construction contractors for the SSC could be compensated by two methods which form the basis for distinguishing between two fundamental contract types: (a) fixed-price contracts where the contractor is compensated in accordance with the price it has bid (unit prices or lump sums), or (b) cost-type contracts where the contractor is reimbursed the allowable costs actually incurred and is compensated by a fee which can be fixed or made redeterminable for incentive purposes. A comparison of the advantages and disadvantages between both of these types of contracts can be found in Table 5.1.

\section{Fixed-Price Contracts \\ (Lump Sum or Unit Price)}

\section{Prerequisites}

Construction projects with the following characteristics lend themselves to fixed-price contracting:

- well defined geotechnical conditions,

- established design without expectation of significant changes,

- firm and detailed bid package,

- modular and repetitive work,

- a sufficient number of firms available for bidding, and

- contractor responsibility requirements to be rigorously enforced.

\section{Advantages}

Fixed-price contracting is conventional and relatively simple. It is common in the industry and consistent with both FAR and DEAR. Once bids are received, contractors can be selected and contracts put in place relatively promptly.

Fixed-price contracting promotes price competition among bidders. After contract award, it forces the contractor to keep its costs low so as to maximize its reward. For the owner, the fixed-price method makes the final cost relatively predictable (excluding costs that arise from additional work or differing site conditions).

\section{Disadvantages}

Detailed plans and specifications are required prior to bidding. This requirement necessarily postpones the start of construction. The firming of plans for bidding purposes reduces the ability to accommodate innovations in design that 
TABLE 5.1 Advantages and Disadvantages of Fixed-Price and Cost-Type Contracts

\begin{tabular}{|c|c|c|}
\hline Contract Type & Advantages & Disadvantages \\
\hline Fixed-Price & $\begin{array}{l}\text { - maximum price competition } \\
\text { incentive for lowering costs } \\
\text { - } \quad \text { reasonable assurance of cost control } \\
\text { - consistency with FAR, DEAR, and } \\
\text { industry practice } \\
\text { conventional and relatively simple } \\
\text { contractual instrument } \\
\text { - final cost more nearly predictable }\end{array}$ & $\begin{array}{l}\text { - possibility of contractors "buying in" } \\
\text { potential overextension of contractor resources } \\
\text { contractor motivated to provide minimum effort bidding } \\
\text { detailed plans and specs required before bidding } \\
\text { probably greatest elapsed time for design and construction } \\
\text { unless anticipated and properly dealt with, claim costs can increase total } \\
\text { price substantially } \\
\text { reduces flexibility to accommodate innovations in design } \\
\text { may reduce flexibility of contractor with regard to innovative construction } \\
\text { methods identified post-bid (may be mitigated by Value Engineering Change } \\
\text { Proposal (VECP) procedure) }\end{array}$ \\
\hline Cost-Type & $\begin{array}{l}\text { - } \quad \text { can encourage contractor ingenuity and } \\
\text { innovation } \\
\text { reduces potential for adversarial } \\
\text { relationships } \\
\text { no incentive for contractor to cut corners } \\
\text { generally deemed appropriate for projects } \\
\text { without precedent in size, design, or site } \\
\text { forces better consideration of contractor } \\
\text { construction contract can be formed based } \\
\text { on incomplete design }\end{array}$ & $\begin{array}{l}\text { - } \text { more difficult to control costs } \\
\text { - } \quad \text { substantial contract administration resources required } \\
\text { definition of cost elements may lead to disputes } \\
\text { - some procurement regulatory constraints (e.g., cost and pricing data } \\
\text { qualifications analysis) } \\
\text { lengthy negotiation time } \\
\text { negotiation costs for constructors and AE/CM } \\
\text { will require broader range of skills and experience in AE/CM } \\
\text { not traditional in turnel ing industry } \\
\text { - early design "freeze" required to maximize cost control }\end{array}$ \\
\hline
\end{tabular}


may be warranted when actual ground conditions are revealed, although to some extent this problem may be mitigated by incorporating the Value Engineering Change Proposal (VECP) technique in the contract. The VECP allows the contractor to propose changes in design and construction procedures subject to approval by the owner. Any cost savings which result from the change are shared by the contractor and the owner.

In unusually competitive situations, contractors may submit a low bid that does not reflect the truly predictable cost of doing the work. In such cases, there will be intense pressure to increase the contractor's compensation through claims and associated litigation. In addition, in fixed-price contracting the contractor has little motivation for increasing the quality of its work beyond the minimum requirements of the contract documents.

\section{Cost-Type Contracts \\ (Including Appropriate Incentive and Penalty Arrangements)}

\section{Prerequisites}

The project characteristics that lend themselves to cost-type contracts include:

- demanding design and construction schedule,

- limited or no competition,

- many geotechnical unknowns,

- work not modular and repetitive,

- several concurrently performing contractors,

- owner resources available for administration, and

- premium for contractor innovation.

\section{Advantages}

The construction contract can be awarded prior to completion of the detailed design. With proper incentives, cost-type contractors have scope to exercise ingenuity and innovation, and there is no incentive to cut corners. Further, adversarial relationships between owner and constructor are less likely to develop. Finally, potential contractors are not dissuaded from participating by considerations of large size, unusual design, or adverse site conditions.

\section{Disadvantages}

Cost-type contracting is not traditional or well understood in the U.S. tunneling industry. This unfamiliarity on the part of both contractors and $\mathrm{AE} / \mathrm{CM}$ may cause administrative problems in the startup phase and during the course of the work. Lengthy negotiations with proposers will be required, with a formal selection process involving subjective judgments, and emphasis on the establishment and verification of proposed costs through audit procedures.

Cost-type contracting will require a broader range of skills and experience in the $\mathrm{AE} / \mathrm{CM}$ than is needed for the traditional fixed price contract. 
Cost control will entail substantial contract administration resources, including auditors. Cost elements must be carefully defined in the contract to avoid disputes. Changes in design, while facilitated, can escalate costs-sometimes dramatically.

\section{Discussion and Evaluation}

The report Avoiding and Resolving Disputes in Underground Construction (Underground Technology Research Council, 1989) identified numerous situations where a cost-type contract would be the better contracting method. In such circumstances, it was stated that it would be advisable to include in the fee arrangements some well-defined incentives to the contractor for achieving or surpassing cost, quality, and time goals. One such arrangement was described as follows:

The contract is entered into with a prequalified and preselected bidder on the basis of its proposal, which includes a target cost estimate, target fee estimate, minimum and maximum fee, fee adjustment formula, plan for performing the work, organization chart, equipment availability, and such other information as desired by the owner. Off-site expenses (including home office overhead), the basis for reimbursement covering use of contractor-owned equipment, and incentives for advancing the completion date and implementation of innovative techniques are included in the contract negotiated.

On the other hand, in its report, Tunneling-Improved Contract Practices, the Construction Industry Research and Information Association (CIRIA) of Great Britain observed that given the tendency to include risk-sharing provisions in fixed-price contracts, the use of cost-type contracts was normally deemed appropriate only when the following circumstances existed:

- insufficient information about site conditions;

- insufficient time to prepare unit price contract documents;

- a desire to utilize innovative methods for which little or no cost experience is available; and

- contractors are not willing to respond to a high-risk venture.

None of those criteria are clearly apparent for the Texas site of the SSC.

Traditional fixed-price contracting appears satisfactory for the SSC tunnel construction, in light of what is known about the Texas site. The homogeneous nature of the subsurface material and the history of successful tunneling projects in this material reduce the need to stimulate alternative designs and construction methods by the contractor.

\section{ALTERNATIVE CONTRACT TYPES (BASED ON CONTRACTING STRUCTURE)}

Contracts can also be described in terms of contracting structure. There are three principal types of contracting structures: 'single-prime (one general contractor plus several subcontractors for one contract segment), multi-prime (two 
or more contracts directly with the owner for work on a given project segment), and design-construct. The advantages and disadvantages of each type are listed in Table 5.2 and discussed below.

\section{Single-Prime Contracts (Per Reach of Tunnel)}

\section{Prerequisites}

The characteristics of single-prime contracting are as follows:

- Most of the contract in each portion of the project must be performed by the prime contractor.

- Reasonably detailed plans and specifications are needed.

- There may be more than one prime contract for the entire project.

\section{Advantages}

The single-prime contract is common to tunnel construction practice. Contract formation, contract administration and supervision, and disputes resolution are all simplified.

\section{Disadvantages}

Competition is reduced, because the size of the contracts tends to require large firms or joint ventures of large firms. As a result, there may be fewer opportunities for Small Business Enterprises and Disadvantaged Business Enterprises to participate.

\section{Multi-Prime Contracts \\ (Per Project Segment)}

\section{Prerequisites}

The characteristics of a multi-prime contracting structure are as follows:

- The project segment is susceptible to the multi-prime approach, i.e., each discrete portion-surface work, spoil disposal, HVAC (heating, ventilation, and air conditioning), electrical, and tunneling-is large enough for performance by a single contractor.

- The lead contractor or the $A E / C M$ has authority and personnel resources to coordinate the work of the other participating contractors.

\section{Advantages}

Opportunities for small firms, including Small Business Engerprises (SBE) and Disadvantaged Business Enterprises (DBE) are increased. Overall competition is 
TABLE 5.2 Advantages and Disadvantages of Single-Prime, Multi-Prime, and Design-Construct Contracts

\begin{tabular}{|c|c|c|}
\hline Contract Type & Advantages & Disadvantages \\
\hline single-Prime & $\begin{array}{l}\text { - } \quad \text { single line of responsibility to } A E / C M \\
\text { simplified administration and supervision } \\
\text { simplified contract formation } \\
\text { simplified disputes resolution } \\
\text { consistent with existing practice in the } \\
\text { tunneling industry }\end{array}$ & $\begin{array}{l}\text { - reduces contracting opportunities for SBE/DBE } \\
\text { tends to favor larger firms and even joint } \\
\text { ventures of large firms, thereby reducing competition }\end{array}$ \\
\hline Multi-Prime & $\begin{array}{l}\text { - } \\
\text { - more contracts, therefore more opportunity } \\
\text { for local/small/MBE/DBE ent ities } \\
\text { stimulates competition for smaller packages } \\
\text { of work }\end{array}$ & $\begin{array}{l}\text { - inherent coordination problems } \\
\text { - } \quad \text { additional contract administration staffing required } \\
\text { - AE/CM vulnerabilitity to disputes arising from coordination problems }\end{array}$ \\
\hline Design-Construct & $\begin{array}{l}\text { documented use by federal government } \\
\text { single point of responsibility and control } \\
\text { accommodates alternative construction methods } \\
\text { increased flexibility } \\
\text { permits fast-tracking } \\
\text { less conservative designs } \\
\text { less conflict between constructor } \\
\text { and designer } \\
\text { cost savings by matching design to } \\
\text { constructability } \\
\text { simplified contract administration } \\
\text { saves time }\end{array}$ & $\begin{array}{l}\text { - inconsistent with current tunnel design and construction practice } \\
\text { - mamits competition due to fewer experienced firms } \\
\text { - potential for significant conflicts at contract-to-contract } \\
\text { interfaces } \\
\text { potential loss of control over final product unless functional specs } \\
\text { are carefully drafted } \\
\text { requires additional form for independent inspecting work }\end{array}$ \\
\hline
\end{tabular}


increased because a larger number of firms will have the resources to compete for the smaller projects.

\section{Disadvantages}

The AE/CM's coordination responsibility requires increased staffing. In addition, delays by any single contractor may delay all others, leading to slips in schedule, downtime, and increased costs. Moreover, the need and time required for coordination between participating contractors may induce disputes between contractors.

\section{Design-Construct Contracts \\ (For Identified Segments of Project)}

\section{Prerequisites}

The characteristics of a design-construct contract type are as follows:

- The project is discrete, large, and on a compressed time schedule.

- It is necessary to remove existing regulatory constraints.

- The large scale of project justifies the high costs of proposals covering both design and construction.

- Funding support is necessary from AE/CM to obtain competitive proposals.

\section{Advantages}

Overall design and construction time is reduced in a design-construct scenario, since one entity is responsible for both elements. Also, flexibility is provided for rapid decision making during construction once the actual ground conditions have been revealed. In addition, the designs may be less conservative, and cost savings can be attained because the designs will be compatible with the contractor's methods and the revealed ground conditions. Further, there is a single point of responsibility and control, thereby simplifying contract administration. Since both design and construction are controlled by a single entity, which is solely responsible, disputes can be avoided.

\section{Disadvantages}

The U.S. tunneling industry is unfamiliar with the design-construct method, and its use therefore may be limited to a few firms, thereby limiting competition. Bonding and insurance for design-construct entities may be difficult to assemble, although a wrap-up insurance program may mitigate the insurance aspect of this problem. In addition, if the design-construct entity is a joint venture of a design firm with a construction firm, the advantages of single control may be illusory. Moreover, the owner will not have control over design features and interfaces between separate contractors may therefore produce design inconsistencies and other conflicts. Finally; an independent construction inspection entity will be necessary to comply with regulatory guidance. 


\section{Discussion}

The multi-prime contracting structure does not appear advisable for the conventional construction portion of the SSC project. For example, tunneling is a major element of the project, and the nature of tunneling does not lend itself to several different prime contractors working concurrently at the same location. The federal government's experience with multi-prime contracting (except for certain time-critical building-construction project segments managed by a strong professional construction manager) has generally been unsatisfactory. The potential for one contractor's problems to cause delays for all the other contractors, to the detriment of the project as a whole, is also worrying.

With respect to design-construct, it is true that the SSC would not be the first major federal project to be undertaken utilizing the design-construct mode. Actual design-build experiences of federal agencies, such as the Corps of Engineers, General Services Administration, Air Force, and the Postal Service, are summarized in The Design-Build Approach to Acquiring Facilities (Federal Construction Council, 1988).

Notwithstanding the appeal of a new mode of contracting structure, the scheduling of the SSC project recommended in this report, whereby construction is timed to coincide with magnet production and installation, does not require exceptional acceleration of early construction, for which design-construct might be suitable. However, if the large experimental halls were on the critical path, choice of contracting structure might depend on whether the construction method is cut-and-cover or underground excavation. The first method is relatively conventional, although the effort would be large in scale. Its principal design challenge would be the sidewall supporting structures. The other method, mining, would entail unusual means and techniques, not only for side and ceiling support (which would be of an exceptional character), but also for solving special problems of heavy equipment installation, access, and maintenance. For these reasons, if the mining method is utilized, design-construct should be considered. However, as indicated above, for other portions of the SSC project, designconstruct of fers no significant advantages.

\section{PREQUALIFICATIONS}

The DOE should consider the use of prequalification procedures for bidders on the larger and more complex underground construction aspects of the projectlong tunnel drives and experimental halls. As the project progresses, it may be desirable to match smaller contracts with the capability of less experienced contractors, at which point the prequalification requirements might be waived.

\section{SUMMARY AND RECOMMENDATIONS}

- Either cost-plus or fixed-price contracts could be readily utilized.

- It is important to offer a "performance"-type specification in the contract, encouraging contractor innovation and input to constructibility.

- The considerations usually cited for cost-type contracting-insufficient information about site conditions; need to use equipment with little cost experience; no time to prepare adequate bid documents; and dearth of firms able to do the work-do not appear to apply to the site chosen for the SSC. 
- The risk allocation methods recommended in this report-Geotechnical Design Summary Report without disclaimers, a geotechnical basis for bids, and disputes review boards to resolve disputes concurrently with work performanceameliorate the risks usually imposed on contractors under traditional fixed-price contracts.

- The packaging of contract tasks, separate contracts for experimental halls and tunnel segments, and the limitation of contract size to $\$ 100$ million, as recommended in this report, open up opportunities to a large number of contractors.

- Under these circumstances, the benefits usually associated with fixedprice contracting-lower price fostered by competition, incentive to complete the project on time within budget, and relative certainty of owner's cost exposureappear desirable and attainable for the SSC project.

- Accordingly, fixed-price contracting is recommended. Design-construct contracting could be utilized to advantage for the experimental halls if they are to be excavated underground, assuming adequate performance specifications for equipment access and installation, and detailed specifications for interfaces with the tunnels. The project-wide wrap-up insurance recommended in Chapter 6 can be adapted to any of the discussed types of construction contract. The main segments of the conventional construction should be framed as "single-prime" contracts. However, some shaft construction, tunnel muck handling, and infrastructure work could be separated from the principal underground or highly technical contracts to enhance competition for small business, including SBE/DBEs.

- To the extent permitted by the federal guidelines, bidders on the larger and more complex underground construction should be required to be qualified by experience record and proven financial capability. As project work is well advanced, an effort should be made to package contracts to match the capability of smaller, less experienced contractors. For these increments, prequalification could be relaxed. 


\section{OTHER ISSUES}

\section{QUALITY CONTROL}

The establishment of quality standards is imperative for the successful completion of the SSC project. To perform acceptably, accelerator components must be manufactured and installed to appropriate tolerances. In addition, the physical location and orientation of this equipment is critical and the entire underground structure housing it must be constructed with great care and precision.

Without listing specific critical dimensions, orientations, or allowable deviations from line of grade, the subcommittee assumes for the purpose of this report that virtually all of the accelerator and collider rings, the shafts, and the experimental halls will require construction to strict tolerances. A clearly defined, tightly administered quality assurance and quality control program will do much to assure the attainment of this goal.

\section{Quality Control or Quality Assurance}

It is important to distinguish between quality assurance and quality control. Quality control is generally the responsibility of the contractor and serves to insure that the work done complies with plans and specifications and attains the required tolerances. Quality assurance, on the other hand, provides a system of checks external to the contractor's operations and integrated into the actual construction process. The contractor's system of establishing and documenting that his construction work complies with contract specifications and tolerances and the construction manager's verification and independent confirmation effort, coupled with his notification and enforcement procedures, provides the necessary assurance that project specifications have been met.

The issue for the SSC project is whether or not the tolerances on the work will require a quality assurance program in addition to quality control provided by the contractor. This issue should be discussed early on in the planning phases of the project so that it can be determined whether and where a quality assurance program is preferred to a quality control program. The costs of a quality assurance program are likely to be higher than those for a quality control program, since an objective quality assurance program requires an independent organization and will result in some duplication of efforts. 


\section{Characteristics}

Experience on major civil works projects has identified several characteristics of an effective quality assurance or quality control program:

- Standards, requirements, dimensions, and tolerances must be clearly and precisely defined. Measurement of these specifications must be possible using standard field practices.

- Critical elements of the design must be identified as such and construction contractors must be informed that under no circumstances will deviations be permitted.

- The criteria for determining acceptable versus unacceptable construction must be identified and communicated so there can be no doubt about how workmanship is judged. Simply stated, the criteria must be enforceable, without any room for judgment calls.

- Go/no-go milestones should be built into the process of quality measurement. The construction contractor must be clearly and unambiguously advised of the go/no-go points and their application should be automatic.

- The communication lines between quality control/assurance personnel, construction contractor, and construction engineer or management must be clear and well defined. Casual communication and informal passing of information should be discouraged. At the same time, to avoid proceeding with defective work, identification of a problem at the lowest level should not delay communication of the information.

- Standards and tolerances established must be reasonable, purposeful, and attainable. Imposing requirements that simply cannot be met in the field only creates the climate for major disagreements and disputes. Likewise, where possible, there should be allowance for deviations from specified tolerances, pursuant to an established waiver procedure.

- Absolute requirements must be red-flagged and all parties alerted. Provisions for monitoring progress towards these points should be recognized in stages, so that an identified deviation does not require correction of previously approved elements of the work.

- Record keeping and final approval must be fail-safe.

On a recent major civil construction project where tight dimensional tolerances were clearly spelled out, a quality assurance program failed for lack of enforceability in the approval process. The quality assurance team became nothing more than a recorder of conditions as built. The contractor resisted efforts by the construction manager to point out errors and correct them as the work was performed, claiming that the deviations were harmless. Moreover, the contract failed to provide the engineer with authority to stop the work. The result was a costly, after-the-fact correction process with a lengthy dispute over responsibility for the expense.

If standards are regarded as requiring rigid application, no deviation should be permitted. The contract should state unequivocally that such standards are absolute and nonwaivable, regardless of whether some consider them meaningless or excessive. In addition, the consequences of noncompliance should be explicitly spelled out in the contract language. 


\section{CONSTRUCTIBILITY}

Constructibility-the ease with which a designed project can be built-is a concept that should receive high-level management attention to ensure that it is fully integrated into the planning, design, and construction of the SSC. The achievement of maximum constructibility requires optimum use of construction knowledge and experience and the employment of this expertise by all $\mathrm{AE} / \mathrm{CM}$ personnel involved from the conceptual stage through the design phase, and during the actual construction process (Construction Industry Institute, 1986, 1987).

Maximum constructibility can best be achieved by the establishment and support of an organization consisting of one or more individuals to provide an ongoing review and critique of the concepts and designs being developed. While this organization should be ultimately accountable to the project management, its thoughts and suggestions should be communicated on a continuing basis to those responsible for the project's concepts, designs, and construction.

Some of the items to be addressed in constructibility reviews include:

- accurate depiction and adaptation of design features to site conditions and restrictions such as access, utility availability, drainage, storage, existing underground utilities, and general configuration,

- appropriateness of contract sequencing, relationship to other work, contract performance time, contractor quality control (QC), submittal requirements, and network analysis system provisions for the specific project,

- adequacy of working area, storage space, and access for all site contractors, as well as provisions for coordination among them to preclude on-site conflicts,

- clarity and simplicity of the bid schedule,

- local availability of special materials and labor skills,

- special installation requirements,

- potential ambiguities in plans and specifications,

- appropriateness of submittal requirements (for shop drawings, samples, catalogs, etc.), and

- consideration of alternate approaches.

As a minimum, the constructibility program should accomplish the following (Construction Industry Institute, 1986):

- clearly communicate the M\&O's and the AE/CM's commitment to constructibility and generate a similar commitment from all project participants,

- encourage teamwork, creativity, and new approaches,

- assign one individual as constructibility coordinator,

- begin constructibility reviews as early as feasible,

- emphasize total project integration,

- establish a constructibility procedure for inclusion in project execution plans, and

- evaluate progress and results. 


\section{COMMUNITY IMPACTS}

Effective management of the SSC project's impacts on the immediate and regional communities surrounding the site must be an explicit project goal of both the $M \& O$ and the $A E / C M$. The DOE may choose to shift contractually some of the day-to-day management of community impacts to the AE/CM, but the M\&O's structural relationships to the Texas National Research Laboratory Commission and the long duration of the project past the completion of its civil works portion warrants the M\&O's continuing and high-level concern with the project's impacts. To be successful, the SSC must be seen by the community as an asset, not as a liability.

The community impact management and public affairs program must go far beyond routine public relations. It must begin with a comprehensive assessment of the project's impact on Ellis County and the surrounding community during the construction and the operation of the project. The need for augmenting existing roads, utilities, and other infrastructure elements, as well as local social organizations, must be identified and dealt with. But meeting these needs must include the education and involvement of the community, not just the accomplishment of the physical improvements. The project management must strive for partnership with the community for successful and productive community relations to evolve.

The progress and timing of infrastructure improvements designed to insure access of people and materials to the jobsites and allow the removal of spoils will substantially affect the pace at which construction contracts can be packaged, bid, and executed. Therefore, the community management function needs to be integrated into overall schedule management.

Early attention to labor impacts, whether by commuters or local residents, will be required. Attention must also be given to the availability of medical resources. Fire protection issues can generally be resolved with low community impact, but should not be ignored.

The process of managing community impacts should not be viewed as ending with the commencement of civil works construction, when it is handed over to the construction contractors. There must be on-going discipline to assure adherence to any previously agreed rules on traffic and materials movement. There must also be a mechanism to solicit community feedback to assess performance and impacts, with dollars available to make midcourse corrections.

There should be continuing efforts to educate the community and its leadership about the project and to prepare for the impacts of its operational phase, in which the demands on the local infrastructure will be different. The project management must be prepared to make commitments and investments for the project as a whole. The impacts of the construction phase should not be ignored or minimized as "temporary." This effort, while managed by the M\&O and the $\mathrm{AE} / \mathrm{CM}$, must be explicitly linked to the construction contract, so that the contractor is a part of the process.

The ground rules for contractor involvement must be substantially established at the time construction begins, so that bids can realistically reflect local conditions and expectations. The AE/CM must have available sufficient funds to pay quickly for any agreed-to changes that impact the contractors.

The process is not one way. An effective community management program will identify project needs so that the unforeseen is minimized and the satisfaction of community or institutional demands does not impede the progress of the work. 


\section{LABOR ISSUES}

The contractual language of the SSC construction contract should address several critical labor issues:

- regulatory requirements with respect to labor,

- affirmative action goals,

- the extent of prevailing wage coverage and the administrative mechanisms governing any prevailing wage requirements,

- any insurance-driven or regulatory-driven limitations on the contractor's right to hire and fire labor, and

- any labor-community issues that must be specified.

There are several recent regulatory requirements with respect to labor that place a substantial onus on owners for effective job-site management. Among these are:

- the hazardous communication standard,

- the plant closing notification requirement, and

- the drug-free workplace standard.

The application of these standards to multiemployer construction sites is still not fully clear. Any "flow-down," "flow-across," "hold-harmless," and reporting requirements that flow from the extension of these regulations and any other DOE health and safety reporting requirements must be clearly specified in the construction contract. The AE/CM should be given both a mandate and sufficient funding to insure the requisite project compliance.

Affirmative action and training requirements, common elements in all federally aided construction projects, will apply to the SSC project. The management of these requirements by either the $M \& O$ or the $A E / C M$ will involve close working relationships with the construction contractors.

The effective management of any wrap-up insurance program involves extensive loss prevention and safety-related activities, including on-site injury management. The labor dimensions of this program, including any threshold injury exclusions and employment restrictions demanded by the program must be clearly specified. These provisions will, in some areas, interact with the drug-free workplace standards and enforcement of the hazard communication standard.

As described above, the project will have an impact on the local community and it can be expected that the M\&O and the $A E / C M$ will both be involved in extensive community relations efforts. The extension of these activities to contractor personnel must be clearly specified in the contract language. Such issues as parking, traffic routing, site housing, and site security may be the subject of community agreements and thus affect the contractor.

It is presumed that there will be no local rules, such as skilled craft licensing or work hour restrictions, that affect the performance of any work on the site. If there are any such restrictions, the extent of their application to the project must be clearly incorporated in the bidding documents and the contract.

Finally, there will be issues of job harmony and labor relations to manage. The AE/CM must be given the task, and provided with the staff, to insure that any labor disputes do not impede the work of unaffected contractors. 


\section{INSURANCE}

\section{Concept of "Wrap-Up" Insurance}

- A "wrap-up" insurance program, administered by the architect-engineer/ construction manager, provides a single comprehensive and controlled insurance program covering all contractors, subcontractors, and sub-subcontractors working on the project.

Such a wrap-up insurance program would provide Workers Compensation, Employers Liability, Commercial General Liability, Excess Liability, and Builders Risk insurance for the benefit of the $A E / C M$ and contractors of any tier. $A$ "project policy" outside the wrap-up program, providing professional liability coverage for Architects and Engineers Errors and Omissions, would be furnished by the $A E / C M$ and would insure the $A E / C M$ and its employees, as well as its consultants and their employees. The AE/CM would obtain and pay the insurance premiums on behalf of all the parties insured under the wrap-up program.

The wrap-up insurance plan would not include the furnishing of bonds or insurance for Automobile Liability, Contractors Equipment, or Office Equipment. The contractor would provide these and other coverages not specifically provided under the wrap-up insurance program at its own expense.

The principal goals of a wrap-up insurance program are:

- to provide reduced insurance and administrative costs,

- to ensure that adequate and uniform insurance coverage is maintained by all parties, and

- to coordinate loss prevention and loss control activities to produce a safe working environment.

A detailed outline of the specifications for the various types of project insurance can be found in Appendix 5.

\section{Advantages of Wrap-Up Insurance}

There are many advantages to instituting a wrap-up insurance program on a large project such as the SSC. First, such a program offers the certainty of uniform and adequate insurance protection for all parties involved in the project. The overlapping of insurance coverages from many separate policies is eliminated in such a program and administrative costs are lessened through the centralization provided.

Also, because of the pooling of insurance premiums, the AE/CM will be able to buy broader coverage and higher limits than that carried by most contractors under their separate programs. Significantly, this coverage may come at reduced cost. This is especially important for small or disadvantaged business enterprises who might otherwise have difficulty in obtaining broad insurance coverage for adequate limits.

An effective wrap-up program will also reduce the likelihood of litigation in the event of a major, or even a minor, accident. If each contractor carries his own insurance, then the probability of suits and countersuits between the contractors is considerable in the case of an accident. The resulting costs could be astronomical. 
In contrast, under a wrap-up insurance program the potential for expensive legal action among the various contractors is greatly reduced as differences would be solved internally. This potential for reduced legal expenses should result in lower insurance premiums.

Lower costs should also result from centralizing claims handling services. When claims processing and investigation duties are managed by a single insurer, a significant reduction in claims costs can result through elimination of disputes over coverages, jurisdictions, and who pays the bills.

Finally, centralizing loss prevention and loss control activities assures uniform, quality services in all aspects of safety engineering. This can lead to reduced costs by eliminating the need for many different safety engineers, representing different contractors or insurance companies, to visit the work site.

\section{Disadvantages of Wrap-Up Insurance}

Unfortunately, there are also disadvantages to adopting a program of wrapup insurance. For example, there will likely be an increased administrative burden and higher costs incurred by the $\mathrm{AE} / \mathrm{CM}$ as it assumes responsibility for such tasks as preparing a wrap-up program manual, issuing certificates of insurance, and implementing a safety program. Also, under the wrap-up program, all contractors share liability limits. This limit could be exhausted more quickly than if the contractors were providing their own insurance with separate limits of liability.

In addition, insurance cost savings may be less than expected. Although instructed to bid excluding the cost of insurance, contractors may include a contingency in their bid to include the cost of purchasing "difference in conditions insurance" to cover any real or perceived deficiencies in the wrap-up insurance.

\section{Instituting a Centralized Safety Program}

In light of the above discussion, a key element of a successful wrap-up insurance program for the SSC project, should such a program be instituted, must be an effective project-wide safety program. The AE/CM should work with the insurance company safety engineers and loss control consultants to develop, implement, and maintain this program. The safety program should focus on the following areas:

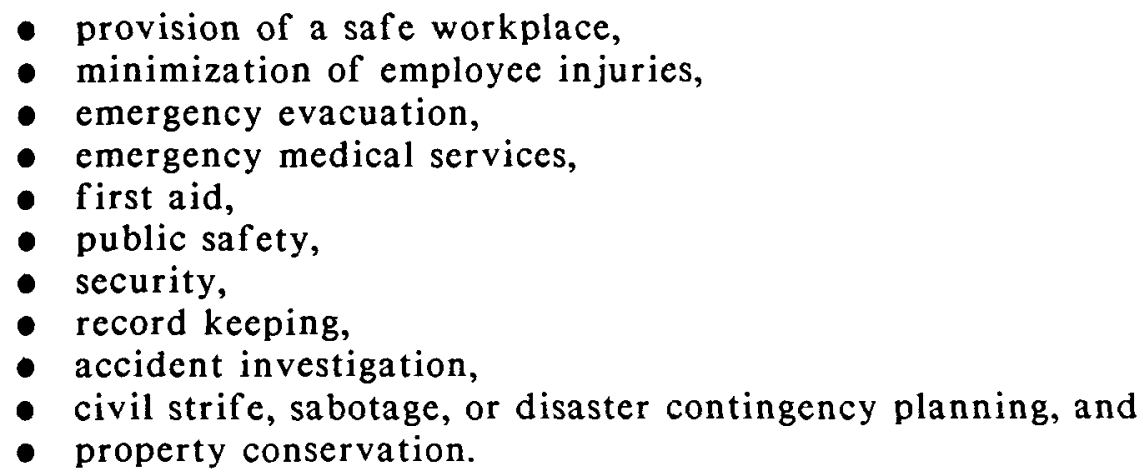


The AE/CM's safety responsibilities should include reinforcing the loss control program by implementing actions identified by the project safety engineers and loss control consultants and by enforcing loss control. The AE/CM should also be responsible for developing emergency response procedures and providing personnel training and equipment as necessary to handle on-site emergencies.

\section{Safety Incentives}

The wrap-up insurance program should include safety incentives in the form of a financial benefit to the contractor. This could be accomplished by returning to the contractor a substantial portion of Worker's Compensation premium refunds resulting from retrospective rating or dividend programs. Such refunds, of course, would only be the result of a good claim-loss record for the project and for the particular contractor.

\section{Wrap-Up Insurance Recommendations}

The subcommittee believes the advantages of wrap-up insurance for this project outweigh the disadvantages and recommends that a wrap-up insurance program be adopted for the SSC project. Because the SSC project will involve the letting of multiple construction contracts, a wrap-up insurance plan offers substantial advantages of uniform insurance coverage, reduction of litigation and disputes between the various contractors, and centralization and coordination of loss prevention, loss control, and claims handling services.

Another important advantage of a wrap-up insurance program is that it will allow greater participation of small and disadvantaged business enterprises who would otherwise have difficulty in obtaining required insurance with adequate insurance limits. 


\section{APPENDIX 1}

\section{Geologic Details of the SSC Site}

The proposed site of the Superconducting Super Collider surrounds the community of Waxahachie, within Ellis County, in north central Texas. A thick sequence of sedimentary rocks underlies this north central region, dipping southeastward toward the Gulf of Mexico. These rocks form broad northeast-trending outcrops. The units decrease in age from Paleozoic inland to Quaternary at the Coast. The outcropping units in Ellis County belong to the Upper Cretaceous Gulf Series, except for thin deposits of alluvial material along streams and on terraces.

The Gulf Series includes the Taylor, Austin, Eagle Ford, and Woodbine Groups; the Austin and Taylor groups outcrop at the site. These are covered locally by Quaternary Terrace deposits and recent alluvium in the modern streams.

\section{QUATERNARY DEPOSITS AND RECENT ALLUVIUM}

The recent alluvium consists of unconsolidated, brown to black clays and brown silty clays with local occurrences of calcareous, clayey sand and gravel. Thickness commonly ranges from 0-20 $\mathrm{ft}$.

Quaternary terrace deposits consist primarily of unconsolidated dark gray to tan calcareous clay, silt, and sand. The basal portions of these commonly include stratified, water-bearing, clayey sands and gravels. The thickness of these terrace deposits is commonly $25 \mathrm{ft}$ or less, but one boring on the proposed site encountered a thickness of $52 \mathrm{ft}$.

\section{TAYLOR GROUP}

The Taylor Group consists of four formations. Only the lowermost Ozan Formation outcrops at the site and is penetrated by the collider ring. The overlying Wolf City Formation outcrops adjacent to the ring alignment near Ennis, but will not likely influence the underground features of the project. In this report, the traditional name, Taylor Marl, is used as an equivalent for the Ozan Formation.

The Taylor Marl is characteristically a green-gray to blue-gray, fine-grained, laminated, calcareous claystone with interbedded chalk. It is massive when fresh. The claystones normally contain 60-70 percent illite and montmorillonite clays bound with a calcium carbonate cement. Thin beds of calcareous claystone containing bentonite are present, but do not make up an appreciable percentage of the total mass. 
The maximum thickness of the unit in the site area is about $500 \mathrm{ft}$. The contact between the Taylor Marl and the underlying Austin Chalk is unconformable and marked by 1-4 in. of reddish-brown clay containing reworked fossils and phosphate nodules.

\section{AUSTIN GROUP}

The Austin Chalk, which will host 70 percent of the tunnel, is primarily light to medium gray chalk (microgranular calcite) with interbedded calcareous claystone. The calcium carbonate content of the chalk is commonly greater than 75 percent and averages 85 percent.

Geologists subdivide the Austin Chalk based on fossil zones and characteristics of surface exposures. The primary lithic characteristics that distinguish subdivisions in the chalk are variations in bed thickness, concentrations of fossil material, and thin marly zones containing bentonite developed from volcanic ash falls. The subdivisions recognized at the surface are not identified by these lithic variations in the subsurface.

Except for the local variations mentioned previously, the physical characteristics of Austin Chalk are quite uniform. Thickness ranges from less than $300 \mathrm{ft}$ in southern Ellis County to about $500 \mathrm{ft}$ in northern Ellis County.

\section{EAGLE FORD GROUP}

The Eagle Ford Group is divided into two units in the Dallas-Fort Worth area. Only the upper unit, the South Bosque Formation, is relevant to site construction and is called the Eagle Ford Shale. The Eagle Ford Shale consists of a dark gray to black, calcareous to noncalcareous shale. This marine shale may contain pyrite on bedding planes, weathering tan to brown at the surface. The upper portion of the section contains bentonite seams, while flaggy limestone beds are more common toward the base. The formation is a montmorillonite shale with high shrink/swell properties.

The physical properties of the Austin Chalk, the Taylor Marl, and the Eagle Ford Shale are shown in Table A-1.1. 
TABLE A-1.1 Physical Properties of the Geologic Materials Underlying the Superconducting Super Collider Site

\begin{tabular}{|c|c|c|c|}
\hline Parameter & Taylor Marl ${ }^{5}$ & Aust in Chalk & Eagle Ford Shale $e^{6}$ \\
\hline $\begin{array}{l}\text { Unaxial Compressive } \\
\text { Strength, psi }\end{array}$ & $23 \cdot 1136(400)$ & $642 \cdot 3807(2230)$ & $14.670(310)$ \\
\hline Point Load Index, psi & $9,260-78,700(38,300)$ & $75,000-66,000(356,000)$ & $10,700-21,700(17,300)$ \\
\hline Dry Density, PCF & $98-135(120)$ & $110-151(128)$ & $114 \cdot 131(120)$ \\
\hline Water Content, Percent & $11-22(16)$ & $5-20(12)$ & $11-19(15)$ \\
\hline $\begin{array}{l}\text { Brazilian Tensile } \\
\text { Strength, psi }\end{array}$ & $18-117(64)$ & $79-405(257)$ & $73-174(141)$ \\
\hline RQD-Value ${ }^{1}$ & $90-100$ & $85-100$ & $90-100$ \\
\hline Slake Durability, Percent ${ }^{2}$ & $0.55(23)$ & $46-97(91)$ & $3-22(9)$ \\
\hline Carbonate Content, Percent & $14-34(23)$ & $32 \cdot 100(85)$ & $5-9(6)$ \\
\hline Absorption Pressure, psi $i^{3}$ & $7-300(30)$ & - & $5-18(14)$ \\
\hline Absorption Swell, Percent ${ }^{4}$ & $0.2 \cdot 5.2$ & $\cdot$ & $1.0-2.6$ \\
\hline Liquid Limit & $58-97(80)$ & $25-51(30)$ & $76 \cdot 104(93)$ \\
\hline Plasticity Index & $33-70(51)$ & $0-28(10)$ & $46-73(63)$ \\
\hline
\end{tabular}

Notes:

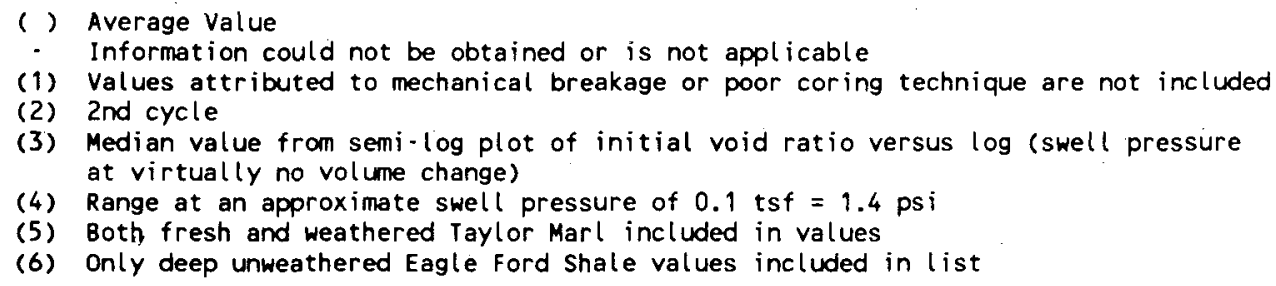

SOURCE: Texas National Research Laboratory Commission. 1988. Proposal for site selection submitted to DOE. Germantown: U.S. Department of Energy. Reprinted with permission. 


\section{APPENDIX 2}

\section{Guidelines on Contractual Sharing of Risks ${ }^{1-}$ International Tunnelling Association}

The following guidelines were developed by the Working Group on Contractual Sharing of Risk of the International Tunnelling Association (ITA). The goal of the Working Group has been the development of advice to ITA member nations on ways to distribute equitably the risk of underground construction among the owner, the contractor, and the engineer, and thus a number of ancillary issues that must be considered in the development of the contract are also discussed.

1. Changed Conditions Clauses. A "changed conditions" clause should be incorporated in all tunneling contracts.

2. Full Disclosure of Available Subsurface Information. All available subsurface information, including both factual and interpretive data, should be fully disclosed to tenderers.

3. Elimination of Disclaimers. Adequate resources should be employed on ground investigations before the tender stage, and disclaimer clauses should be eliminated in the presentation of this data.

4. Prequalification of Contractors. Owners should seek bids only from contractors who have satisfied a rigorous technical and financial prequalification procedure.

5. Contract Variations in Price. Variation in price clauses, preferably of the index reimbursement type and applicable to (1) labor supervision and staff, (2) materials used in significant quantities (whether permanent, temporary, or expendable), (3) energy, and (4) equipment incorporated in the works, should be included in all tunneling projects,

6. Disputes. With respect to disputes: (1) Early resolution should be given high priority at all levels of government. (2) Steps should be taken to avoid any influence of the resolution of disputes on the development of the works. (3) Where possible, disputes should be disposed of by the parties at the work site, as soon as they arise. (4) As a minimum, agreement with regard to the facts should be recorded (a daily, written, countersigned report is advised). (5) The use of a conciliation procedure, such as a referral to one or more mediators selected prior to the works, should be considered. (6) If mediation proves ineffective, arbitration should be considered before resorting to litigation in the courts.

1"ITA Recommendations on the Contractual Sharing of Risks." 1988. Tunnelling and Underground Space Technology 3(2):103-140. 
7. Ground Support. All tender and contract documents should define: (1) The assumed character of the ground throughout the site. (2) The parameters required for the design of ground supports, and more particularly, whether the ground support has been included in the design of the "permanent" structure. (3) Bills of quantities for ground support, covering a reasonable range of site conditions. (4) Methods to take account of changes in the quantity or type of ground support, dictated by actual site conditions. when they differ from those assumed.

8. Ground Characterization. All tunneling contracts should incorporate the following: (1) Definitions of the character of the site or ground as they vary over the proposed extent of tunneling. (2) An estimate of the extent and occurrence of each discrete set of site characteristics, as a uniform basis for bids. (3) Procedural provisions by which the owner and the contractor may, during the course of the work, agree in the shortest possible time on changes to the work plan and the contractor's payment as a result of encountering actual site conditions differing from those understood to exist at the time of contracting.

9. Tendering and Award of Contracts. With the objective of enhancing the fairness of the tender process, the following procedures should be followed during the tendering and awarding of contracts: (1) All tenders that contain unpriced conditions or qualifications should be disallowed. (2) Alternative tenders offering other methods of construction or means of fulfilling the owner's objectives should be encouraged. (3) Alternative offers will preferably be accompanied by an offer conforming to the owner's invitation. (4) All tenderers' alternative offers may be considered. (5) All tenders should be evaluated on bases that include methods and specific means (equipment and personnel), as well as price. (6) Pre-tender meetings between all tenderers and owner's representatives should be recommended. (7) Sufficient time for tendering should be allowed. (8) Precontract meetings with short-listed tenderers should be held to confirm both parties' understandings of what is required and offered. (9) Tenderers who have no chance to be awarded the contract should be informed as soon as possible.

10. Mobilization Payments. All tunneling contracts should include suitable mobilization items.

11. Measurement Problems in Rock. All tunneling contracts should make provision for the following: (1) Specifications and the bill of quantities are to be based on distinct sets of geological conditions that are expected to prevail on site. (2) Measurement of work is based on a geologic classification system appropriate to the geology as well as to the tendered method: and rate of excavation. (3) Bills of quantities are to be structured and priced in such a way that the implication on price of any changes in the work can be established easily. (4) The price tendered for any billed item must be deemed to be sufficient to cover the cost of all activities implicit in that item. (5) Items that cover both the excavation and filling of overbreak should be provided for each rock class measured per unit area of specified excavation surface. (6) If the owner elects to make use of "payment lines" and "clearance lines," these limits must be clearly defined geometrically in the contract documents.

12. Performance Bonds. It is recommended that: (1) All types of bonds (bid bonds and performance bonds) should aim at a balance between the rights and the obligations of the parties and at a reasonable coverage of the risks, (2) An international effort should be made to standardize the rules and formats under which bonds are required. (3) The value of the bonds should be limited to moderate and equitable levels. (4) Prequalification procedures of the tenderers should reduce the size of the performance bonds required. (5) The value of the 
performance bonds should decrease as the work progresses. (6) On-first-demand or unconditional guarantees shall never be requested because of the risk of an arbitrary call and the increasing cost of covering this risk.

13. Coordinated Insurance Program. All tunneling contracts should be based on the following procedures and stipulations: (1) Prior to preparation of tender documents, the owner should determine whether the scope, complexity, and site conditions of the project warrant proceeding with a coordinated insurance program. (2) If the evaluation reveals the appropriateness of a coordinated insurance program, the owner shall determine the types of coverage, limits, deductibles, and discovery periods that best fit the project, and shall obtain such a coordinated insurance program.

14. The Engineer's Role During Construction. Irrespective of what role, responsibilities and authority the owner desires to delegate to the Engineer, it is recommended that all tunneling contracts: (1) Identify what entity will represent the owner as Engineer during construction. (2) Clearly define the duties, responsibilities, and authority of the Engineer and the limitations that apply in the Engineer's service to the owner during construction.

15. Rights-of-Way and Permits. The following guidelines concerning rightsof-way and permits are suggested: (1) All tunneling contracts shall clearly define the owner's and contractor's responsibilities to acquire rights-of-way for the tunnel and the agreements and permits necessary to build and operate it. (2) The owner's responsibilities should include the securing of all permanent rights-of-way, agreements, and permits essential to constructing and operating the project, including all rights to underpin adjacent structures. (3) Only in cases where rights-of-way or permits are required by the particular method of construction proposed by a particular contractor should the contractor be responsible for securing such rights.

16. Provision of Plant. Equipment. Services and Materials by the Owner. It is recommended that: (1) The contractor normally should be required to provide all plant, equipment, and materials necessary for the completion of the work. (2) When the owner decides, under special circumstances, to provide plant, equipment, services, or materials, the following (as a minimum requirement) should be clearly defined in the contract documents:

(a) ownership of the property before, during, and after completion of the work;

(b) quantity, quality, and condition of plant, equipment, or materials;

(c) the terms under which plant, equipment, services, or materials will be made available;

(d) the contractor's obligations with respect to maintenance, damage, operating costs, insurance, etc.;

(e) the procedure for inspection, handover, and return to the owner;

(f) the point of delivery and responsibility for loading, transport, and unloading; and

(g) the procedure for dealing with any oversupply or shortage of materials.

17. Alternative Tenders. It is recommended that: (1) Whenever possible, an alternative offer should be accompanied by a basic offer in accordance with the specifications. (2) The tenderer should be obliged to draw up contract documents for the alternative offer that are comparable in scope, detail, intent, and content to those prepared by the owner for the basic offer. (3) The tenderer should clearly indicate how the risks associated with the basic documents will be 
altered by adopting the alternative. (4) If an alternative entails a major departure from the design prepared by the owner, the owner must evaluate such a design to the extent that he or she can assume full responsibility for it.

18. Protection of Project Surrounds. It is recommended that: (1) Advance investigations should be conducted by the owner to obtain a full knowledge of the risks that will be encountered, the nature of the subsoil, the water conditions, and the surrounding buildings and structures (including their foundations and services). (2) During the owner's design phase, the maximum amount of information should be obtained in order to allow a judicious choice of:

(a) the type of temporary works and other support structures;

(b) the working methods to be anticipated by the owner and selected by the contractor;

(c) the quality controls to be carried out;

(d) any necessary measures to protect or reinforce the existing buildings themselves or installations in the buildings;

(e) a scope of preconstruction surveys to record the existing conditions of nearby buildings, other structures, services, and the property surrounds generally.

(3) The owner should be responsible for developing whatever designs are reasonably needed for construction and specification of protection methods for anticipated methods of construction and their impacts on project surrounds, and for including such structural, construction, and mitigation methods in the tender documents to be priced by the tenderers. (4) The contractor should be responsible, beyond faithful execution of the specified work, for additional efforts, distress, and damages caused by construction methods or operations that may produce or do produce adverse impacts on project surrounds beyond those reasonably anticipated by the owner. (5) The owner should be responsible for establishing monitoring systems and procedures in advance of construction by which the Engineer may be alerted to evolving conditions that could adversely affect the project surrounds or the incomplete work in progress.

19. Measurement Problems Related to Water. It is recommended that: (1) During the ground investigation, special care should be taken by the owner to detect the presence of water and to monitor fluctuations in the level of water; to measure strata permeabilities; and to determine the pressure, temperature, and chemical composition of the ground water. (2) If lowering of water tables might be a problem, it should be clearly indicated in the ground investigation report. (3) The tender documents should clearly indicate the different types of precautions that the owner anticipates may be taken to handle water in the tunnel or at the construction site. (4) If the contractor decides that dealing with some amount of water should be included in unit prices for other works, e.g., tunnel excavation, the contract documents should clearly state this need, and the statement should set a limiting quantity of such work. (5) To evaluate the effect of changes to the works caused by variations in the quantities of water expected, detailed programs should be submitted by the tenderers, based on bill items in the tender documents. (6) Practical procedures for notification, inspection, verification, measurement, and control of water occurrence should be established and specified in the contract documents in order to avoid lost time later in prolonged discussions and disputes. 


\section{APPENDIX 3}

\section{Establishing the Geotechnical Basis for Bid}

The Geotechnical Design Summary Report recommended in Chapter 4 is intended to fully disclose the geotechnical data developed during the site investigations, their application to the design, and their anticipated effect on construction. Although relatively new to the tunneling industry, one approach to managing underground construction is to apply the geotechnical information in a stricter sense, by predicting the quality of ground in specific terms as the basis for a unit price bid per foot of length of each type of expected ground.

This is accomplished by including in the tunnel contracts the following items:

1. A statement of basic tunnel design criteria: required geometry of final cross section, design loadings, required degree of watertightness, etc.

2. A prediction, in terms of quality, of the the types of ground to be encountered, estimating their characteristics and the lengths of tunnel and stationing to which each ground type applies.

3. An acceptable tunnel section design for each defined type of ground, showing the minimum required temporary support, permanent support, and waterproofing. An example of these prescriptions is shown in Table A-3.1.

4. A requirement for a unit price per foot of tunnel length for each ground type totalling the overall contract length.

Bidders and/or the apparent low bidder should be invited to offer an alternative design cross section appropriate for each one of the defined ground types. If necessary, negotiations can be conducted with each qualified proposer with a view to determining the most advantageous and realistic agreement. As actual ground conditions are revealed in construction, the pay lengths for the various defined ground types are adjusted accordingly.

\section{EXAMPLES}

Early examples of the quantitative definition of ground quality as the basis for bid are provided by the Washington Metropolitan Area Transit Authority in construction of tunnels for its subway (Sections B-1Oe, B-1Oa and A-8a). WMATA used a lump sum contract for which the percentage of ground of different classes is predicted in contract documents. Price adjustments are made only if the percentages actually encountered vary from those defined. In this case, the contracting of ficer issues a change order based on supporting evidence supplied by the contractor of the difference in unit cost for completing the tunnel given the 
new percentages. Since designs for initial and final support associated with the different ground types are already in the contract document, the cost adjustment can be worked out on a logical basis.

The Lehigh Tunnels, owned by the Pennsylvania Turnpike Commission, were contracted in a somewhat different mode. Various ground types are defined with their associated initial and final support, plus detailed requirements for an appropriate mining method. Bids were taken per lineal foot of each ground type, extending to a total sum for the contract. In addition, unit prices were required for certain structural quantities which might be needed in addition to the specified initial support. These additional quantities are invoked at the direction of the commission's resident engineer. The resident engineer directs the transition in support type from one ground condition to another. If the contractor objects, it must file its objection with a review panel, but continue with the work under the engineer's direction. The review panel consists of three qualified industry experts whose function is to assess contractor assertions of changed ground conditions.

\section{DEFINING GROUND QUALITY FOR THE SSC MAIN TUNNEL}

Table A-3.1 illustrates a hypothetical scheme for describing quality of ground, structural support and drainage arrangement for the SSC tunnels. This division is highly tentative, based on the TNRLC geotechnical investigation, and derives specifically from a detailed version of Figure No. 3.1-2, Volume 3. In this simplified analysis, the ground is divided into five major categories. These include two qualities of tunneling in the Austin Chalk, two in the Taylor Marl and one in mixed-face conditions crossing the transition between the two formations. The table divides materials at the nearest mileposts without attempting further refinement. Assessment of quality in the various formations is based on the degree of weathering, the persistence of joints, and the condition of cover materials. For each one of these defined conditions a specific type of structural support is envisioned with a particular drainage arrangement to accommodate expected seepage. In the actual evaluation of some ten or more separate tunneling contracts (based on a greatly expanded geotechnical study) the definitions of ground quality will be much more detailed.

If such a scheme is implemented, each one of the contracts would define and illustrate ground quality types, and include a unit price in the proposal per lineal foot of tunnel in each ground type. It might be desirable to provide separate unit prices for the addition of structural material required for support beyond those concepts envisioned in the table. In any case, the length of tunnel in each ground type and the quantities of supplementary support will be carefully defined, then extended to a total bid.

The purposes of this procedure are to narrow the uncertainty as to quality of ground, to provide advance knowledge of the response that is required to changing ground types, and to establish an equitable basis for bid, since all parties propose on the same strictly defined work. Agreement on changing ground conditions would be made directly in the heading, whereupon the mining would switch from one predetermined style of support and drainage to another prescribed alternative. It is perhaps inevitable that special supplementary measures would be needed that would not fall within the defined patterns, and these would be paid for on separate unit price bases. However, this procedure for defining ground quality greatly limits the opportunity for unexpected extras. The scheme 
can be supplemented by a three-person review panel to assess controversies between the AE/CM and contractor as to quality of ground encountered. 
TABLE A-3.1 Example of Ground Quality Definition for SSC Main Tunnel

\begin{tabular}{|c|c|c|c|c|}
\hline $\begin{array}{l}\text { Principal Formation and } \\
\text { Ground Characteristics }\end{array}$ & $\begin{array}{l}\text { Between the } \\
\text { Following } \\
\text { Mile Posts }\end{array}$ & $\begin{array}{l}\text { Total Length, } \\
\text { Miles } \\
\text { (Percent) }\end{array}$ & Structural Support of Tunnel & $\begin{array}{l}\text { Drainage Arrangement } \\
\text { With in Tunnel }\end{array}$ \\
\hline $\begin{array}{l}\text { AUSTIN CHALK, FULL FACE } \\
\text { Unweathered; } \\
\text { Minimum leakage; } \\
\text { Homogeneous rock, } \\
\text { minimum jointing. }\end{array}$ & $\begin{array}{l}0 \text { to } 3 / 52 \text { to } 53+ \\
4 \text { to } 7 \\
8 \text { to } 15 \\
16 \text { to } 22\end{array}$ & $25+$ miles $(47 \%)$ & $\begin{array}{l}\text { No initial or final lining } \\
\text { rock bolts average } 1 \text { in } 5 \text { '; } \\
\text { mine straps average } 1 \text { in } \\
20^{\prime} ; \text { provide shotcrete and } \\
\text { mesh at overbreak; invert } \\
\text { paved at random spots. }\end{array}$ & $\begin{array}{l}\text { Individual seeps carried by } \\
\text { single drain lines to track } \\
\text { invert; closed collector drain } \\
\text { to sump. }\end{array}$ \\
\hline $\begin{array}{l}\text { AUSTIN CHALK, FULL FACE } \\
\text { Limited weathered cover; } \\
\text { Leakage in roof; } \\
\text { Frequent joints w/clay } \\
\text { seams. }\end{array}$ & $\begin{array}{l}3 \text { to } 4 / 45 \text { to } 88 \\
7 \text { to } 8 / 50 \text { to } 52 \\
15 \text { to } 16 \\
22 \text { to } 24 \\
41 \text { to } 42\end{array}$ & 11 miles (21\%) & $\begin{array}{l}\text { No final lining; } \\
\text { rock bolts average } 1 \text { in } 3 \text { '; } \\
\text { mine straps average } 1 \text { in } \\
12 \text { '; lattice girder average } \\
1 \text { in } 50 \text { '; shotcrete initial } \\
\text { lining over } 15 \% \text { of length; } \\
\text { invert paved in } 10 \% \text { of length. }\end{array}$ & $\begin{array}{l}\text { Shotcrete over seeps backed by } \\
\text { by drains or strips of drain- } \\
\text { age fabric, collected by side } \\
\text { drains to sump. }\end{array}$ \\
\hline $\begin{array}{l}\text { MIXED FACE TUNNEL } \\
\text { AUSt in Chalk in invert; } \\
\text { Taylor Marl in crown; } \\
\text { Irregular hardness and } \\
\text { irregular contact. }\end{array}$ & $\begin{array}{l}24 \text { to } 26 \\
39 \text { to } 41\end{array}$ & 4 miles $(7 \%)$ & $\begin{array}{l}\text { No final lining; } \\
\text { lattice girder, bolts and } \\
\text { shotcrete over } 80 \% \text { length; } \\
\text { remaining } 20 \% \text { stabilized } \\
\text { by bolts and straps; invert } \\
\text { paved over } 30 \% \text { of length. }\end{array}$ & $\begin{array}{l}\text { Shotcrete backed by drain lines } \\
\text { or drainage fabric, collected } \\
\text { by side drains to sump. }\end{array}$ \\
\hline $\begin{array}{l}\text { TAYLOR MARL, FULL FACE } \\
\text { Thick cover; } \\
\text { Minimum leakage; } \\
\text { Chalk-marl chiefly }\end{array}$ & $\begin{array}{l}28 \text { to } 32 \\
33 \text { to } 39\end{array}$ & 10 miles (19\%) & $\begin{array}{l}\text { Precast concrete segmented } \\
\text { final liner; spiling boards } \\
\text { ahead of face required over } \\
10 \% \text { of length. }\end{array}$ & $\begin{array}{l}\text { Caulking of liner, contact } \\
\text { grouting outside of liner. } \\
\text { occasional special grouting } \\
\text { of ground to control leakage. }\end{array}$ \\
\hline $\begin{array}{l}\text { TAYLOR MARL, FULL FACE } \\
\text { Limited cover, softened } \\
\text { Some leakage; } \\
\text { Clay-marl chiefly }\end{array}$ & $\begin{array}{l}26 \text { to } 28 \\
32 \text { to } 33\end{array}$ & 3 miles $(6 \%)$ & $\begin{array}{l}\text { Cast-in-place concrete final } \\
\text { liner; initial lining of con- } \\
\text { crete segments over } 100 \% \text { of } \\
\text { length; spiling boards ahead } \\
\text { of face required over } 20 \% \text { length. }\end{array}$ & $\begin{array}{l}\text { Drainage panels placed on con- } \\
\text { crete segments, drainage to } \\
\text { side drains carried to sump. }\end{array}$ \\
\hline
\end{tabular}

NOIE: This data not to be used for construction.

SOURCE: Texas National Research Laboratory Commission. 1988. Proposal for site selection submitted to DOE. Germantown: U.S. Department of Energy. Vol. 3. Reprinted with permission. 


\section{APPENDIX 4 \\ Guidances from FAR and DEAR}

The various federal regulations pertinent to the acquisition of design and construction services for the SSC provide adequate flexibility to employ the acquisition methods and contract types recommended in this report.

Under current planning, the SSC project will be managed for the Department of Energy by a Management and Operating contractor (M\&O). Subject to the Department's approval, the M\&O will select and enter into a subcontract with a qualified firm for architect-engineering, construction management (AE/CM) and related services, to include conceptual design and site surveys, preliminary studies, and cost estimates (called Title I services). At a later time, the M\&O may exercise an option for the AE/CM subcontractor to perform complete (preliminary and final) design services (called Title II services) and related construction management services and may subsequently exercise another option for the $\mathrm{AE} / \mathrm{CM}$ subcontractor to provide architect-engineer supervisory and inspection services during construction (called Title III services). The actual construction work will be subcontracted to third-party firms by the AE/CM subcontractor.

Accordingly, the design and construction of the SSC will be contracted for by a contractor/subcontractor rather than directly by the Department of Energy. Under these circumstances, the Federal Acquisition Regulations (FAR) and the Department of Energy Acquisition Regulations (DEAR) do not, generally speaking, directly govern that acquisition. Acquisitions by the M\&O are judged not by compliance with federal regulation but by conformance to what is known as the "federal norm" and certain policies set forth in the regulations as "guides" or incorporated in prescribed "flow-down" clauses. The DOE's contracting officers are charged with assuring that the $M \& O$ adhere to the federal norm and the specified policies and flow-down provisions.

The federal norm is commonly understood as consisting of general notions of fundamental fairness, such as fair and effective competition and the awarding of subcontracts objectively based on selection criteria that are spelled out in advance. The DEAR Section 970.7103 sets forth federal norm concepts in some detail. Certain sociocconomic policies of the federal government are included as guides within the federal norm, such as equal employment opportunity and setasides for labor surplus areas. Lastly, certain specific procurement policies are flowed-down to subcontractors, such as the "truth-in-negotiation" requirements for cost and pricing analysis, certification, and validation for most negotiated subcontracts over $\$ 100,000$, and the reimbursement only of costs that are "allowable" by government prescription.

With specific reference to acquisition of architect-engineer services and construction by the Department's $M \& O$, the DEAR states that the provisions of 
the FAR and the DEAR relating to such acquisitions are to be "used as guides," not as inflexible commands that are legally enforceable. In addition, the DEAR contains certain specific policies to which the acquisition of architect-engineer and construction services are to conform (DEAR 970.7104-28(a)). These policies generally are the same as those that govern direct procurements by federal agencies, but not slavishly so.

For example, in direct procurements by Federal agencies, selection of architect-engineer subcontractors is to be based "solely" upon the comparative qualifications of the proposers (and the reasonableness of the negotiated price). The M\&O may, on the other hand, base its selection of architect-engineer subcontractors "primarily" on the relative qualifications of the proposers but also on other factors, including cost or price (DEAR 970.7104-28(e)).

Another policy guidance is that, to avoid confusion in segregating costs between different subcontracts, a cost-reimbursement subcontract and a fixedprice subcontract are not to be awarded to the same firm if any portions of the work under the subcontracts will be performed concurrently in the same general location (DEAR 970.7104-28(f)(1)(ii)).

In addition, to avoid "self-inspection" and to prevent biased decision making, subcontracts are not, generally speaking, to be awarded to the same firm or affiliated companies for both architect-engineer and construction services on the same construction project. (DEAR 970.7104-28(f)(1)(i)). This guidance corresponds to the general rule that a federal agency may not award a contract for the construction of a project to the firm that designed the project, except with the approval of the head of the agency (FAR 36.209).

There are two exceptions to this guidance to the M\&O. First, the head of the DOE's Contracting Activity, who overseeing the M\&O, may authorize award of a subcontract to the same firm for both architect-engineer and construction services on the same construction project. In this event, however, architectengineer inspection services during construction must be performed by another organization approved by the DOE. (DEAR 970.7104-28(f)(1)(i)).

The other exception is that a single subcontract for delivery of a discrete facility--for example, on a "turnkey" basis--may be awarded if the subcontractor assumes all liability for defects in design and construction and consequential damages. (DEAR 970.7104-28(f)(1)(iii)).

It should also be noted that in inviting expressions of interest from $\mathrm{AE} / \mathrm{CM}$ firms (i.e., submissions of updated Standard Forms 254 and 255) for evaluation by the M\&O, the DOE stated that the subcontract resulting from the invitation "will bar the subcontractor, its member firms, any subcontractor or consultant performing work thereunder, and any affiliates of the foregoing from award of any SSC construction or related supply contract or subcontract and from otherwise performing any such construction related activity with its own forces, unless an exception to the bar is obtained" from the Department (Commerce Business Daily, October 27, 1989, page 3).

In applying these policies to the procurement techniques and contract types discussed in this report, it will be observed, first, that these policies fully accommodate both fixed-price and cost-reimbursement subcontracting (except concurrently to the same firm in the same location, which is not recommended in this report). Second, even "design-construct" subcontracting (which, contrary to some assertions, is not "illegal" in federal construction, when suitably authorized) may be utilized, if justified to the DOE in particular circumstances, and if inspection of the actual construction is performed by a firm other than the design-construct firm. 
The policy objection to design-construct that is identified in the Department's regulations is the undesirability of having a constructor inspect (and approve) its own construction work. If that potential conflict-of-interest is avoided by appropriate provision for independent inspection, design-construct may be considered, if other factors warrant.

While the invitation issued by the DOE to potential proposers for the AE/CM subcontract declared that the successful candidate would be barred from performing any SSC construction work itself, a provision was made for exceptions. Moreover, the bar, even if enforced against the AE/CM subcontractor itself, would apparently not prevent the $\mathrm{AE} / \mathrm{CM}$ from subcontracting to another firm for a portion of the work on a design-construct basis. It would appear advisable, of course, to obtain the concurrence or approval of the DOE in such a circumstance.

Lastly, the subcontract to be awarded for the AE/CM work will extend only through conceptual design and Title I services. Options must be exercised for Title II and Title III services. It would seem prudent for the M\&O to negotiate some flexibility in the subcontract provisions governing option exercise to permit carving out discrete portions of Title II and Title III work for other subcontractors to perform, without invalidating the general option to extend. Such flexibility is not only generally advisable, but it could also permit some designconstruct subcontracting in appropriate circumstances.

It does not seem likely that any portion of the SSC subsurface construction activity would be awarded on a "turnkey" basis, in vicw of the guidance that the turnkey subcontractor must assume all liability for defects and consequential damages. Because of the vast scope, national importance, and tight time schedule of the SSC project, such a requirement may be expected to be too stringent for any potential subcontractor or surety to risk. However, some particular surface facilities of a conventional character might be suitable for the turnkey method, and if so, the pertinent regulatory guidance would permit it. 


\title{
APPENDIX 5 \\ Possible SSC Insurance Specifications
}

\author{
WRAP-UP INSURANCE
}

The following specifications are suggested in the event that the ArchitectEngineer/Construction Manager (AE/CM) determines that a wrap-up insurance program is desirable for the Superconducting Super Collider project. If the decision is made to adopt a wrap-up program, the AE/CM should consider providing the following insurance coverages, which will cover the person or organizations designated below as "named insured":

\section{Insurance Coverages:}

- Workers Compensation and Employers Liability,

- Commercial General Liability,

- Excess Liability,

- Builders Risk Insurance.

Named Insured:

- $\mathrm{AE} / \mathrm{CM}$,

- Any contractor or subcontractor of any tier who has a contract for which insurance is to be provided by the $\mathrm{AE} / \mathrm{CM}$ under the terms of the SSC Project Insurance Specifications.

\section{Additional Insured:}

- Department of Energy (Liability Insurance only),

- M\&O (except Workers Compensation).

The insurance provided for Workers Compensation, Commercial General Liability and Excess Liability will apply: (1) at the job site including operations elsewhere in connection therewith, and (2) at other locations during the time such locations are exclusively used by the contractor for work performed for the $\mathrm{AE} / \mathrm{CM}$, including operations elsewhere in connection therewith from each other locations while so exclusively used.

Other Coverages:

- Professional Liability Insurance Coverage,

- Architects and Engineers Errors and Omissions Coverage.

Named Insured:

- $\mathrm{AE} / \mathrm{CM}$, its employees and consultants and their employees. 


\section{Workers Compensation Insurance}

The AE/CM will obtain and pay premiums for Workers Compensation and Employers Liability insurance covering the $\mathrm{AE} / \mathrm{CM}$ and each contractor and subcontractor under a separate policy issued to each of them.

\section{Coverages:}

Coverage A - Statutory Workers Compensation (for the state in which the SSC project is located).

Coverage B - Employers Liability.

Limits:
Each Accident
$\$ 2,000,000$
Policy Limit (Disease)
$\$ 2,000,000$
Each Employee (Disease)
$\$ 2,000,000$

Coverage $\mathrm{C}$ - Workers Compensation in other states.

\section{Covered Employees:}

All employees engaged in construction operations performed in connection with the SSC project working at or from the project site.

\section{Coverage Extensions:}

- U.S. Longshoremen \& Harbor Workers' Act,

- Voluntary Compensation,

- Stop Gap Employers Liability insurance in the states of Nevada, North Dakota, Ohio, Washington, West Virginia and Wyoming for the same limits which are shown above for Employers Liability.

\section{Commercial General Liability Insurance}

The AE/CM will obtain and pay premiums for Commercial General Liability insurance covering the named insured designated below for the coverages and limits indicated.

Named Insured:

- $\mathrm{AE} / \mathrm{CM}$,

- Any contractor or subcontractor of any tier who has a contract for which insurance is to be provided by the $\mathrm{AE} / \mathrm{CM}$ under the terms of the SSC Project Insurance Specifications.

Additional Insured:

- Department of Energy

- M\&O

Policy Period:

From policy inception date until cancelled.

Limits:

Each Occurrence

$\$ 2,000,000$

Personal \& Advertising Injury

$\$ 2,000,000$ 
General Annual Aggregate

Products-Completed Operations

Annual Aggregate

Fire Damage

Medical Expense

Deductible:

Property Damage Liability $\$ 5,000$
$\$ 4,000,000$

$\$ 4,000,000$

$\$ 2,000,000$

$\$ 5,000$

\section{Coverage:}

Bodily Injury Liability, Property Damage Liability and Personal Injury Liability arising out of operations performed by the contractor or subcontractor: (1) at the job site including operations elsewhere in connection therewith, and (2) at other locations during the time such other locations are exclusively used by the contractor or subcontractor for work performed for the $A E / C M$ including operations elsewhere in connection therewith from such other locations while so exclusively used.

\section{Coverage Extensions:}

A. Primary Insurance. The insurance afforded by the policy shall apply as primary insurance without right of contribution from any other insurance policy providing coverage for: (a) the named insured, and (b) any additional insured for whom the named insured has agreed by written contract to provide insurance on a primary basis.

B. Additional Insured coverage for any person or organization for whom the named insured has agreed by written contract or permit to provide bodily injury, property damage or personal injury liability insurance except that coverage for such additional insured shall not apply to: (1) a labor union, (2) a railroad company, (3) an architect surveyor or engineer with respect to design error and professional liability, (4) liability assumed under contract by such additional insured, and (5) the products-completed operations hazard. Liability"

C. Contractual Liability with respect to coverage for "Personal Injury

D. Contractual Liability-delete the Railroad exclusion with respect to construction operations within 50 feet of a railroad.

E. Subrogation rights are waived by the company against any person or organization: ( 1 ) who is a named insured, additional insured, or insured under this policy, and (2) if the named insured has agreed, prior to loss, under a written contract to waive subrogation against such person or organization.

\section{Coverage Limitation:}

The insurance afforded by the policy does not apply to bodily injury, property damage, or personal injury liability arising out of the professional liability services of any architect, engineer, or surveyor who is an employee of or consultant to the $\mathrm{AE} / \mathrm{CM}$. 


\section{Excess Liability Insurance}

The AE/CM will obtain and pay premiums for Excess Liability insurance covering the named insured designated below for the coverages and limits indicated.

Named Insured:

- $\mathrm{AE} / \mathrm{CM}$,

- Any contractor or subcontractor of any tier who has a contract for which insurance is to be provided by the $\mathrm{AE} / \mathrm{CM}$ under the terms of the SSC Project Insurance Specifications.

Additional Insured:

- Department of Energy,

- M\&O.

Policy Period:

From policy inception date until cancelled.

Each Occurrence

General Aggregate (Annual)

Products-Completed Operations

$$
\text { Aggregate (Annual) } \$ 100,000,000
$$

$\$ 100,000,000$

$\$ 100,000,000$

\section{Coverage:}

- "Occurrence" coverage, not "Claims Made,"

- Bodily Injury Liability, Property Damage Liability and Personal Injury Liability arising out of operations performed by the contractor or subcontractor: (1) at the job site including operations elsewhere, in connection therewith, and (2) at other locations during the time such other locations are exclusively used by the contractor or subcontractor for work performed for the AE/CM including operations elsewhere in connection therewith from such other locations while so exclusively used.

\section{Coverage Extensions:}

A. Primary Insurance. The insurance afforded by the policy shall apply as primary insurance without right of contribution from any other insurance policy providing coverage for: (1) the named insured and (2) any additional insured for whom the named insured has agreed by written contract to provide insurance on a primary basis.

B. Additional Insured coverage for any person or organization for whom the named insured has agreed by written contract or permit to provide bodily injury, property damage, or personal injury liability insurance except that coverage for such additional insured shall not apply to: (1) a labor union, (2) a railroad company, (3) an architect, surveyor, or engineer with respect to design error and professional liability, (4) liability assumed under contract by such additional insured, and (5) the products-completed operations hazard.

C. Cross Liability. Except with respect to the policy limits of liability, the insurance applies separately to each insured against whom claim is made or suit is brought. 
D. Subrogation rights are waived by the Company against any person or organization: (1) who is a named insured, additional insured or insured under this policy, (2) if the Named Insured has agreed, prior to loss, under a written agreement to waive subrogation against such person or organization.

\section{Coverage Limitations:}

A. Automobiles. Coverage is excluded for liability arising out of the ownership, maintenance or use of autos.

B. Professional Liability. The insurance afforded by the policy does not apply to bodily injury, property damage or personal injury liability arising out of the professional services of any architect, engineer, or surveyor who is an employee of or consultant to the Architect-Engineer Construction Manager.

\section{Builders Risk Insurance}

The AE/CM will obtain and pay premiums for Builders Risk Insurance covering the named insured designated below for the coverages and limits indicated.

Named Insured:

- $\mathrm{M} \& \mathrm{O}$,

- $\mathrm{AE} / \mathrm{CM}$,

- Any contractor or subcontractor of any tier who has a contract for which insurance is to be provided by the AE/CM under the terms of the SSC Project Insurance Specifications.

\section{Policy Period:}

From policy inception date to projection completion date.

Limits:

Per Occurrence:

$\$ 100,000,000$ or highest limit at reasonable cost

Sublimits:

Earthquake to be negotiated

Flood

to be negotiated

Debris Removal to be negotiated

Transit to be negotiated

Offsite Storage to be negotiated

Deductibles:

Contractors and subcontractors of any tier to be responsible for the following deductibles:

Fire and Extended Coverages

(Including Vandalism \&

Malicious Mischief) $\$ 5,000$

All Other Perils $\quad \$ 25,000$

All risks of physical loss or damage including work and labor and loss: caused by earthquake, land movement, flood, and water damage. The insurance shall be 
primary insurance without right of contribution from any other insurance carried by any person or organization insured under this policy.

\section{Professional Liability Insurance--Architects and Engineers Errors and Omissions}

The AE/CM will obtain and pay premiums for a "project":Architects and Engineers Errors and Omissions policy covering the named ensured designated below for the coverages and limits indicated.

\section{Named Insured:}

$\mathrm{AE} / \mathrm{CM}$ and its employees and its consultants and their employees who have a contract for which insurance is to be provided by the $A E / C M$ in connection with the SSC Project.

Policy Period:

From policy inception date through conceptual, design and construction phases and extended for a five year discovery period following substantial completion of the project.

Limits:

$\$ 100,000,000$ project aggregate limit

Deductible:

$\$ 350,000$ per claim

\section{Coverage:}

A "Claims Made" project policy covering negligent acts. errors or omissions arising out of the performance or failure to perform the professional services of an architect, engineer, land surveyor, landscape architect, or construction manager.

Coverage is also to be included for bodily injury, false arrest, wrongful entry or eviction, invasion of right of private occupancy, malicious prosecution, humiliation, libel, and slander arising out of professional services.

Automatic coverage for limited form Contractual Liability is also to be provided by the policy.

The policy cannot be cancelled except for non-payment of premiums breach of policy conditions; or misrepresentation or concealment in the application.

\section{Railroad Protective Liability Insurance}

If Railroad Protective Liability Insurance is required by a railroad, the $\mathrm{AE} / \mathrm{CM}$ will obtain and pay premium for such insurance.

\section{Automobile Liability Insurance}

The contractor or subcontractor of any tier shall provide Automobile Liability Insurance at its own expense covering all automobiles whether owned, non-owned, leased or hired for not less than the following limit of liability: 
Bodily Injury Liability and Property Damage Liability
$\$ 1,000,000$ combined single limit per accident

\section{Aircraft and Watercraft Liability Insurance}

If the contractor or subcontractor of any tier uses owned or non-owned aircraft or watercraft in connection with its operations for this project, it shall provide Aircraft or Watercraft Liability Insurance for no less than the following limit of liability:

Bodily Injury Liability and Property Damage Liability
$\$ 1,000,000$ combined single limit per occurrence 


\section{REFERENCES}

American Society of Civil Engineers. 1979. Construction Risks and Liability Sharing. New York: ASCE.

Construction Industry Institute. 1987. Guidelines for Implementing a Constructibility Program. Constructibility Task Force. Austin: University of Texas.

Construction Industry Institute. 1986. Constructibility: A Primer. Constructibility Task Force. Austin: University of Texas.

Federal Construction Council. 1988. The Design-Build Approach to Acquiring Facilities. National Research Council. Washington, D.C.: National Academy Press.

"ITA Recommendations on Contractual Sharing of Risk." 1988. Tunnclling and Underground Space Technology 3(2):103-140.

"Management and Operating Contractor for Establishment, Management, and Initial Operation of Superconducting Super Collider (SSC) Laboratory." 1988. Commerce Business Daily, October 27:3.

Sperry, P.E. 1976. Evaluation of Savings for Underground Construction (Contract DOT-OS-40022). Washington, D.C.: U.S. Department of Transportation.

Sperry, P.E. 1981. "Evaluation of Savings for Underground Construction." Underground Space 6(July/August):29-42.

Underground Technology Research Council. 1989. Avoiding and Resolving Disputes in Underground Construction. New York: American Society of Civil Engineers.

U.S. National Committee on Tunneling Technology. 1974. Better Contracting for Underground Construction. National Research Council. Washington D.C.: National Academy Press.

U.S. National Committee on Tunneling Technology. 1976. Executive Presentation-Recommendations on Better Contracting for Underground Construction. National Research Council. Washington, D.C.: National Academy Press. 
U.S. National Committee on Tunneling Technology. 1978. Better Management for Underground Projects. National Research Council. Washington D.C.: National Academy Press.

U.S. National Committee on Tunneling Technology. 1984. Geotechnical Site Investigations for Underground Projects. National Research Council. Washington, D.C.: National Academy Press. 